\section{Review Article}

Check for updates

\section{OPEN ACCESS}

Received: Sep 27, 2018

Accepted: Oct 8, 2018

Correspondence to

Boyoung Joung, MD, PhD

Division of Cardiology, Department of Internal Medicine, Yonsei Cardiovascular Hospital,

Yonsei University Medical College, 50,

Yonsei-ro, Seodaemun-gu, Seoul 03722, Korea.

E-mail: cby6908@yuhs.ac

Copyright (c) 2018. The Korean Society of Cardiology

This is an Open Access article distributed under the terms of the Creative Commons Attribution Non-Commercial License (https:// creativecommons.org/licenses/by-nc/4.0) which permits unrestricted noncommercial use, distribution, and reproduction in any medium, provided the original work is properly cited.

ORCID iDs

Boyoung Joung (i)

https://orcid.org/0000-0001-9036-7225

Jung Myung Lee (D)

https://orcid.org/0000-0002-1904-5335

Tae-Hoon Kim (iD)

https://orcid.org/0000-0003-4200-3456 Eue-Keun Choi (D)

https://orcid.org/0000-0002-0411-6372

Woo-Hyun Lim (iD)

https://orcid.org/0000-0001-9298-8500 Ki-Woon Kang (iD)

https://orcid.org/0000-0002-1361-0022 Jaemin Shim (D)

https://orcid.org/0000-0001-8251-1522 Hong Euy Lim (D)

https://orcid.org/0000-0001-8102-8352

\title{
2018 Korean Guideline of Atrial Fibrillation Management
}

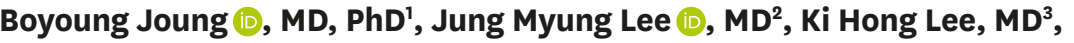 \\ Tae-Hoon Kim (1), MD², Eue-Keun Choi $10, M^{4}$, Woo-Hyun Lim $(1), M^{4}$, \\ Ki-Woon Kang $\left(\mathbb{D}, M^{5}\right.$, Jaemin Shim $\mathbb{1}, M^{6}$, Hong Euy Lim $(1), D^{6}$,

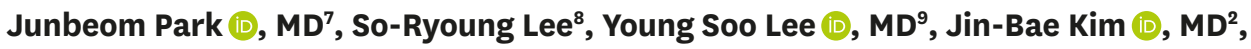 \\ and KHRS Atrial Fibrillation Guideline Working Group
}

\begin{abstract}
'Division of Cardiology, Department of Internal Medicine, Yonsei University College of Medicine, Seoul, Korea ${ }^{2}$ Division of Cardiology, Department of Internal Medicine, Kyung Hee University Medical College, Seoul, Korea ${ }^{3}$ Department of Cardiology, Chonnam National University Hospital, Gwangju, Korea

${ }^{4}$ Department of Internal Medicine, Seoul National University College of Medicine, Seoul, Korea ${ }^{5}$ Division of Cardiology, Eulji University College of Medicine, Daejeon, Korea

${ }^{6}$ Division of Cardiology, Department of Internal Medicine, Korea University College of Medicine, Seoul, Korea ${ }^{7}$ Department of Cardiology, Ewha Woman University, Seoul, Korea

${ }^{8}$ Division of Cardiology, Department of Internal Medicine, Soon Chun Hyang University Hospital, Seoul, Korea ${ }^{9}$ Division of Cardiology, Department of Internal Medicine, Daegu Catholic University, Daegu, Korea
\end{abstract}

\section{ABSTRACT}

Atrial fibrillation (AF) is the most common sustained cardiac arrhythmia in the general population. The Korean Heart Rhythm Society organized a Korean AF Management Guideline Committee and analyzed all available studies regarding the management of AF, including studies on Korean patients. This guideline is based on recent data of the Korean population and the recent guidelines of the European Society of Cardiology, European Association for Cardio-Thoracic Surgery, American Heart Association, and Asia Pacific Heart Rhythm Society. Expert consensus or guidelines for the optimal management of Korean patients with AF were achieved after a systematic review with intensive discussion. This article provides general principles for appropriate risk stratification and selection of anticoagulation therapy in Korean patients with AF. This guideline deals with optimal stroke prevention, screening, rate and rhythm control, risk factor management, and integrated management of AF.

Keywords: Atrial fibrillation; Guideline; Anticoagulants; Therapy

\section{PREAMBLE}

This guideline is based on recent data of the Korean population and the recent guidelines. ${ }^{1-5)}$ The level of evidence and strength of the recommendation of particular management options were weighed and graded according to predefined scales as outlined in Tables $\mathbf{1}$ and $\mathbf{2}$. The Korea Heart Rhythm Society (KHRS) Committee for Practice Guidelines supervises and coordinates the preparation of a new guideline produced by task forces, expert groups, or consensus panels. The Committee is also responsible for endorsing this guideline. 


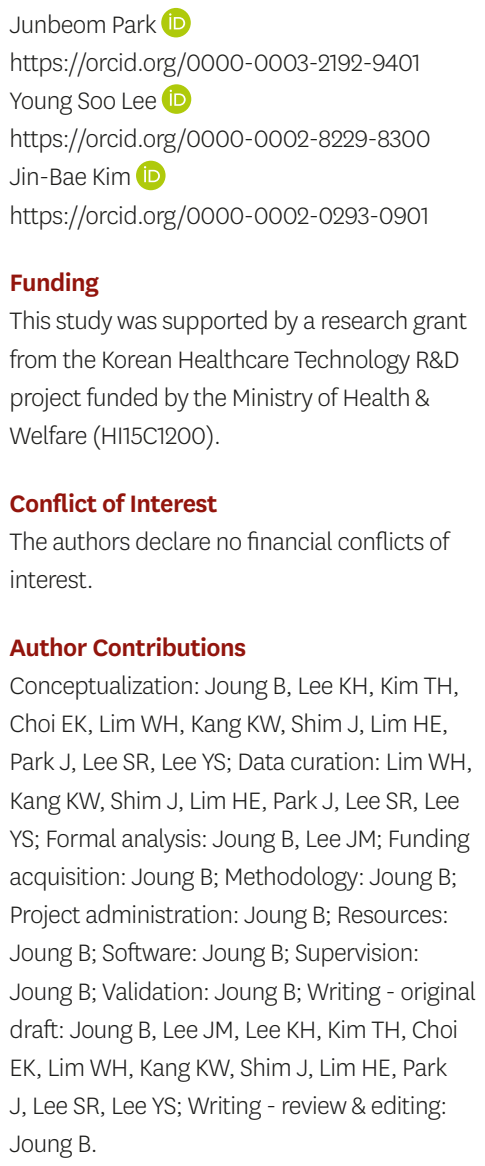

\section{Author Contributions}

Conceptualization: Joung B, Lee KH, Kim TH, Choi EK, Lim WH, Kang KW, Shim J, Lim HE, Park J, Lee SR, Lee YS; Data curation: Lim WH, Kang KW, Shim J, Lim HE, Park J, Lee SR, Lee YS; Formal analysis: Joung B, Lee JM; Funding acquisition: Joung B; Methodology: Joung B; Project administration: Joung B; Resources: Joung B; Software: Joung B; Supervision: Joung B; Validation: Joung B; Writing - original draft: Joung B, Lee JM, Lee KH, Kim TH, Choi EK, Lim WH, Kang KW, Shim J, Lim HE, Park J, Lee SR, Lee YS; Writing - review \& editing: Joung $B$.

\begin{tabular}{llc}
$\begin{array}{l}\text { Table 1. Recommendation classes } \\
\text { Classes of } \\
\text { recommendations }\end{array}$ & Definition & Suggested wording to use \\
\hline Class I & $\begin{array}{l}\text { Evidence and/or general agreement that a given treatment or } \\
\text { procedure is beneficial, useful, effective. }\end{array}$ & $\begin{array}{c}\text { Is recommended/ } \\
\text { is indicated }\end{array}$ \\
Class II & $\begin{array}{l}\text { Conflicting evidence and/or a divergence of opinion about the } \\
\text { usefulness/efficacy of the given treatment or procedure. }\end{array}$ & Should be considered \\
Class IIa & Weight of evidence/opinion is in favour of usefulness/efficacy. \\
Class IIb & Usefulness/efficacy is less well established by evidence/opinion. & May be considered \\
Class III & $\begin{array}{l}\text { Evidence or general agreement that the given treatment or procedure } \\
\text { is not useful/effective, and in some cases may be harmful. }\end{array}$ & Is not recommended \\
\hline
\end{tabular}

Table 2. Levels of evidence

\begin{tabular}{ll}
\hline Levels of evidence & \multicolumn{1}{c}{ Definition } \\
\hline Evidence A & Data derived from multiple RCTs or meta-analyses. \\
Evidence B & Data derived from a single RCT or large non-randomized studies. \\
Evidence C & Consensus of opinion of the experts and/or small studies, retrospective studies, registries. \\
\hline
\end{tabular}

$\mathrm{RCT}=$ randomized controlled trial.

\section{INTRODUCTION}

Atrial fibrillation (AF) is the most common sustained cardiac arrhythmia in the general population. ${ }^{6-9)} \mathrm{AF}$ increases the risk of mortality and morbidity resulting from stroke, congestive heart failure (HF), and impaired quality of life, explaining its enormous socioeconomic and healthcare implications. ${ }^{10)}$ The prevalence of AF has been projected to increase to 12 million people in the USA by the year 2050 and 17.9 million in Europe by the year 2060, with more than half of these patients being $\geq 80$ years of age, leading to substantial public health and economic burdens. ${ }^{11-13)}$ Consequently, the healthcare burden associated with $\mathrm{AF}$ is growing considerably and is mainly driven by hospitalizations. ${ }^{14) 15}$ As populations continue to age, $\mathrm{AF}$ is likely to become a greater public health burden.

\section{EPIDEMIOLOGY OF ATRIAL FIBRILLATION IN KOREA}

Many of the risk factors for developing AF also lead to complications related to AF such as stroke and death. The prediction of incident AF has been the focus of reviews, and risk factors have been used to derive clinical risk scores for incident AF. ${ }^{1617)}$ The largest derivation and validation in an Asian population (including Korea) is the simple $\mathrm{C}_{2} \mathrm{HEST}$ score: $\mathrm{C}_{2}$ : coronary artery disease (CAD)/chronic obstructive pulmonary disease (COPD) (1 point each); H: Hypertension; E: Elderly (Age $\geq 75$, doubled); S: Systolic HF (doubled); T: Thyroid disease (hyperthyroidism). ${ }^{18)}$

\section{Prevalence and incidence of atrial fibrillation}

Reliable prevalence and incidence figures are needed for clinicians and policymakers. ${ }^{19)}$ The prevalence of AF progressively increased by 2.10 -fold from $0.73 \%$ in 2006 to $1.53 \%$ in 2015 in Korea. The prevalence was significantly greater in men than in women for all years (Figure 1A). The annual trends of AF incidence were stable with the 10-year overall incidence of 1.77 per 1,000 person-years. The 10-year overall incidence in men was 1.89 per 1,000 person-years, 1.16 times higher than 1.65 per 1,000 person-years in women, and the tendency was consistent over the study period (Figure 1B). ${ }^{20)}$ The prevalence of AF in Korea was similar to the recent prevalence rates of 1.07-1.6\% in Asia; 1.07\% in 2011 in Taiwan, ${ }^{21}$ 

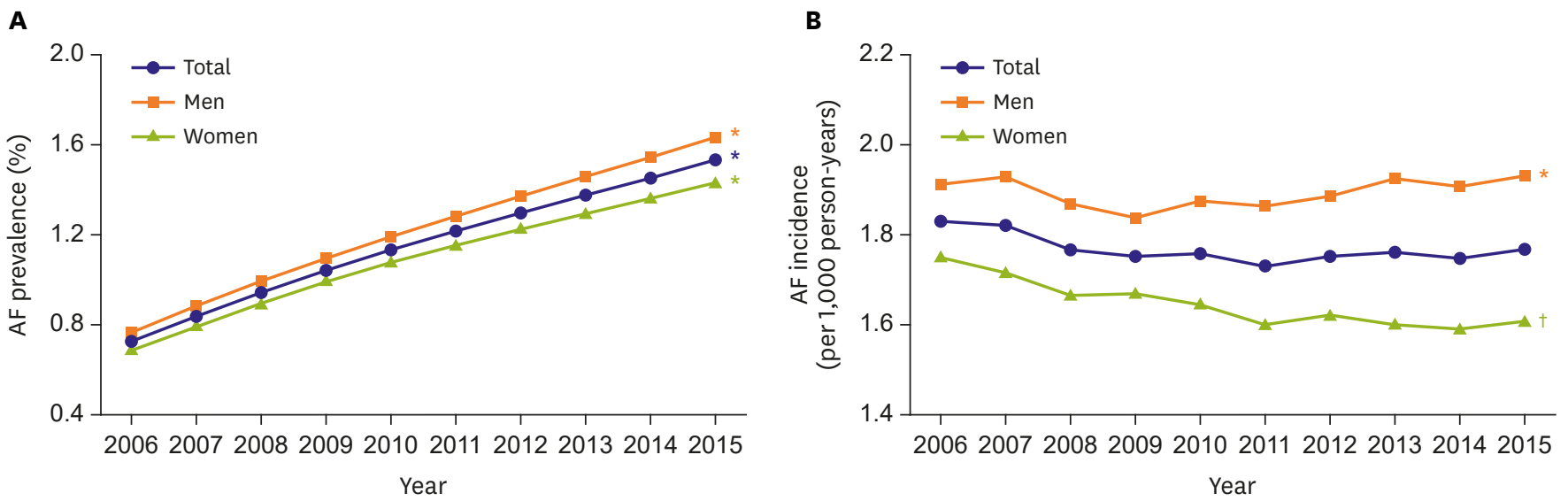

Figure 1. Annual prevalence (A) and incidence (B) of AF, 2006-2015, stratified by sex. $\mathrm{AF}=$ atrial fibrillation

${ }^{*} p$ value for increasing trends $<0.001 .{ }^{\dagger} p$ value for decreasing trends $<0.001$.

A

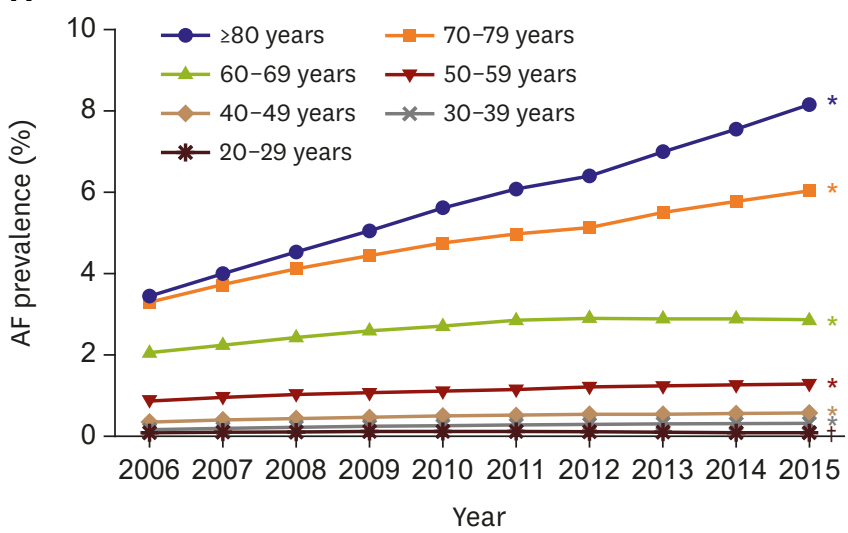

B

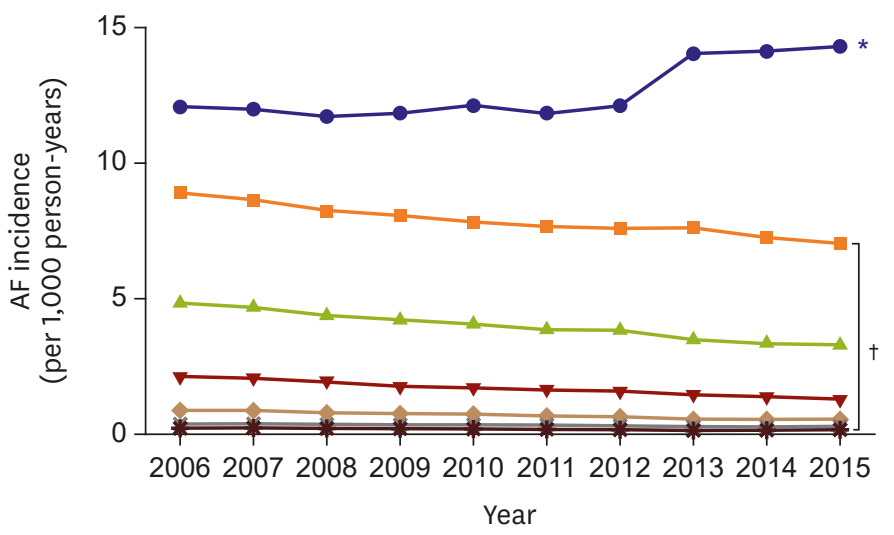

Figure 2. Annual incidence (A) and prevalence (B) of AF, 2006-2015, stratified by age. $\mathrm{AF}=$ atrial fibrillation.

${ }^{*} p$ value for increasing trends $<0.001 .{ }^{\dagger} p$ value for decreasing trends $<0.001$.

$1.5 \%$ in Singapore ${ }^{22)}$ and $1.6 \%$ in 2006 in Japan. ${ }^{23)}$ Across all age groups, the prevalence consistently increased over the study period, except the prevalence among those aged 20-29 years decreased significantly (Figure 2A). The annual AF incidence in subjects aged $\geq 80$ years increased significantly from 12.1 in 2006 to 14.3 per 1,000 person-years in 2015, while the incidences in all other age groups decreased (Figure 2B). ${ }^{20)}$ Patients with regular hospital visits showed a lower prevalence of $\mathrm{AF}$ and an increasing trend of the incidence of $\mathrm{AF}^{24) 25}$ )

The prevalence of Korean AF is expected to be 5.81\% (2,290,591 AF patients) in 2060 (Figure 3), while the prevalence of Taiwan AF is estimated to be $4.01 \%$ in 2050. ${ }^{21)}$ Although the prevalence of $\mathrm{AF}$ is increasing steeply in Asia, it remains lower in Korea (and many Asian countries) than that of Western populations. Because AF is becoming an important public health burden, regional and socioeconomic inequality of AF patterns and treatment is also important. ${ }^{26)}$ The prevalence of AF differs according to geographical regions and income levels. ${ }^{27)}$

The proportion of patients with a congestive HF, hypertension, age $\geq 75$ (doubled), diabetes mellitus, prior stroke or transient ischemic attack (doubled), vascular disease, age 65-74, 


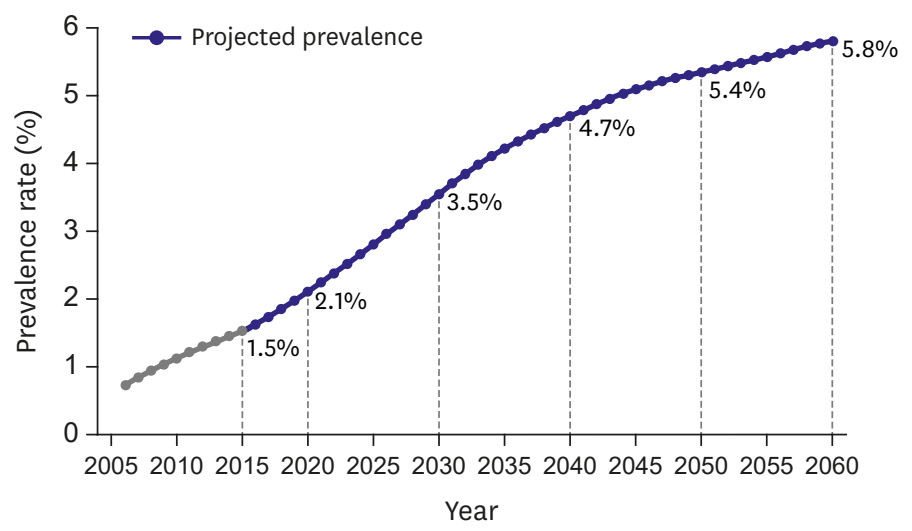

Figure 3. The projected prevalence of atrial fibrillation.

female $\left(\mathrm{CHA}_{2} \mathrm{DS}_{2}\right.$-VASc) score $\geq 2$ increased from $68.8 \%$ to $81.2 \%$ from 2006 to 2015 . The proportion of patients with high bleeding risk according to HAS-BLED (hypertension, abnormal renal/liver function [1 point each], stroke, bleeding history or predisposition, labile international normalized ratio [INR], elderly [0.65], drugs/alcohol concomitantly [1 point each]) (score $\geq 3$ ) increased from 39.3\% in 2006 to $59.1 \%$ in 2015 (Figure 4). ${ }^{20)}$
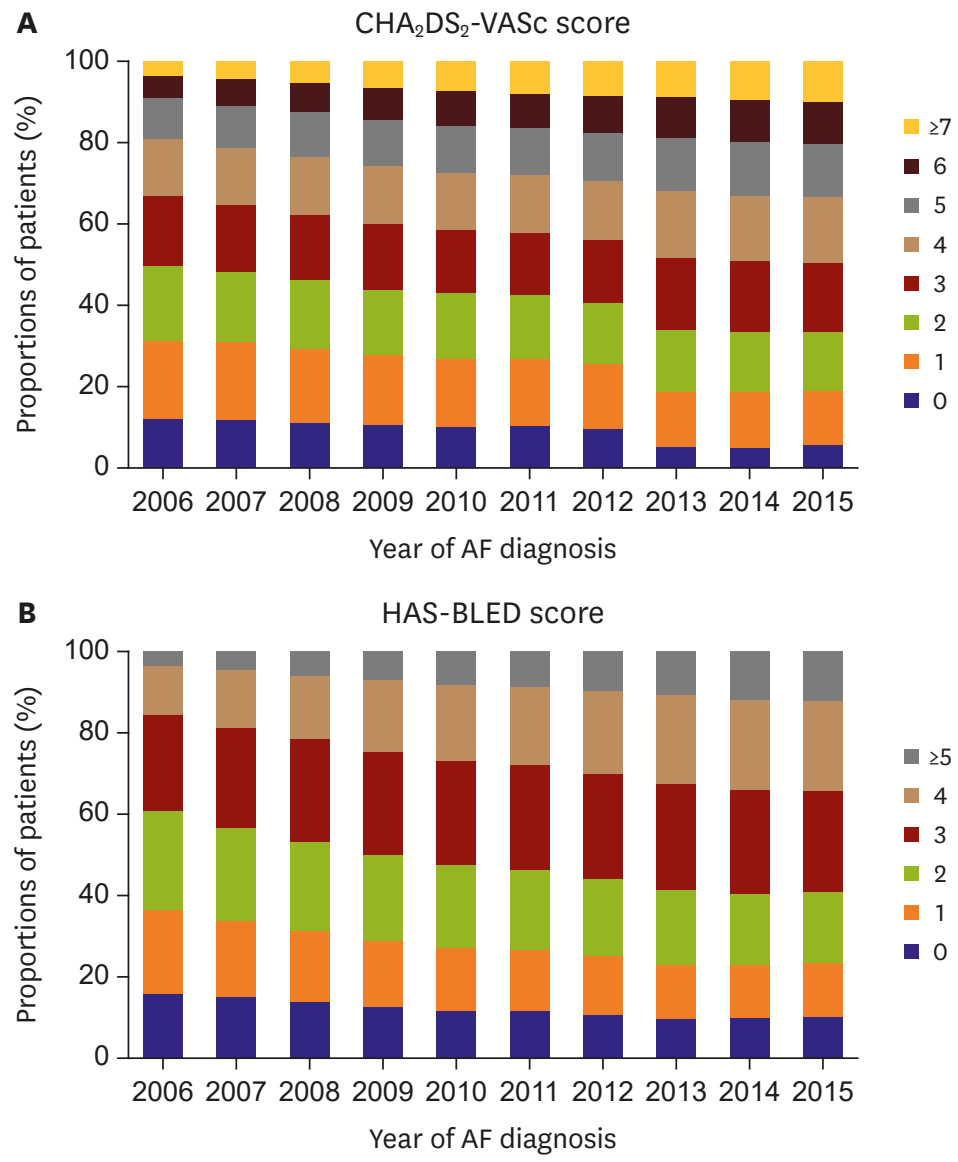

Figure 4. Temporal trends of newly diagnosed AF patient by $\mathrm{CHA}_{2} \mathrm{DS}_{2}$-VASc and HAS-BLED scores, 2006-2015. $\mathrm{AF}=$ atrial fibrillation . 


\section{Hospital care burden of atrial fibrillation}

Overall, hospitalizations for AF increased by 420\% from 767 to 3,986 per 1 million Korean population from 2006 to 2015. Most admissions occurred in patients aged $\geq 70$ years, and the most frequent coexisting conditions were hypertension, HF, and COPD. Hospitalizations mainly due to major bleeding and $\mathrm{AF}$ control increased, whereas those mainly due to ischemic stroke and myocardial infarction decreased. ${ }^{8228}$

The total cost of care increased even after adjustment for inflation from $\$ 8.79$ billion ( $€ 68.4$ million) in 2006 to 49.8 billion ( $€ 388.4$ million) in 2015, equivalent to $0.78 \%$ of the Korean National Health Insurance Service (NHIS) total expenditure (Figure 5). The total care cost related with AF was estimated as \$16-26 billion in the United States, accounting for $1 \%$ of the national healthcare budget in the United Kingdom. ${ }^{15} 22930$ )

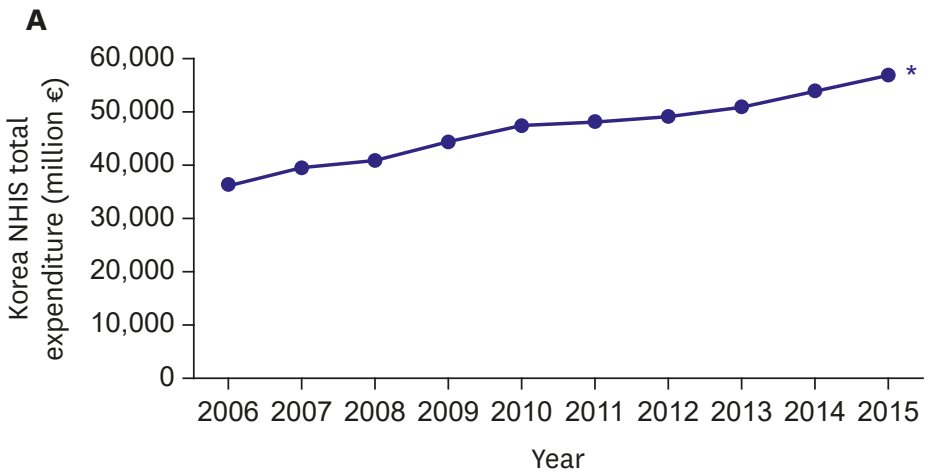

B
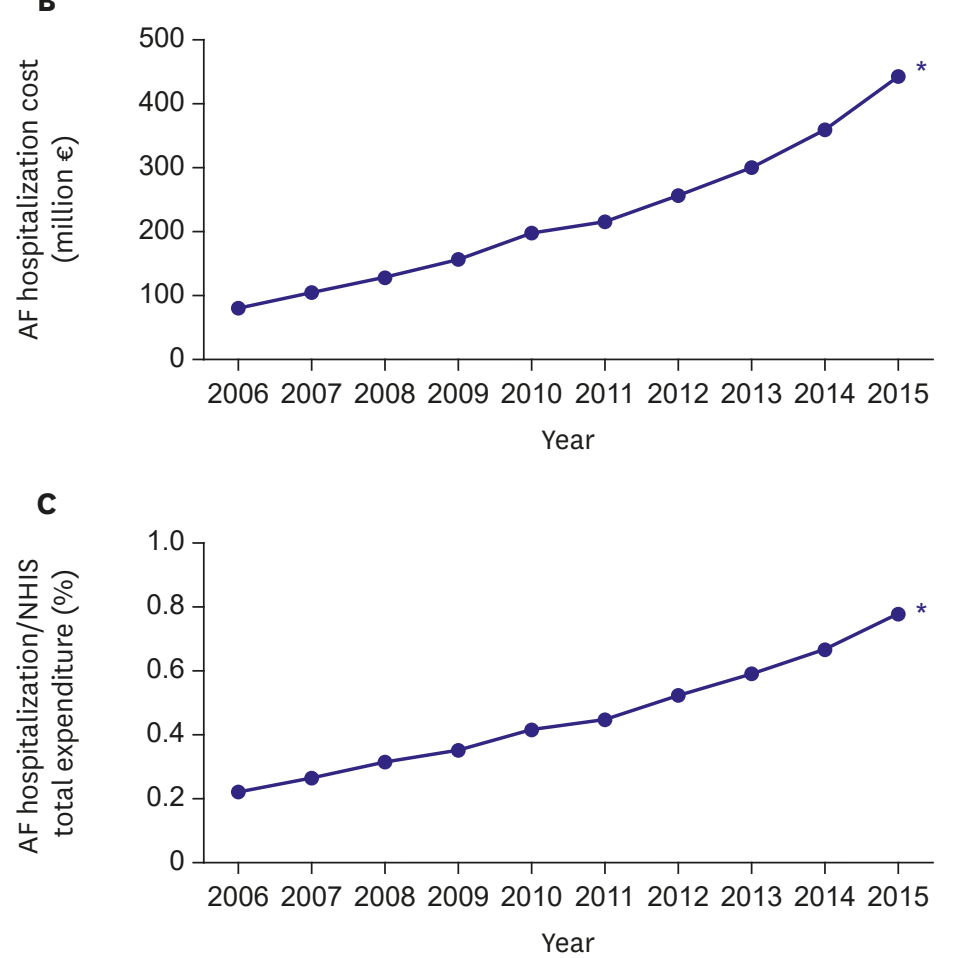

Figure 5. Temporal trends of medical costs, 2006-2015. (A) Korean NHIS total expenditures (million $€$ ), (B) total AF hospitalization costs (million $€$ ), and (C) the proportion of total AF hospitalization costs to Korean NHIS total expenditures (\%).

$\mathrm{AF}=$ atrial fibrillation; NHIS = National Health Insurance Service.

${ }^{*} \mathrm{p}$ value for trends $<0.001$. 


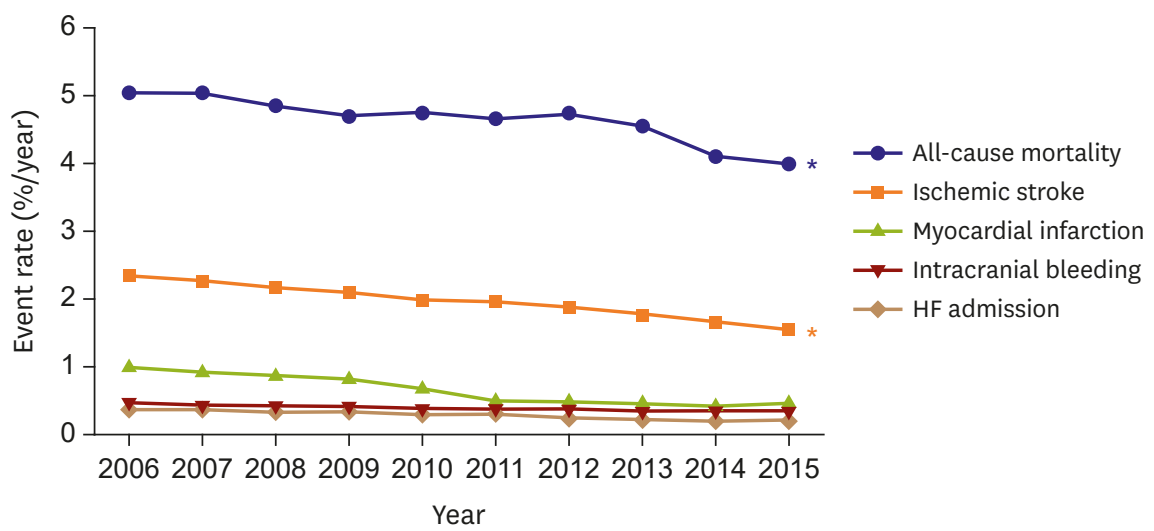

Figure 6. Temporal trends in 1-year adverse event rates of prevalent AF Korean population each year. $\mathrm{AF}=$ atrial fibrillation; $\mathrm{HF}=$ heart failure

${ }^{*} \mathrm{p}$ value for trends $<0.001$

\section{Prognosis of atrial fibrillation}

Among prevalent AF patients, annual event rates for all-cause mortality, ischemic stroke, intracranial bleeding, HF admission, and myocardial infarction significantly declined for a decade. In contrast, these events did not change among the non-AF Korean population (Figure 6). Over the last 5 decades, AF-associated mortality decreased by $25 \%$ in the Framingham Heart Study. ${ }^{31}$

In Korea, we observed a 20\% reduction in mortality over a decade from 5.0\%/year in 2006 to $4.0 \%$ /year in $2015 .{ }^{20)}$ Overall in-hospital mortality decreased from $7.5 \%$ in 2006 to $4.3 \%$ in $2015 .{ }^{28)}$ The in-hospital mortality was highest in patients $\geq 80$ years of age $(7.7 \%)$ and in those with chronic kidney disease (7.4\%). Improved survival after AF onset may arise from: 1) earlier detection (lead time) owing to heightened awareness; 2) changed diagnostic criteria (as described above); 3) enhanced surveillance of AF patients; 4) advances in guideline-recommended treatments for $\mathrm{AF}^{32}$ including oral anticoagulation (OAC) therapy to reduce the risk of embolization ${ }^{3}$; and 5) more aggressive treatment of complications and comorbidities such as hypertension, ischemic heart disease, HF, and hypercholesterolemia. ${ }^{18}$

Given the high mortality associated with $\mathrm{HF}^{33)}$ and stroke, ${ }^{34)}$ the $52 \%$ reduction in $\mathrm{HF}$ subsequent to AF observed over the study period and the $9 \%$ reduction in risk of ischemic stroke is likely to have contributed substantially to the improved survival. Although our results showing a declining associated risk for $\mathrm{HF}$ and stroke following $\mathrm{AF}$ are in line with those for other Western populations, ${ }^{311}$ the 1-year rates of HF and stroke are $0.2 \% / y e a r$ and $1.8 \% / y e a r$, which are still higher than $0.1 \% / y e a r$ and $0.6 \% / y e a r$ in an age- and sex-matched non-AF population in 2013.

\section{SCREENING FOR ATRIAL FIBRILLATION}

The early detection of asymptomatic AF could prevent associated ischemic stroke associated by instituting appropriate anticoagulation. ${ }^{3530)} \mathrm{AF}$ first diagnosed at the event of stroke comprise nearly $10 \%$ of total ischemic stroke cases. The incidence of screen-detected AF strongly depends on the population screened and screening duration/intensity. ${ }^{37}$ 


\section{Screening for atrial fibrillation by 12-lead electrocardiography}

To diagnose AF, its documentation on electrocardiogram (ECG) is mandatory. As the misdiagnosis of AF could cause unnecessary risks and costs for patient management, confirming the diagnosis on ECG is essential. The American College of Cardiology/ American Heart Association/Heart Rhythm Society guideline of the management of AF recommends the ECG documentation of AF as a class I indication. ${ }^{2)}$ Moreover, $\mathrm{AF}$ is frequently asymptomatic, especially in older people. ${ }^{38}$ As such, symptom-driven ECG has a substantial limitation for detecting AF. One study revealed that 161 of 476 individuals with new subclinical AF were at an increased risk of cardiovascular and all-cause mortality compared to patients with typical symptoms after the adjustment for age and stroke risk score. ${ }^{39)}$ Another study showed that a single-point screening of a general population $\geq 65$ years of age detects subclinical AF in $1.4 \%$ of cases and that $\mathrm{AF}$ is almost always persistent. ${ }^{40)}$ In the prospective EURObservational Research Programme registry, mortality at 1 year was more than 2 -fold higher in asymptomatic than symptomatic patients $(9.4 \%$ vs. $4.2 \%$, $\mathrm{p}<0.001)$ independent of age and comorbidities. ${ }^{41)}$ In the Belgrade AF study including consecutive first-diagnosed AF patients, 10-year survival free of ischemic stroke or AF progression was worse in patients with an asymptomatic presentation. ${ }^{42}$ The SAFE study ${ }^{43}$ showed that targeted and total population screening for subclinical AF seems cost-effective in people aged $\geq 65$ years, and similar results were repeatedly reported using intermittent ECG screening in different populations. ${ }^{44 / 45)} \mathrm{A}$ systemic review showed screening of elderly people revealed a prevalence of $2.3 \%$ for persistent AF using short-term ECG monitoring or ECG after pulse palpation. ${ }^{40}$ These findings encourage the further evaluation of systematic AF screening programs in elderly or increased risk populations, such as stoke survivors or patients with intracardiac devices.

\section{Extended-term screening for atrial fibrillation}

As elderly populations continue increasing, the incidence of subclinical AF is also increasing ${ }^{46)}$ Furthermore, due to recent advances in new technologies, underdiagnosed AF could be detected. Stepwise screening with 12-lead ECG and handheld ECG recordings increased the rate of diagnosis of asymptomatic paroxysmal AF in unselected residents of Halmstad, Sweden aged 75-76 years. ${ }^{47}$ Long-term monitoring with implantable or wearable devices like smartphones or smart watches has been validated for the detection of short-term asymptomatic AF.

In the REHEARSE-AF study, self-screening using a handheld ECG device once or twice weekly demonstrated a hazard ratio of 3.9 for the detection of $\mathrm{AF}$ at 12 months compared with routine care ${ }^{48)}$ A nongovernmental organization-led community-based screening program based around community centers demonstrated that the prevalence of AF was $2.3 \%$ and newly diagnosed $\mathrm{AF}$ was $0.69 \%$ with a mean $\mathrm{CHA}_{2} \mathrm{DS}_{2}$-VASc score of $3.9 \pm 1.5 .{ }^{49)}$ The ASSERTII study investigated the prevalence of subclinical AF among 256 patients with an average left atrial volume of $76.5 \mathrm{~mL}$ using implantable loop recorders, and subclinical AF lasting $\geq 5$ minutes was detected among $34.4 \%$ of patients per year over a mean follow-up of 16 months. ${ }^{50)}$ From these data, the AF-SCREEN group, an international collaboration including more than 100 physicians, nurses, allied health professionals, health economists, and patient advocates, endorsed the use of routine screening of at-risk populations. ${ }^{35)}$

\section{Screening of patients with intracardiac device or previous stroke}

A cardiac-implanted electronic device (CIED) could continuously monitor atrial rhythm and detect atrial high-rate episodes (AHRE). However, AHRE has been not used to detect AF. A 
minimum 5-minute AHRE duration had clinical relevance in the MOST study. ${ }^{51)}$ Alternative arbitrary or data-derived AHRE burden cut points ranging from 5 minutes to 24 hours have been explored over the subsequent 10 years. ${ }^{52}$ The ASSERT study indicated that stroke risk was increased only in patients with AHRE $\geq 24$ hours. ${ }^{53)}$ The stroke risk in AHRE patients seemed lower than that in patients with diagnosed $\mathrm{AF}^{54}{ }^{54}$ and strokes often occur without AHRE being detected within 30 days before the event. ${ }^{55-58)}$ Patients with CIED should be regularly screened for AHRE, while those with AHRE should undergo further assessments for stroke risk factors and overt AF, including ECG monitoring.

Stroke is the first manifestation of AF in $>25 \%$ of AF-related stroke cases. ${ }^{59)}$ In the Swedish registry of ischemic strokes, approximately $9 \%$ were associated with subclinical AF and $20 \%$ with undertreated $\mathrm{AF},{ }^{5960)}$ whereas in a global registry, $10 \%$ were caused by previously unknown AF. ${ }^{61)}$ Sequential ECG monitoring detected AF in $23.7 \%$ of stroke survivors ${ }^{(2)}$ and in $11.5 \%$ in different meta-analyses of prospective observational studies or randomized controlled trials (RCTs), ${ }^{50)}$ with variations depending on optimal timing, methods, and duration of monitoring for the detection of AF. Cryptogenic stroke defined as the cause of ischemic stroke remains uncertain despite a complete diagnostic evaluation. ${ }^{63} \mathrm{AF}$ detection is not uncommon in unselected stroke patients (hazard ratio [HR], 6.2; 95\% confidence interval [CI], 4.4-8.3), ${ }^{64)}$ but is more likely in patients with cryptogenic stroke with implantable loop recorders or who have undergone prolonged ECG monitoring. ${ }^{.4)(5)}$ Accordingly, prolonged ECG monitoring seems reasonable in all survivors of ischemic stroke without overt AF.

\section{Summary of recommendations for AF screening}

\begin{tabular}{|c|c|c|}
\hline Recommendations & Class & Level \\
\hline $\begin{array}{l}\text { Opportunistic screening for AF is recommended by pulse taking or ECG rhythm strip in } \\
\text { patients }>65 \text { years of age. }\end{array}$ & 1 & B \\
\hline $\begin{array}{l}\text { In patients with transient ischemic attack (TIA) or ischemic stroke, screening for AF is } \\
\text { recommended by short-term ECG recording followed by continuous ECG monitoring for at } \\
\text { least } 72 \text { hours. }\end{array}$ & 1 & B \\
\hline $\begin{array}{l}\text { It is recommended to interrogate pacemakers and ICDs on a regular basis for AHRE. In cases } \\
\text { of AHRE detected by a CIED of at least } 5 \text { minutes duration, we suggest that direct analysis } \\
\text { of electrograms corresponding to AHRE is clinically indicated to exclude artifacts or other } \\
\text { causes of inappropriate detection of atrial tachyarrhythmias or AF (ungraded consensus- } \\
\text { based statement). }\end{array}$ & Ila & B \\
\hline $\begin{array}{l}\text { In stroke patients, additional ECG monitoring by long-term noninvasive ECG monitors or } \\
\text { implanted loop recorders should be considered to document silent atrial fibrillation. }\end{array}$ & Ila & B \\
\hline $\begin{array}{l}\text { Systematic ECG screening may be considered to detect AF in patients aged }>75 \text { years, or those } \\
\text { at high stroke risk. }\end{array}$ & $\mathrm{IIa}$ & $B$ \\
\hline
\end{tabular}

\section{DETECTION AND MANAGEMENT OF RISK FACTORS AND CONCOMITANT CARDIOVASCULAR DISEASE}

Several concomitant conditions are closely related to AF development, recurrence, and complications. The prevention, detection, and treatment of these conditions are essential to preventing AF and reducing its burden. AF independently increases allcause mortality, and only 1 in 10 deaths in AF patient are related to stroke, while > 7 in 10 are cardiovascular. ${ }^{66)}$ Hence, cardiovascular and comorbidity risk management is essential as part of the holistic or integrated care of AF management to reduce deaths and hospitalisations. ${ }^{66)}$ 
$\mathrm{HF}$ and $\mathrm{AF}$ coexist in many patients and can exacerbate each other. $\mathrm{HF}$ is a risk factor of $\mathrm{AF}$ (HR, 1.43; 95\% CI, 0.85-2.40). ${ }^{6768)}$ The principal of AF management in HF patients does not differ from that in patients without HF, and these efforts should be performed regardless of left ventricular ejection fraction (LVEF) ${ }^{69}$ Appropriate OAC therapy by patient stroke risk is crucial and optimal HF therapy by guideline is also important. ${ }^{69)}$ Angiotensin-converting enzyme inhibitors (ACEIs)/angiotensin receptor blockers (ARBs) with a beta-blocker or eplerenone reduced the risk of new-onset AF in patients with reduced LVEF HF patients. ${ }^{70-74)}$ According to recently published data in the CASTLE-AF trial, catheter ablation of AF reduced the risk of all-cause death $(47 \%)$ and cardiovascular death $(51 \%)$ in patients with $\mathrm{HF}$ and reduced LVEF. ${ }^{75}$ Catheter ablation of AF in HF patients could be a treatment option for improvement outcomes in selected patients.

Hypertension is a risk factor of AF development (HR, 1.32; 95\% CI, 1.08-1.60) and a risk factor of stroke and bleeding in AF patients. Good blood pressure control should be considered part of the optimal care of AF patients. ${ }^{687(6) 77)}$ Several previous reports suggested that ACEIs or ARBs had a beneficial effect on new-onset $\mathrm{AF}$ and the prevention of $\mathrm{AF}$ recurrence. ${ }^{\text {.0-72) } 78-82)}$

Diabetes is a commonly prevalent comorbidity with AF sharing common risk factors. ${ }^{83-86)}$ Diabetes is a risk factor of AF (HR, 1.25; 95\% CI, 0.98-1.60) and a risk factor of stroke in AF patients, with no profound differences between type I and type II diabetes. ${ }^{6887788)}$ Although there is no evidence that intensive glycemic control does not reduce AF development, diabetes severity is associated with an increased risk of AF development (e.g. diabetic retinopathy)..$^{8789)}$

\section{INTEGRATED TREATMENTS FOR ATRIAL FIBRILLATION PATIENTS}

One important issue for implementing integrated care management of AF is how to get people to remember the components of such an approach. The latter should streamline the holistic management pathway whether in primary care, hospitals and even understanding by patient.

Use of the ABC pathway of integrated care management is suggested as follows: 1) 'A' Avoid stroke with Anticoagulation; 2) 'B' Better symptom management (i.e. patientcentered, symptom directed decisions on rate vs. rhythm control); 3) 'C' Cardiovascular and comorbidity management, including lifestyle factors (Figure 7) ${ }^{90}$ ) Application of the simple $\mathrm{ABC}$ pathway allows the streamlining of integrated care for AF patients in a holistic manner and has been reported to be associated with a lower risk of adverse outcomes, including recent data in a Korean cohort. ${ }^{66)}$ An integrated approach for AF management is the basis of consistent guideline-based treatment of AF and such guideline adherence helps improve patient outcomes. ${ }^{91-94)}$

To accurately assess the effect of AF on cardiovascular disease, it is necessary to refer to a cardiologist after an initial diagnosis, especially if acute treatment is required, as follows: 1) unstable vital signs including uncontrollably fast heart rate; 2) symptomatic bradycardia despite reduction or stopping of nodal blocker; 3 ) ongoing or severe angina with reduced left ventricular function; and 4) transient ischemic attack, stroke, or thromboembolic events. 


\section{The ABC pathway for integrated care management}

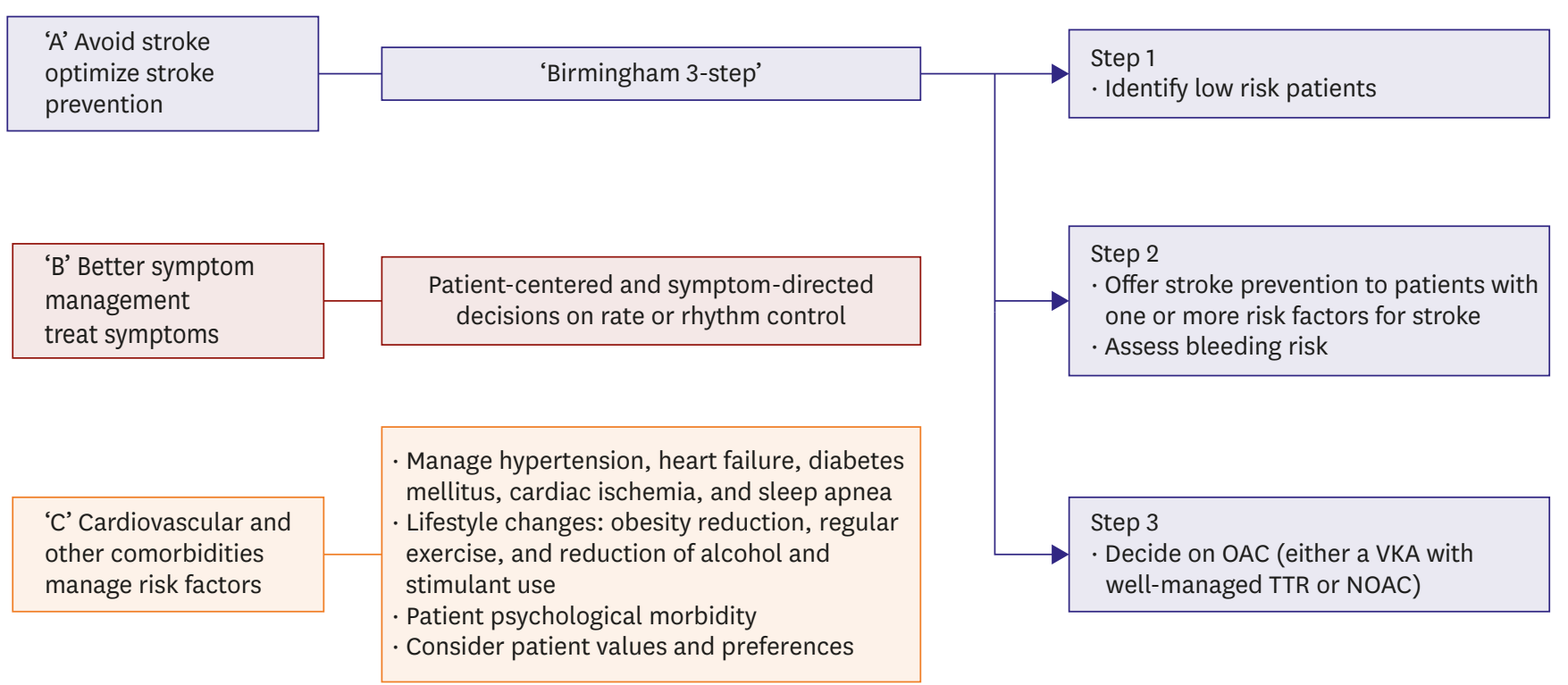

Figure 7. The basic concept of acute and chronic management of AF. Modified from Lip et al..5)

$\mathrm{AF}=$ atrial fibrillation; $\mathrm{NOAC}=$ non-vitamin $\mathrm{K}$ antagonist oral anticoagulant; $\mathrm{OAC}=$ oral anticoagulation therapy; $\mathrm{TTR}=$ time in therapeutic range.

\section{Components of integrated care}

Integrated $\mathrm{AF}$ care include patient's active participation, multidisciplinary approach technology use, and all treatment approach (Table 3).

\section{Active patient participation}

Chronic diseases such as AF can be expected to have a better long-term therapeutic effect if the patient is well aware of the disease and his or her responsibility in the treatment process. ${ }^{95}$ Patient-oriented treatment, including the involvement of patients in the decisionmaking stage, can increase compliance and respect individual preferences, requirements, and autonomy. ${ }^{96)}$ However, the awareness rate of $\mathrm{AF}$ was $<10 \%$ in 2017, which was conducted by the KHRS (release in press conference). Therefore, the KHRS is making diverse efforts to increase awareness of the general public through information campaigns, including risk factor information, recognition, treatment, and self-management of the disease.

Table 3. Integrated AF treatment

\begin{tabular}{|c|c|c|c|}
\hline Patient's active participation & Multidisciplinary approach & Technology use & All treatment approach \\
\hline - Patients oriented treatment & $\begin{array}{l}\text { - Physicians (primary care physicians, } \\
\text { cardiologists, cardiovascular surgeons, } \\
\text { arrhythmia specialists, and stroke } \\
\text { specialists) and allied health professionals }\end{array}$ & $\begin{array}{l}\text { - Technical support for free } \\
\text { communication among team } \\
\text { members }\end{array}$ & - Life style modification \\
\hline - Patient education by specialists & $\begin{array}{l}\text { - Good communication and education } \\
\text { between the patient and the physician }\end{array}$ & $\begin{array}{l}\text { - Checklist and communication } \\
\text { tools }\end{array}$ & - Anticoagulation \\
\hline $\begin{array}{l}\text { - Encouragement for autonomy, } \\
\text { self-management }\end{array}$ & & $\begin{array}{l}\text { - Monitoring tool on therapy } \\
\text { adherence and effectiveness }\end{array}$ & - Rate control \\
\hline $\begin{array}{l}\text { - Proper control on related } \\
\text { comorbidities }\end{array}$ & & & - Rhythm control by AADs \\
\hline $\begin{array}{l}\text { Patient's active participation on } \\
\text { decision marking }\end{array}$ & & & $\begin{array}{l}\text { - Catheter ablation and surgical interventions } \\
\text { (ablation, LAA occluder, AF surgery, etc.) }\end{array}$ \\
\hline
\end{tabular}


Self-management includes adapting to the treatment process, changing lifestyles, such as smoking cessation and weight control, and requires patients to be aware of the treatment method and goal. ${ }^{97 / 98)}$

\section{Multidisciplinary approach}

A multidisciplinary approach involving primary care physicians, cardiologists, cardiovascular surgeons, arrhythmia specialists, and stroke specialists who first encounter the patient can help the patient actively participate in treatment. By engaging the patient in the stage, the patient can adhere to the treatment, which enhances its effect. ${ }^{991100)}$ Thus, a multidisciplinary approach to AF involves not only specialized medical knowledge but also good communication and education between the patient and physician.

\section{Technological use for smooth communication among medical staff}

For the integrated treatment of AF, it is essential to communicate and exchange smoothly among members. This requires technical support for free communication between patients and physicians, primary care physicians, and arrhythmia specialists. Digital programs and smartphone apps can help with this process. ${ }^{101)}$ One pilot study using a smartphone App shows how this can be operationalized. ${ }^{102)}$ Because Korea has high rate of smartphone use, a smartphone App can potentially be used for the management of AF.

\section{All treatments for atrial fibrillation}

The ABC pathway described above includes proactive assessment and management of cardiovascular disease and risk factors (cardiovascular and comorbidity risk reduction). ${ }^{90}$ To this end, the active management of related diseases such as obesity, hypertension, sleep apnea and diabetes should be performed, and lifestyle corrections such as smoking, drinking, and exercise should be corrected..$^{90103 / 104)}$

\section{Diagnostic approach to atrial fibrillation}

\section{Integrated assessment of patients with atrial fibrillation}

A review of the history of systemic embolism including cardiac infarction and symptoms of AF and causes should be performed. The possible causes of correction should be assessed through interviews regarding lifestyle habits such as diabetes, hypertension, COPD, obesity, and sleep apnea; underlying diseases such as hyperthyroidism; and drinking or smoking. ${ }^{103-110)} \mathrm{An}$ analysis of standardized Korean NHIS screening data showed that increased blood pressure and fasting blood sugar alone increased the incidence of AF in pre-hypertensive and pre-diabetic patients. ${ }^{103}$ Even in an analysis of Asian patients with relatively low degree of body mass index, the incidence of AF increased and the prognosis was poor when obesity was comorbid. ${ }^{1041111}$ A 12-lead ECG should be used to evaluate the presence of cardiac conduction disturbances, ischemic heart disease, and structural heart disease. Transthoracic echocardiography should be performed on all patients to determine the treatment strategy for AF.

\section{Additional diagnostic methods for patients with atrial fibrillation}

Twenty-four-hour Holter monitoring is useful for evaluating heart rate and the relationship between symptoms and AF. In particular, information about heart rate during exercise or activity provided by 24-hour Holter monitoring can be used to determine if the goal of heart rate modulation through drug therapy has been achieved. Transesophageal echocardiography (TEE) is useful for evaluating left atrial function and screening for thrombus in the left atrium. Therefore, the evaluation of intracardiac thrombi through TEE is essential in patients who are undergoing invasive sinus rhythm conversion or radiofrequency ablation. ${ }^{112) 113)}$ 


\section{Follow-up of patients with atrial fibrillation}

Most AF patients require periodic follow-up for continuous optimal treatment. Follow-up can be performed by primary care physicians, cardiologists, or arrhythmia specialists. Follow-up of the treatment plan, continued patient participation, and any needed treatment modifications are necessary. The treatment of AF involves prognosis-related treatment (anticoagulant therapy and treatment of cardiovascular disease) and symptom-related treatment (heart rate or cardiac rhythm control). ${ }^{901144}$ In addition, if AF is partially recurrent, if the overall frequency, duration of AF decrease, and clinical symptoms are controlled, it is considered successful. The management of diseases (obesity, hypertension, HF, diabetes mellitus, sleep apnea) related to AF should be provided continuously, ${ }^{1031106111115) 116)}$ while lifestyle factors such as smoking and drinking should be monitored in an integrated manner. ${ }^{117) 118)}$

\section{STROKE PREVENTION THERAPY IN ATRIAL FIBRILLATION PATIENTS}

\section{Prediction of stroke risk}

Stroke prevention is the principal management priority in patients with AF. Compared to control or placebo, OAC therapy reduces the risk of stroke by $64 \%$ and the risk of death by $26 \%{ }^{119)}$ but also increases bleeding risk, which can be fatal. As non-vitamin K oral anticoagulants (NOAC) showed improved efficacy and safety compared with warfarin, the threshold for initiating OAC therapy decreased from an annual stroke rate of $1.7 \%$ with vitamin $\mathrm{K}$ antagonists to $0.9 \%$ with NOAC. ${ }^{120)}$

The $\mathrm{CHA}_{2} \mathrm{DS}_{2}$-VASc score is now used in most guidelines for stroke prevention in patients

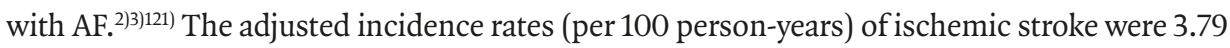
in Korea, being 0.26 in low-risk patients $\left(\mathrm{CHA}_{2} \mathrm{DS}_{2}\right.$-VASc score 0 [male] or 1 [female]), 1.18 in intermediate-risk patients ( $\mathrm{CHA}_{2} \mathrm{DS}_{2}$-VASc score 1 [male]), and 5.30 in high-risk patients $\left(\mathrm{CHA}_{2} \mathrm{DS}_{2}-\mathrm{VASc} \geq 2\right)$. The incidence rates of patients with a $\mathrm{CHA}_{2} \mathrm{DS}_{2}-\mathrm{VASc}$ score of 1 (male), 2 , 3, 4, 5, 6, and 7 or more were 1.04, 1.91, 2.54, 4.72, 5.79, 8.36, and 8.82, respectively (Table 4).9.

The more recent focus of stroke prevention in patients with non-valvular AF has shifted away from predicting "high-risk" patients toward initially identifying patients at a "truly low risk" of ischemic stroke in whom OAC has no net clinical benefit. ${ }^{122-125)}$ Korean patients who were categorized as "low risk" by the $\mathrm{CHA}_{2} \mathrm{DS}_{2}$-VASc score (i.e. score 0 in males or 1 in females) consistently had an event rate of $<1 \% / y e a r .{ }^{9)} \mathrm{CHA}_{2} \mathrm{DS}_{2}$-VASc had the best sensitivity $(98.8 \%$ vs.

Table 4. Ischemic stroke or composite thromboembolism endpoint/100 years at risk in relation to $\mathrm{CHA}_{2} \mathrm{DS}_{2}$-VASc scores in Korean patients without anticoagulation throughout follow-up ${ }^{4}$

\begin{tabular}{|c|c|c|c|c|c|}
\hline \multirow{2}{*}{$\mathrm{CHA}_{2} \mathrm{DS}_{2}$-VASc score } & \multirow{2}{*}{ Number of patients } & \multicolumn{2}{|c|}{ Ischemic stroke } & \multicolumn{2}{|c|}{ Ischemic stroke/systemic embolism } \\
\hline & & Unadjusted & Adjusted for aspirin* & Unadjusted & Adjusted for aspirin* \\
\hline 0 (male) or 1 (female) & 860 & 0.23 & 0.26 & 0.26 & 0.29 \\
\hline 1 (male) & 550 & 1.04 & 1.18 & 1.20 & 1.35 \\
\hline 2 & 975 & 1.91 & 2.21 & 2.04 & 2.35 \\
\hline 3 & 911 & 2.54 & 2.88 & 2.67 & 3.04 \\
\hline 4 & 836 & 4.72 & 5.34 & 5.10 & 5.76 \\
\hline 5 & 770 & 5.79 & 6.54 & 5.98 & 6.76 \\
\hline 6 & 513 & 8.36 & 9.50 & 8.61 & 9.77 \\
\hline 7 or more & 440 & 8.82 & 9.97 & 9.03 & 10.21 \\
\hline Total & 5,855 & 3.32 & 3.79 & 3.49 & 3.98 \\
\hline
\end{tabular}

TE $=$ thromboembolic event.

*Adjustment made for exposure to aspirin treatment, assuming that aspirin provides a 19\% reduction in TE risk, to give an indication of 'untreated' rates. 
$85.7 \%$ in $\mathrm{CHADS}_{2}$ and $74.8 \%$ in the ATRIA study) and negative predictive value ( $98.8 \%$ vs. $95.3 \%$ for $\mathrm{CHADS}_{2}$ and $93.7 \%$ for the ATRIA study) for the prediction of stroke incidence and was best for predicting the absence of ischemic stroke during 5 years of follow-up (odds ratio, 16.4; $95 \%$ $\mathrm{CI}, 8.8-30.8) .{ }^{125}$ However, the $\mathrm{CHA}_{2} \mathrm{DS}_{2}$-VASc score had lower net reclassification improvement and c-index suggesting that it is specifically better to discriminate true low-risk AF for stroke. ${ }^{125) 126)}$

\section{Individual stroke risk factors: sex, age, and hypertension}

On multivariate analysis, significant associations between $\mathrm{CHA}_{2} \mathrm{DS}_{2}$-VASc risk factors and ischemic stroke were observed. The significance of vascular disease or diabetes mellitus were attenuated after multivariate adjustment, and female sex (HR, 0.73; 95\% CI, 0.64-0.84) had a lower risk of ischemic stroke than male sex in Korean NHIS sample cohort (Table 5).9126) Coronary and peripheral artery disease have been reported to be important independent risks for stroke in $\mathrm{AF}^{127) 128)}$ Several cohort studies have shown that female sex is a risk factor for stroke, although this is dependent on age and the presence of other non-sex risk factors. ${ }^{129-133)}$ Recently, female sex was suggested as a risk modifier for stroke in patients with AF, rather than a risk factor. ${ }^{134)}$ Several Asian cohort studies from Hong Kong, ${ }^{135}$ China, ${ }^{136)}$ Taiwan, ${ }^{127)}$ and Japan ${ }^{137}$ have suggested that female sex was not an independent risk factor for ischemic stroke, again suggesting some potential ethnic differences in the risk of stroke between Asian and non-Asian populations. Consistent with previous Asian studies, female sex was not a risk factor for stroke in a Korean cohort; instead, it was associated with a lower stroke risk of ischemic stroke than male sex. Other risk factors in our population such as older age, previous stroke or TIA history, HF, and hypertension remained independent stroke risk factors consistent with findings in western cohorts. ${ }^{9)}$

Older age is the most important predictor of ischemic stroke in Korean and Taiwan patients with AF. ${ }^{138) 139)}$ Patients aged 65-74 years without other risk factors showed a significantly higher risk of stroke than those with one risk factor other than age. Lowering the current age threshold (age $\geq 65$ years) in the $\mathrm{CHA}_{2} \mathrm{DS}_{2}$-VASc score to age $\geq 55$ years might be appropriate among Asian patients with AF. ${ }^{139)}$ Two recent Korean studies suggested that blood pressure should be controlled more strictly in AF patients. ${ }^{77103)}$

Table 5. Associations between baseline factors and ischemic stroke in patients without anticoagulant treatment ${ }^{4)}$

\begin{tabular}{|c|c|c|c|c|c|}
\hline & \multicolumn{5}{|c|}{ Ischemic stroke } \\
\hline & \multirow{2}{*}{ Number with event } & \multicolumn{2}{|c|}{ Univariable } & \multicolumn{2}{|c|}{ Multivariable } \\
\hline & & $\mathrm{HR}$ & $95 \% \mathrm{Cl}$ & $\mathrm{HR}$ & $95 \% \mathrm{Cl}$ \\
\hline \multicolumn{6}{|l|}{ Age (years) } \\
\hline$<65$ & $161 / 2,594$ & Ref & & Ref & \\
\hline $65-74$ & $320 / 1,700$ & 3.44 & $2.84-4.16$ & 2.11 & $1.73-2.58$ \\
\hline$>75$ & $338 / 1,561$ & 4.70 & $3.90-5.68$ & 3.11 & $2.51-3.85$ \\
\hline Women & $385 / 2,835$ & 0.94 & $0.82-1.07$ & 0.75 & $0.63-0.86$ \\
\hline Ischemic stroke/TIA & $411 / 1,433$ & 3.81 & $3.32-4.37$ & 2.58 & $2.23-2.97$ \\
\hline \multicolumn{6}{|l|}{ Atherosclerotic disease } \\
\hline Myocardial infarction & $139 / 764$ & 1.49 & $1.24-1.79$ & 0.97 & $0.81-1.17$ \\
\hline Peripheral arterial disease & $113 / 611$ & 1.45 & $1.19-1.76$ & 0.95 & $0.78-1.17$ \\
\hline Vascular disease* $^{*}$ & $221 / 1,206$ & 1.54 & $1.32-1.80$ & 0.98 & $0.84-1.15$ \\
\hline HF & $380 / 1,869$ & 2.16 & $1.88-2.48$ & 1.23 & $1.06-1.42$ \\
\hline Hypertension & $750 / 4,422$ & 4.04 & $3.16-5.17$ & 1.85 & $1.43-2.40$ \\
\hline Diabetes & $216 / 1,168$ & 1.53 & $1.31-1.79$ & 1.13 & $0.96-1.32$ \\
\hline ESRD & $23 / 89$ & 2.36 & $1.56-3.57$ & 2.03 & $1.33-3.09$ \\
\hline COPD & $134 / 673$ & 1.72 & $1.43-2.07$ & 1.13 & $0.94-1.37$ \\
\hline Aspirin use & $505 / 2,636$ & 1.93 & $1.68-2.23$ & 1.30 & $1.12-1.50$ \\
\hline
\end{tabular}

$\mathrm{Cl}$ = confidence interval; $\mathrm{COPD}=$ chronic obstructive pulmonary disease; $\mathrm{ESRD}=$ end-stage renal disease; $\mathrm{HF}=\mathrm{heart}$ failure; $\mathrm{HR}=$ hazard ratio; $\mathrm{TIA}=\mathrm{transient}$ ischemic attack.

${ }^{*}$ Vascular disease includes previous myocardial infarction, peripheral arterial disease, or aortic plaque. 


\section{Recommended anticoagulation for Korean patients.}

The performance of $\mathrm{CHA}_{2} \mathrm{DS}_{2}$-VASc score in Korean populations is comparable with that seen in Western populations. For patients with $\mathrm{AF}$ without valvular heart disease, including those with paroxysmal AF, who are at low risk of stroke (e.g., $\mathrm{CHA}_{2} \mathrm{DS}_{2}$-VASc score of 0 in males or 1 in females), we suggest no antithrombotic therapy (class III). The next step is to consider stroke prevention (i.e., OAC therapy) for patients with 1 or more non-sex $\mathrm{CHA}_{2} \mathrm{DS}_{2}$-VASc stroke risk factors. For patients with a single non-sex $\mathrm{CHA}_{2} \mathrm{DS}_{2}$-VASc stroke risk factor, we suggest OAC rather than no therapy, aspirin, or combination therapy with aspirin and clopidogrel (class IIa); and for those at high risk of stroke (e.g., $\mathrm{CHA}_{2} \mathrm{DS}_{2} \geq 2$ in males or $\geq 3$ in females), we recommend $\mathrm{OAC}$ rather than no therapy, aspirin, or combination therapy with aspirin and clopidogrel (class I) (Figure 8).

Where we recommend or suggest in favor of OAC, we suggest using a NOAC rather than adjusted-dose vitamin $\mathrm{K}$ antagonist therapy. With the latter, it is important to aim for good quality anticoagulation control with a time in therapeutic range (TTR) $>70 \%$. Attention to modifiable bleeding risk factors (e.g., uncontrolled blood pressure [BP], labile INRs, concomitant use of aspirin or nonsteroidal anti-inflammatory drugs (NSAIDs) in an anticoagulated patient, alcohol excess) should be made at each patient contact, and the HASBLED score used to assess the risk of bleeding whereby 'high risk' patients (score $\geq 3$ ) should be reviewed and followed up more frequently. While NOACs are increasingly the preferred option, warfarin is still widely used and the SAMe-TT $\mathrm{R}_{2}$ score (which has been validated even in Asian cohorts) ${ }^{140)}$ can help identify patients less likely to do well on warfarin, so as to arrange more frequent INR checks, education and counselling - or to consider a NOAC instead of warfarin (Figure 9). ${ }^{5}$

\section{Dynamic adjustment of stroke and bleeding risk}

Many clinical variables of stroke and bleeding risk score have "dynamic" variation through follow-up. ${ }^{141143)}$ Age increases annually in all patients, and incident hypertension, diabetes mellitus, vascular disease, congestive HF, and prior stroke or transient ischemic attack may become evident in some patients. These dynamic changes in risk factors may increase the

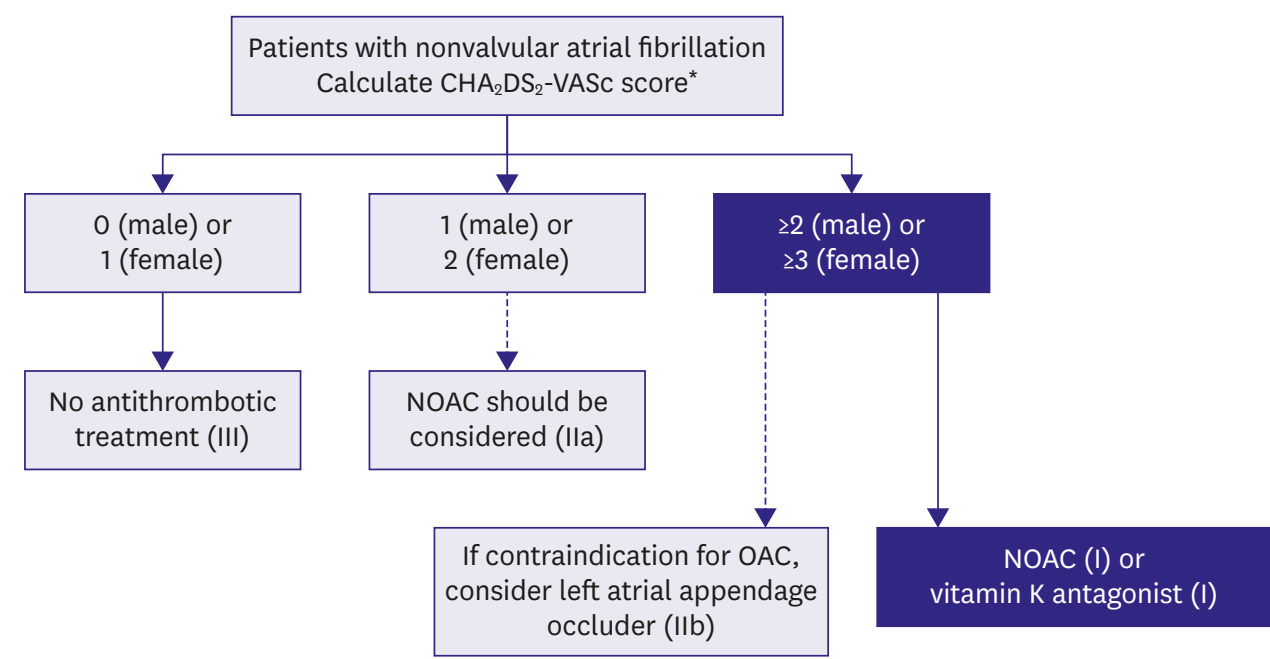

Figure 8. Stroke prevention strategy in patients with AF.

$\mathrm{AF}$ = atrial fibrillation; $\mathrm{HF}$ = heart failure; $\mathrm{NOAC}=$ non-vitamin $\mathrm{K}$ oral anticoagulant; $\mathrm{OAC}=$ oral anticoagulation. ${ }^{*} \mathrm{CHA}_{2} \mathrm{DS}_{2}$-VASs score: a congestive HF, hypertension, age $\geq 75$ (doubled), diabetes mellitus, prior stroke or transient ischemic attack (doubled), vascular disease, age 65-74, female. 


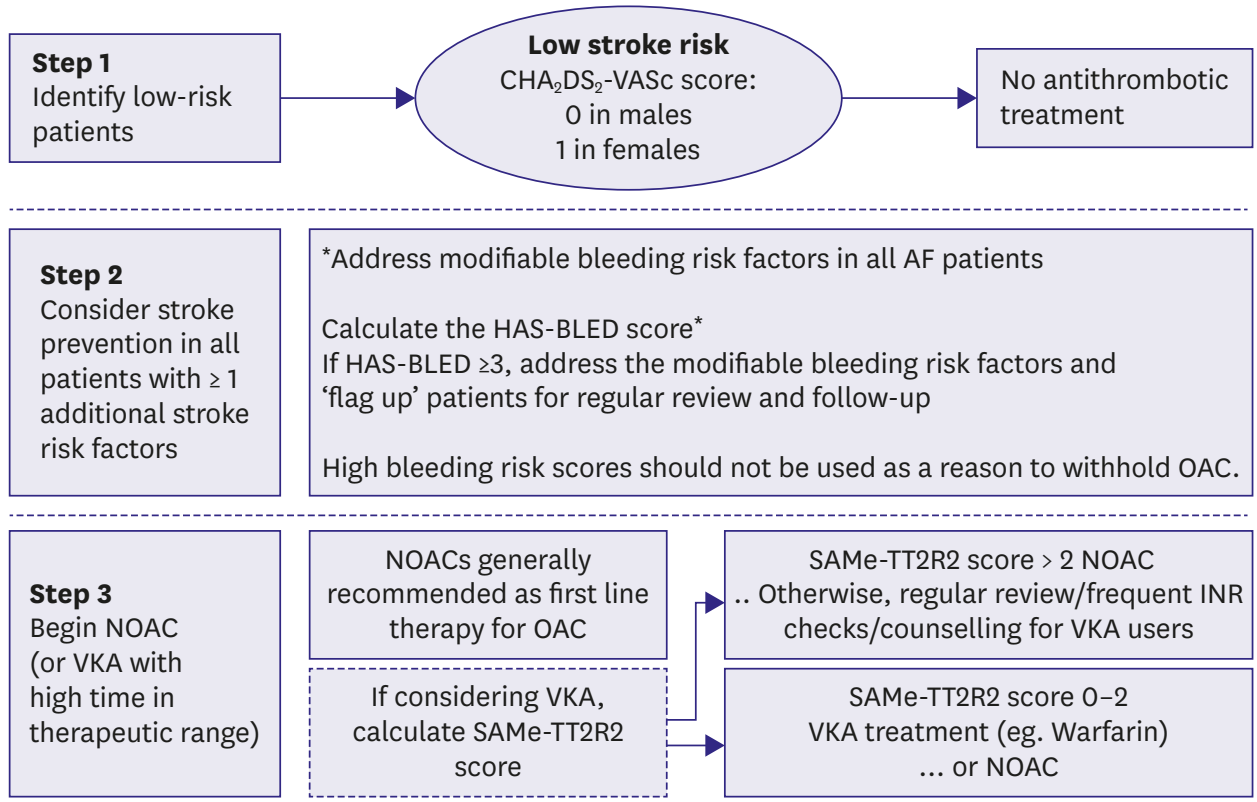

Figure 9. Practical management algorithm in light of the 2018 American College of Chest Physicians guidelines, which are evidence based and GRADE.

$\mathrm{AF}=$ atrial fibrillation; INR = international normalized ratio; NOAC = non-vitamin $\mathrm{K}$ antagonist oral anticoagulant; OAC $=$ oral anticoagulation therapy.

*HAS-BLED: hypertension, abnormal renal/liver function (1 point each), stroke, bleeding history or predisposition, labile INR, elderly (0.65), drugs/alcohol concomitantly (1 point each).

$\mathrm{CHA}_{2} \mathrm{DS}_{2}$-VASc score, stroke risk category, and absolute ischemic stroke rate. Despite using only baseline $\mathrm{CHA}_{2} \mathrm{DS}_{2}$-VASc score to predict the risk of ischemic stroke in AF patients, a time-dependent $\mathrm{CHA}_{2} \mathrm{DS}_{2}$-VASc score and "delta $\mathrm{CHA}_{2} \mathrm{DS}_{2}$-VASc score" (follow-up minus baseline) improved the prediction of ischemic stroke in Korean and Taiwan AF populations (Figure 10). ${ }^{141) 142)}$

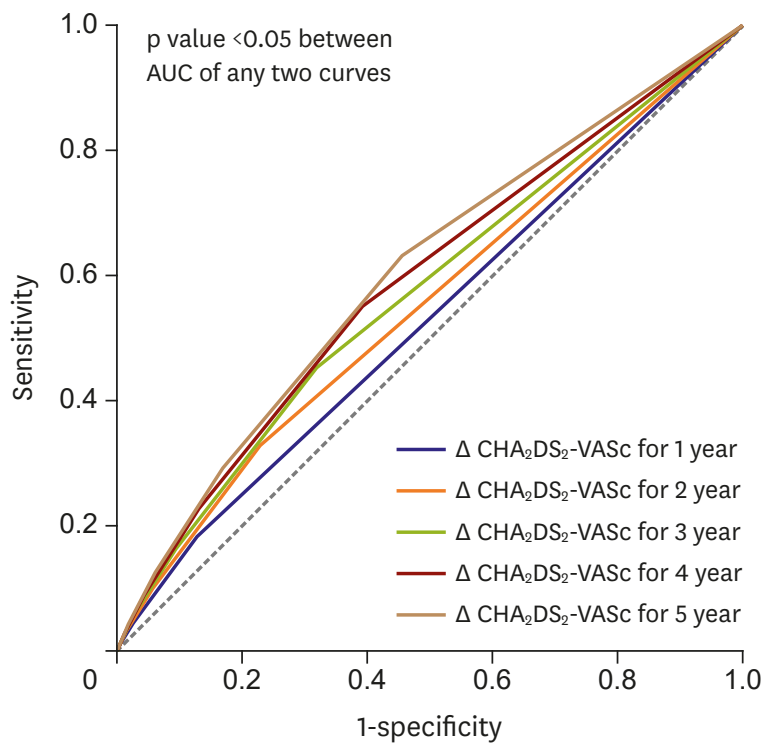

\begin{tabular}{lccc}
\hline & AUC & $95 \% \mathrm{Cl}$ & $\mathrm{SE}$ \\
\hline$\Delta \mathrm{CHA}_{2} \mathrm{DS}_{2}$-VASc for & & & \\
1 year (Baseline-2006) & 0.528 & $0.522-0.533$ & 0.003 \\
2 year (Baseline-2007) & 0.552 & $0.547-0.557$ & 0.003 \\
3 year (Baseline-2008) & 0.572 & $0.567-0.557$ & 0.003 \\
4 year (Baseline-2009) & 0.589 & $0.584-0.594$ & 0.003 \\
5 year (Baseline-2010) & 0.603 & $0.598-0.608$ & 0.003 \\
\hline
\end{tabular}

Figure 10. Receiver operating characteristic curves of $\triangle \mathrm{CHA}_{2} \mathrm{DS}_{2}$-VASc score for predicting ischemic stroke during the entire second follow-up period. $\mathrm{AUC}=$ area under the curve; $\mathrm{Cl}=$ confidence interval; $\mathrm{SE}=$ standard error. 
Table 6. Dose reduction of NOACs ${ }^{281)}$

\begin{tabular}{|c|c|c|}
\hline Drug & Dose reduction criteria & Dose \\
\hline Dabigatran & $\begin{array}{l}\text { Creatinine clearance } 30-50 \mathrm{~mL} / \mathrm{min} \\
\text { P-glycoprotein inhibitors } \\
{ }^{*} \\
\text { Clopidogrel, aspirin, NSAIDs } \\
\text { Increased bleeding risk }{ }^{\dagger} \\
\text { Age } 75 \text { years or more }\end{array}$ & Dabigatran 110 mg b.i.d. \\
\hline Rivaroxaban & $\begin{array}{l}\text { Age } 80 \text { years or more } \\
\text { Creatinine clearance } 15-50 \mathrm{~mL} / \mathrm{min}^{\ddagger}\end{array}$ & Rivaroxaban 15 mg q.d. \\
\hline Apixaban & At least $2: 1$ ) age 80 years or more, 2) body weight $60 \mathrm{~kg}$ or less, 3) creatinine $\geq 1.5 \mathrm{mg} / \mathrm{dL}$ & Apixaban 2.5 mg b.i.d. \\
\hline Edoxaban & $\begin{array}{l}\text { P-glycoprotein inhibitors }{ }^{*} \\
\text { Body weight } 60 \mathrm{~kg} \text { or less } \\
\text { Creatinine clearance } 15-50 \mathrm{~mL} / \mathrm{min}^{\ddagger}\end{array}$ & Edoxaban 30 mg q.d. \\
\hline
\end{tabular}

\section{Recommended non-vitamin $\mathrm{K}$ oral anticoagulants dose regimen for Korean patients}

The benefits of NOAC was more profound in Asian population than non-Asian population. ${ }^{144)}$ Based on the standard dose group, NOAC was more effective (OR of stroke/systemic embolism, 0.65 vs. 0.85 ; p interaction $=0.045$ ) and safer (OR for major bleeding, 0.57 vs. 0.89; p interaction=0.046) in Asians than non-Asians. Among high-risk Asian AF population, dabigatran, rivaroxaban, and apixaban demonstrated similar risk of ischemic stroke and lower risk of intracerebral hemorrhage compared with warfarin. All-cause death was significantly lower only with dabigatran and apixaban, whereas not with rivaroxaban in a Korean study. ${ }^{145}$ ) However, rivaroxaban also decreased all-cause death in a different Korean study. ${ }^{146}$

Elderly patients with $\mathrm{AF}$ (such as those aged $\geq 80$ years) and patients with impaired renal function were included in the landmark NOAC trials, but these important subgroups comprised only a small proportion of the patient populations. For dabigatran, reduction of the daily recommended dose to $110 \mathrm{mg}$ twice daily (b.i.d.) is indicated for patients aged $\geq 80$ years. This dose can be reduced to $110 \mathrm{mg}$ b.i.d. if the patient is aged $75-79$ years and has other comorbidities that could affect bleeding risk such as previous gastritis, peptic ulcer disease, and moderate renal impairment. Indeed, label (or guideline) - adherent use of dabigatran is clearly associated with better outcomes for stroke, major bleeding, and mortality. ${ }^{147) 148)}$ Insufficient published data for apixaban, edoxaban, and rivaroxaban indicate that further work is needed to clarify the bleeding risks of NOAC in the elderly.

For Korean patients with AF, a reduced dosing regimen for dabigatran (110 mg b.i.d.) in patients aged $\geq 75$ years or who have an estimated glomerular filtration rate (eGFR) of 30-50 $\mathrm{mL} / \mathrm{min}$; rivaroxaban ( $15 \mathrm{mg}$ once daily [q.d.]) in patients aged $\geq 80$ years or with an eGFR of $15-49 \mathrm{~mL} / \mathrm{min}$; apixaban ( $2.5 \mathrm{mg}$ b.i.d.) if 2 of the 3 following criteria are present: age $\geq 80$ years or an eGFR $15-29 \mathrm{~mL} / \mathrm{min}$ or body weight $\leq 60 \mathrm{~kg}$; or edoxaban (30 mg q.d.) if eGFR is $15-50 \mathrm{~mL} / \mathrm{min}$ are recommended (Table 6).

\section{Low anticoagulation rate}

The OAC rate of total AF in the Korean nationwide cohort remains very low at about $18 \%$, while the usage rate of aspirin exceeds $35 \%{ }^{825)}$ However, the OAC rate of Korean AF was similar to the recent OAC rates of Taiwan nationwide cohort. Li et al. ${ }^{149}$ reported that the overall guideline adherence rate was only $13 \%$ and even lower among patients with a high 
$\mathrm{CHA}_{2} \mathrm{DS}_{2}$-VASc score in this non-selected nationwide AF registry. Moreover, guidelineadherent antithrombotic management was associated with a 38\% lower risk of mortality.

The analysis of a prospective multicenter study performed in tertiary hospitals in Korea (COmparison study of Drugs for symptom control and complication prEvention of Atrial Fibrillation [CODE-AF] registry) showed the optimistic future of stroke prevention in patients with AF. The current $\mathrm{OAC}$ rate of AF patients with high stroke risk $\left(\mathrm{CHA}_{2} \mathrm{DS}_{2}-\mathrm{VASc}\right.$ score $\geq 2$ ) was about $83 \% .{ }^{150)}$ Consistently, in patients with at least 3-year regular hospital visit, OAC prescription rate was higher than nationwide AF registry and tertiary hospital-based registry. It was increased from $34.7 \%$ to $50.6 \%$, whereas antiplatelet prescription decreased gradually from $48.2 \%$ to $31.5 \%$ between 2008 and $2015 .{ }^{151)}$

However, the recent improvement of OAC rate in tertiary hospitals in Korea is related with increased NOAC use because it was $>50 \%$, whereas that of warfarin was still low at $20 \%$. Among AF patients with a high stroke risk and at least 3-year regular hospital visits, OAC utilization was lower in the suburban/rural regions than that observed in the urban regions (48.2\% vs. $51.8 \%$, respectively; $\mathrm{p}<0.001) .{ }^{27)}$

\section{BLEEDING RISK}

\section{Risk factors for bleeding with non-vitamin $\mathrm{K}$ antagonist oral anticoagulant, vitamin $K$ antagonist, and antiplatelet therapy}

Bleeding risk varies from person to person depending on their pre-existing comorbidities, current antithrombotic regimen and adherence, concomitant medication, and lifestyle choices. Many of these factors cannot be altered but some are modifiable or potentially modifiable.5152)

- BP control: Good control of BP is vital to reduce the risk of stroke and is essential to decrease the risk of bleeding (particularly intracranial haemorrhage) on antithrombotic therapy.

- Anticoagulation control: Among patients receiving vitamin K antagonist, maintenance of an INR in the therapeutic range (2.0-3.0) is essential. The proportion of TTR should be at least $65 \%$ but the ultimate aim/target should be $100 \%$.

- Concomitant medication predisposing to bleeding: Nonessential use of concomitant antiplatelet drugs and NSAIDs should be avoided since these medications increase the risk of bleeding in patients receiving OACs.

- Alcohol intake: Excessive alcohol intake (chronic or binge drinking) increases the risk of bleeding predominantly due to the risk of trauma, but in chronic alcohol abuse through poor medication adherence, hepatic and variceal disease.

- Lifestyle factors: Avoidance of work and/or leisure activities that have the potential to cause serious trauma should be advised.

- Bridging periods off anticoagulation: Interruption of OAC should be avoided to reduce stroke risk since the majority of cardiovascular procedures (e.g., pacemaker implantation or percutaneous coronary intervention [PCI]) can be safely performed on OAC. Bridging (i.e., stopping OAC and providing anticoagulation cover with heparin) should be used in patients with mechanical heart valves but does not appear to be otherwise advantageous. ${ }^{153}{ }^{154)}$

- Appropriate choice of OAC: Choice of OAC should be made on an individual basis after stroke and bleeding risk assessment, discussion with the patient and adherence to the 
prescribing label.

- Falls risk and cognitive impairment: The benefits of ischemic stroke reduction generally outweigh the risk of harm from serious bleeding with OAC use. One estimate was that the patient would need to fall 295 times per year for the risk from falls to outweigh the benefits of stroke reduction. ${ }^{155)}$

- Reversal of biochemical anomalies: Patients with anemia or reduced platelet count or impaired hepatic/renal function should be investigated and proactively managed.

\section{Bleeding risk assessment}

Attention to modifiable bleeding risks are important. However, only relying on this to assess bleeding risk is an inferior strategy to a formal bleeding assessment score, as shown in independent cohorts even from Asia. ${ }^{156-158)}$

There are multiple bleeding risk scores that have been proposed for bleeding risk stratification, with the HEMORR ${ }_{2}$ HAGES (hepatic or renal disease, ethanol abuse, malignancy, older, reduced platelet count/function, hypertension, anemia, genetic factors, excessive fall risk, and stroke), HAS-BLED (hypertension, abnormal renal/liver function [1 point each], stroke, bleeding history or predisposition, labile INR, elderly [0.65], drugs/ alcohol concomitantly [1 point each]), ATRIA, ORBIT, and ABC-bleeding scores that have been derived and validated in $\mathrm{AF}$ populations. ${ }^{159)}$

The simple HAS-BLED score has been shown to be similar or outperform older bleeding scores, as well as more simple bleeding scores that include fewer clinical parameters. A high bleeding risk score is not a reason to withhold OAC, as the net clinical benefit is even greater in those patients with high bleeding risk.

\section{Recommendations for stroke prevention in patients with AF}

\begin{tabular}{|c|c|c|}
\hline Recommendations & Class & Level \\
\hline The $\mathrm{CHA}_{2} \mathrm{DS}_{2}$-VASc score is recommended for stroke risk prediction in patients with AF. & 1 & A \\
\hline $\begin{array}{l}\text { OAC is recommended for all male AF patients with a } \mathrm{CHA}_{2} \mathrm{DS}_{2}-\mathrm{VASc} \text { score } \geq 2 \text {, and all female } \\
\mathrm{AF} \text { patients with a } \mathrm{CHA}_{2} \mathrm{DS}_{2}-\mathrm{VASc} \text { score } \geq 3 \text {. }\end{array}$ & I & A \\
\hline $\begin{array}{l}\text { OAC should be considered in male AF patients with a } \mathrm{CHA}_{2} \mathrm{DS}_{2} \text {-VASc score of } 1 \text {, and female } \\
\text { AF patients with a } \mathrm{CHA}_{2} \mathrm{DS}_{2} \text {-VASc score of } 2 \text { considering individual characteristics and } \\
\text { patient preferences. }\end{array}$ & Ila & B \\
\hline $\begin{array}{l}\text { In male or female AF patients without additional stroke risk factors (i.e., } \mathrm{CHA}_{2} \mathrm{DS}_{2}-\mathrm{VASc} \text { score } \\
\text { of } 0 \text { in males or } 1 \mathrm{in} \text { females), anticoagulant or antiplatelet therapy is not recommended for } \\
\text { stroke prevention. }\end{array}$ & $\begin{array}{c}\text { III } \\
\text { (harm) }\end{array}$ & B \\
\hline $\begin{array}{l}\text { In patients with one episode of AF, then stroke prevention with same principles should be } \\
\text { recommended. }\end{array}$ & IIa & B \\
\hline $\begin{array}{l}\text { Vitamin } \mathrm{K} \text { antagonist therapy (INR } 2.0-3.0 \text { or higher) is recommended in AF patients with } \\
\text { moderate-to-severe mitral stenosis or mechanical heart valves. }\end{array}$ & 1 & B \\
\hline $\begin{array}{l}\text { When OAC is initiated in a patient with } \mathrm{AF} \text { who is eligible for a NOAC, a NOAC is } \\
\text { recommended in preference to a vitamin } \mathrm{K} \text { antagonist. }\end{array}$ & I & A \\
\hline $\begin{array}{l}\text { When patients are treated with a vitamin } \mathrm{K} \text { antagonist, TTR should be kept as high as possible } \\
\text { (ideally aiming for TTR }>65-70 \% \text { ) and be closely monitored. }\end{array}$ & 1 & $A$ \\
\hline $\begin{array}{l}\text { Bleeding risk assessment should be performed for all patients with AF at every patient } \\
\text { contact and should initially focus on potentially modifiable bleeding risk factors. }\end{array}$ & 1 & B \\
\hline $\begin{array}{l}\text { The HAS-BLED score is recommended to address modifiable bleeding risk factors in all AF } \\
\text { patients. Those potentially at high risk (HAS-BLED score } \geq 3 \text { ) warrant more frequent and } \\
\text { regular reviews or follow-up. }\end{array}$ & 1 & A \\
\hline $\begin{array}{l}\text { In patients on vitamin } \mathrm{K} \text { antagonists with consistently low time in INR therapeutic range (e.g., } \\
\text { TTR }<65 \% \text { ), we recommend considering interventions to improve TTR or switching to NOACs. }\end{array}$ & 1 & $A$ \\
\hline
\end{tabular}




\section{LEFT ATRIAL APPENDAGE OCCLUSION AND EXCLUSION}

\section{Left atrial appendage occlusion devices}

Transcatheter left atrial appendage (LAA) occlusion or percutaneous LAA ligation has been performed since LAA was proven to be the major source of thrombus formation in patients with non-valvular AF. Two RCTs (PROTECT AF and PREVAIL) have directly compared the LAA occlusion using a Watchman device ${ }^{\circledast}$ with vitamin K antagonist, and these data suggested that LAA occlusion was non-inferior to vitamin $\mathrm{K}$ antagonist for the prevention of stroke in AF patients with a moderate stroke risk. ${ }^{160-163)}$ Recently published longer-term follow-ups of RCTs have demonstrated that the LAA occlusion might reduce the risk of thromboembolic stroke compared with vitamin K antagonist. ${ }^{164)} \mathrm{A}$ high implantation success rate $(98 \%)$ with an acceptable procedure-related complication rate of $4 \%$ at 30 days was reported in a large recent European registry. ${ }^{165)(166)}$ However, these data were in contrast with the analyses from insurance databases and systematic reviews that claimed higher serious complications related with the implantation procedure, possibly identifying a certain degree of reporting bias. There is also uncertainty how a LAA occlusion would compare against a NOAC. Therefore, the Korean AF guideline recommends that AF patients with contraindications for long-term OAC therapy, a recurrent thromboembolic event, or a high risk of stroke despite OAC therapy may be considered to have LAA occlusion for stroke prevention purposes (class IIb).

\section{Left atrial appendage occlusion or exclusion}

Surgical LAA occlusion or exclusion in conjunction with cardiac surgery has been performed with multiple techniques for many decades. The feasibility and safety of surgical LAA occlusion/exclusion were proven in various observational studies. ${ }^{167)}$ However, limited controlled trial data have been published. The role of concomitant AF surgery and LAA occlusion has been evaluated and reported in an RCT in 2015 without showing a clear benefit of LAA exclusion for stroke prevention in the subgroup undergoing AF surgery. A large RCT is currently underway. ${ }^{168)}$ Therefore, the Korean AF guideline recommends that patients with AF undergoing cardiac surgery may benefit from surgical occlusion or the exclusion of LAA for stroke prevention (class IIb). Patients undergoing thoracoscopic AF surgery may benefit from surgical occlusion or the exclusion of LAA for stroke prevention (class IIb).

\section{RATE CONTROL}

Heart rate control is a substantial part of the treatment of patients with $\mathrm{AF}$ despite the remarkable advancement of pharmacologic and non-pharmacologic rhythm control management. An adequately and appropriately controlled ventricular rate can reduce or eliminate symptoms, improve hemodynamics, and prevent tachycardia-induced cardiomyopathy.

Rate control can be achieved with beta-blockers, non-dihydropyridine calcium channel blockers, digoxin, or combination therapy. Certain antiarrhythmic agents including amiodarone and sotalol also have rate-controlling effects, but they should be reserved for patients requiring rhythm control therapy. When considering which drug to use, clinicians should consider the patient's symptoms, hemodynamic status, presence of HF, and precipitating factors for AF. Medications for acute and long-term rate control are presented in Table 7. 
Table 7. Rate control therapy in patients with $\mathrm{AF}^{25}$

\begin{tabular}{|c|c|c|c|c|}
\hline Drug & Acute rate control (IV) & Long-term rate control (PO) & Adverse effect & Comments \\
\hline \multicolumn{5}{|l|}{ Beta-blockers } \\
\hline Bisoprolol & Not available & $1.25-10 \mathrm{mg}$ q.d. or split & $\begin{array}{l}\text { Bradycardia, AV block, and } \\
\text { hypotension. }\end{array}$ & \multirow{5}{*}{$\begin{array}{l}\text { Bronchospasm is rare. In cases } \\
\text { of asthma, recommend beta- } 1 \\
\text { selective agents. Contra-indicated } \\
\text { in acute HF and a history of severe } \\
\text { bronchospasm. }\end{array}$} \\
\hline Carvedilol & Not available & $\begin{array}{l}3.125-25 \text { mg b.i.d. } \\
8-64 \text { mg q.d. (ER) }\end{array}$ & $\begin{array}{l}\text { Lethargy, headache, peripheral } \\
\text { edema, upper respiratory tract }\end{array}$ & \\
\hline Metoprolol & Not available & $\begin{array}{l}\text { 12.5-100 mg b.i.d. } \\
25-200 \text { mg q.d. (ER) }\end{array}$ & $\begin{array}{l}\text { symptoms, gastrointestinal upset, } \\
\text { and dizziness. }\end{array}$ & \\
\hline Nebivolol & Not available & $1.25-10 \mathrm{mg}$ q.d. or split & & \\
\hline Esmolol & $\begin{array}{l}500 \mathrm{mcg} / \mathrm{kg} \text { IV bolus over } 1 \\
\text { minutes, then } 50-250 \mathrm{mcg} / \mathrm{kg} / \mathrm{min}\end{array}$ & & & \\
\hline \multicolumn{5}{|c|}{ Calcium-channel blockers } \\
\hline \multirow[t]{2}{*}{ Diltiazem } & $\begin{array}{l}0.25 \mathrm{mg} / \mathrm{kg} \text { IV bolus over } 2 \\
\text { minutes, then } 5-15 \mathrm{mg} / \mathrm{h}\end{array}$ & 60-120 mg t.i.d. & $\begin{array}{l}\text { Bradycardia, AV block, and } \\
\text { hypotension. }\end{array}$ & \multirow{3}{*}{$\begin{array}{l}\text { Use with caution in combination } \\
\text { with beta-blockers. Reduce dose } \\
\text { with hepatic impairment and } \\
\text { start with smaller dose in renal } \\
\text { impairment. Contra-indicated in left } \\
\text { ventricular failure with pulmonary } \\
\text { congestion or LVEF }<40 \% \text {. }\end{array}$} \\
\hline & & 90-360 mg q.d. (ER) & $\begin{array}{l}\text { Dizziness, malaise, lethargy, } \\
\text { headache, hot flushes, } \\
\text { gastrointestinal upset, and edema. }\end{array}$ & \\
\hline Verapamil & $\begin{array}{l}0.075-0.15 \mathrm{mg} / \mathrm{kg} \text { IV bolus over } \\
2 \text { minutes, then } 5 \mathrm{mcg} / \mathrm{kg} / \mathrm{min}\end{array}$ & $\begin{array}{l}\text { 40-120 mg t.i.d. } \\
\text { 120-480 mg q.d. (ER) }\end{array}$ & & \\
\hline \multicolumn{5}{|l|}{ Cardiac glycosides } \\
\hline Digoxin & $\begin{array}{l}0.25 \mathrm{mg} \text { IV with repeated dosing } \\
\text { to a maximum of } 0.75-1.5 \mathrm{mg} \\
\text { over } 24 \text { hours }\end{array}$ & $0.0625-0.25$ mg q.d. & $\begin{array}{l}\text { Gastrointestinal upset, dizziness, } \\
\text { blurred vision, headache, and } \\
\text { rash. In toxic states (serum } \\
\text { levels }>2 \mathrm{ng} / \mathrm{mL} \text { ), digoxin is } \\
\text { proarrhythmic and can aggravate } \\
\text { HF, particularly with coexistent } \\
\text { hypokalemia. }\end{array}$ & $\begin{array}{l}\text { High plasma levels associated with } \\
\text { increased risk of death. Check renal } \\
\text { function before starting and adapt } \\
\text { dose in patients with CKD. Contra- } \\
\text { indicated in patients with accessory } \\
\text { pathways, ventricular tachycardia } \\
\text { and hypertrophic cardiomyopathy } \\
\text { with outflow tract obstruction. }\end{array}$ \\
\hline \multicolumn{5}{|c|}{ Specific indications } \\
\hline Amiodarone & $\begin{array}{l}300 \mathrm{mg} \text { IV over } 1 \text { hour, then } \\
10-50 \mathrm{mg} / \mathrm{hr} \text { over } 24 \text { hours } \\
\text { (preferably via central venous } \\
\text { catheter). }\end{array}$ & 100-200 mg q.d. & $\begin{array}{l}\text { Hypotension, bradycardia, } \\
\text { nausea, QT prolongation, } \\
\text { pulmonary toxicity, skin } \\
\text { discoloration, thyroid dysfunction, } \\
\text { corneal deposits and cutaneous } \\
\text { reaction with extravasation. }\end{array}$ & $\begin{array}{l}\text { Suggested as adjunctive therapy } \\
\text { in patients where heart rate } \\
\text { control cannot be achieved using } \\
\text { combination therapy. }\end{array}$ \\
\hline
\end{tabular}

$\overline{\mathrm{AF}}=$ atrial fibrillation; $\mathrm{AV}=$ atrioventricular; b.i.d. = twice a day or twice daily; $\mathrm{CKD}$ = chronic kidney disease; $\mathrm{ER}=$ extended release; $\mathrm{HF}=$ heart failure; IV = intravenous; LVEF = left ventricular ejection fraction; PO = per os; q.d. = once a day or once daily; t.i.d. = 3 times a day.

\section{Acute rate control}

In patients with new-onset $\mathrm{AF}$, heart rate control is often needed to control symptoms. Clinicians should identify causes of increased heart rate, such as infection, anemia, and thyrotoxicosis. Beta-blockers and non-dihydropyridine calcium channel blockers (diltiazem/verapamil) are preferred for acute rate control because of their rapid action and effectiveness at high sympathetic tone. ${ }^{169-175)}$ Lenient rate control (heart rate $<110 / \mathrm{min}$ ) is sufficient in most cases.

In patients with congestive HF or left ventricular dysfunction, beta-blockers, digoxin, or their combination should be used because diltiazem and verapamil have negative inotropic effects in those with an LVEF $<40 \%{ }^{176) 177)}$ In patients with hemodynamic instability or severely reduced ejection fraction (EF), intravenous amiodarone would be an option. ${ }^{178) 179)}$ Urgent electrical cardioversion should be considered in hemodynamically unstable patients despite thromboembolic risk unless they are first anticoagulated (Figure 11).

\section{Long-term rate control}

Beta-blockers are most commonly used to achieve long-term rate control, followed by nondihydropyridine calcium channel blockers (diltiazem/verapamil), digoxin, and amiodarone. Physicians should evaluate the patient's comorbidities, such as HF, asthma, or COPD, to ensure appropriate drug selection. ${ }^{32}$ 


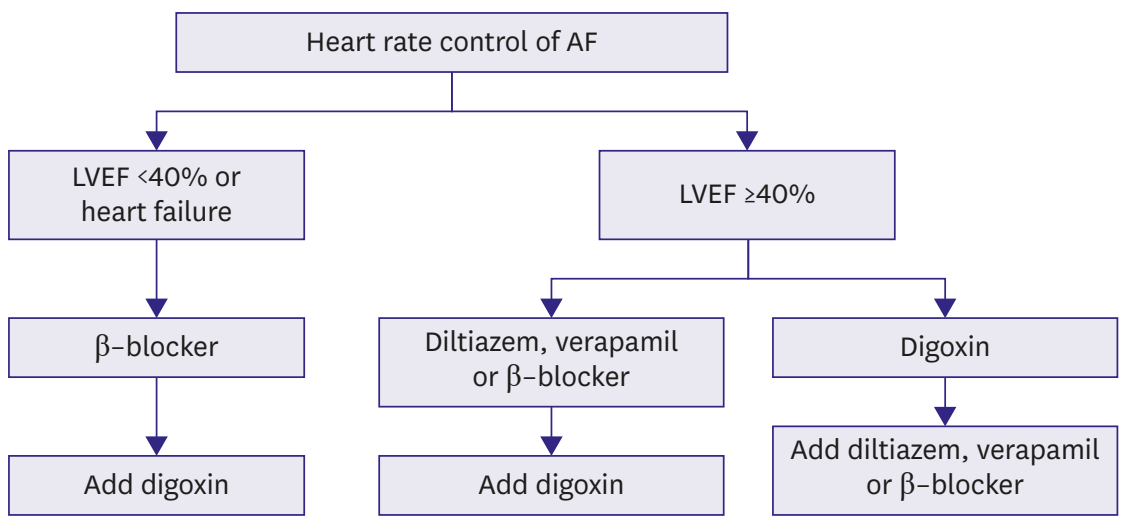

Figure 11. AF rate control management.

$\mathrm{AF}=$ atrial fibrillation; $\mathrm{LVEF}=$ left ventricular ejection fraction.

In patients with left ventricular dysfunction ( $\mathrm{EF}<40 \%)$, beta-blockers, digoxin. or their combination are preferred. ${ }^{116)}$ However, beta-blockers should be avoided in patients with asthma or COPD. Beta-blockers help rate control but may not have prognostic benefit in HF. ${ }^{73)}$ Lenient rate control (heart rate $<110 / \mathrm{min}$ ) is usually acceptable regardless of HF status, but stricter rate control is required if symptoms remain uncontrolled (Figure 11). ${ }^{180)}$

Atrioventricular (AV) nodal ablation consisting of permanent pacemaker implantation could be an option in selected patients with a rapid ventricular rate refractory to medical therapy. However, AV nodal ablation is usually reserved for the elderly because of their life-long pacemaker dependency.

\section{Recommendations for rate control in patients with $\mathrm{AF}$}

\begin{tabular}{lcc}
\hline Recommendations & Class & Level \\
\hline $\begin{array}{l}\text { Beta-blockers, digoxin, diltiazem, or verapamil are recommended to control heart rate in AF } \\
\text { patients with LVEF } \geq 40 \% .\end{array}$ & I & B \\
\hline $\begin{array}{l}\text { Beta-blockers and/or digoxin are recommended to control heart rate in AF patients with } \\
\text { LVEF }<40 \% .\end{array}$ & I \\
\hline $\begin{array}{l}\text { Combination therapy comprising different rate controlling agents should be considered if a } \\
\text { single agent does not achieve the necessary heart rate target. }\end{array}$ & IIa & C \\
\hline $\begin{array}{l}\text { In patients with hemodynamic instability or severely depressed LVEF, amiodarone may be } \\
\text { considered for acute control of heart rate. }\end{array}$ & IIb & B \\
\hline $\begin{array}{l}\text { In patients with permanent AF (i.e. where no attempt to restore sinus rhythm is planned), } \\
\text { antiarrhythmic drugs (AADs) should not routinely be used for rate control. }\end{array}$ & III \\
\hline $\begin{array}{l}\text { A resting heart rate of }<110 \text { bpm (i.e. lenient rate control) should be considered as the initial } \\
\text { heart rate target for rate control therapy. }\end{array}$ & A \\
\hline $\begin{array}{l}\text { Rhythm rather than rate control strategies should be considered as the preferred } \\
\text { management in preexcited AF and AF during pregnancy. }\end{array}$ & B \\
\hline $\begin{array}{l}\text { AV node ablation should be considered to control heart rate in patients unresponsive or } \\
\text { intolerant to intensive rate and rhythm control therapy, accepting that these patients will } \\
\text { become pacemaker dependent. }\end{array}$ & C \\
\hline
\end{tabular}

\section{RHYTHM CONTROL}

The purpose of rhythm control management is to improve hemodynamic instability and AF-related symptoms for restoring and maintaining sinus rhythm. ${ }^{181)}$ The restoration and maintenance of sinus rhythm after AAD treatment are more effective than those after 
placebo treatment. ${ }^{3182-184)}$ However, it remains inconclusive whether superior rhythm control management improves prognosis in anticoagulated patients with $\mathrm{AF}^{18111822185-190)}$ Additional invasive ablation therapy has been developed for and applied in medically refractory AF patients, ${ }^{191-193)}$ and prospective large-scale trials (CODE-AF, EAST-AFNET, and CABANA) attributed quality of life and prognosis improvements to the beneficial effect of rhythm control strategies in patients with AF. ${ }^{194-196)}$

\section{Acute rhythm control strategy}

Electrical direct current cardioversion is the only rapid and effective procedure to restore sinus rhythm in hemodynamically unstable AF patients. ${ }^{197-199)}$ Electrical cardioversion was safely conducted in sedated or anesthetized AF patients with intravenous midazolam or propofol; when used, vital signs, especially $\mathrm{O}_{2}$ saturation, should be monitored. ${ }^{200)}$ During the post-cardioversion period, the skin to which the patch is attached and serial ECG should be monitored for burns or severe bradycardia. ${ }^{1971198)}$

Pretreatment with flecainide, ${ }^{183)}$ propafenone, ${ }^{201)}$ amiodarone, ${ }^{2022203)}$ and sotalol ${ }^{202)}$ (not beta-blocker, verapamil ${ }^{204-206)}$ or digoxin ${ }^{207 / 208}$ ) could improve the efficacy of restoration and maintenance of sinus rhythm during the post-cardioversion period. AADs for pharmacological cardioversion are presented in Table 8. Proper anticoagulation is needed in $\mathrm{AF}$ patients prior to electrical cardioversion ${ }^{209-212)}$ because anticoagulation dramatically reduced the risk of embolic stroke. ${ }^{213214)} \mathrm{AF}$ patients planned to undergo electrical cardioversion should be anticoagulated from 3 weeks before to 4 weeks after unless permanent anticoagulation is indicated. A recent NOAC trial demonstrated the efficacy of preventing the occurrence of embolic stroke in AF patients subjected to electrical cardioversion.

A meta-analysis demonstrated that AADs could also efficiently restore and maintain sinus rhythm as rhythm control management. ${ }^{1112125-225)}$ In AF patients with stable hemodynamic status, prescription AADs could be the main option (easily available) in general practice without sedation or starvation during pretreatment compared with electrical cardioversion. Flecainide and propafenone are the most common AADs for acute rhythm management, ${ }^{222-227)}$ but they are relatively contraindicated in AF patients without structural heart disease. Amiodarone could be prescribed to AF patients with structural heart disease and reduce the heart by $>10-12$ beats per minute within intravenous infusion after 8-12 hours. ${ }^{216)}$ Both amiodarone and flecainide are more efficient at restoring sinus rhythm than sotalol. ${ }^{220221) 228(229)} \mathrm{A}$ single oral dose of flecainide 200-300 mg or propafenone 450-600 mg could be taken to control paroxysmal AF-related symptoms and restore sinus rhythm out of the hospital in experienced AF patients as confirmed in previous hospitalization (Figure 12A). ${ }^{230231)}$

Table 8. AADs for pharmacological cardioversion ${ }^{25)}$

\begin{tabular}{lcll}
\hline Drug & Route & \multicolumn{1}{c}{ Dosage } & \multicolumn{1}{c}{ Risks } \\
\hline Amiodarone & Oral & $\begin{array}{l}\text { Oral } 600-800 \mathrm{mg} \text { daily in divided doses to a total load of } \\
\text { up to } 10 \mathrm{~g} \text {, then } 200 \mathrm{mg} \text { q.d. as maintenance } \\
150 \mathrm{mg} \text { over } 10 \mathrm{minutes} \text {, then } 1 \mathrm{mg} / \mathrm{min} \text { for } 6 \text { hours, then } \\
0.5 \mathrm{mg} / \mathrm{min} \text { for } 18 \text { hours or change to oral dosing }\end{array}$ & $\begin{array}{l}\text { Gastrointestinal upset, constipation, bradycardia/AV } \\
\text { block, hypotension, QT prolongation, torsades de pointes } \\
\text { (rare), phlebitis (IV), increased INR }\end{array}$ \\
Flecainide & IV & $\begin{array}{l}\text { Atrial flutter with 1:1 AV conduction, ventricular } \\
\text { proarrhythmia, hypotension }\end{array}$ \\
Propafenone & Oral & $200-300 \mathrm{mg}$ & $\begin{array}{l}\text { Atrial flutter with 1:1 AV conduction, ventricular } \\
\text { proarrhythmia, hypotension }\end{array}$ \\
\hline
\end{tabular}

$\overline{\mathrm{AAD}}$ = antiarrhythmic drug; $\mathrm{AV}$ = atrioventricular; INR = international normalized ratio; IV = intravenous; q.d. = once a day or once daily. 
A

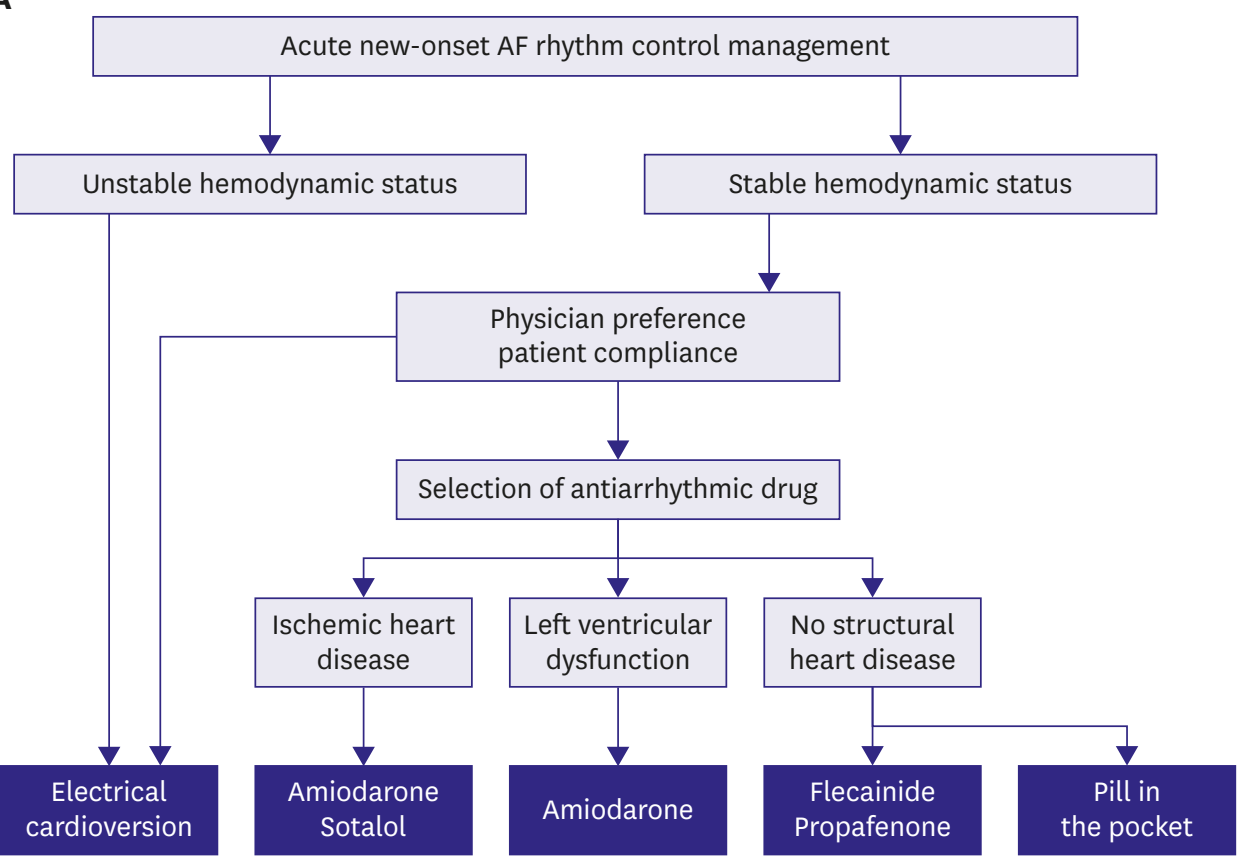

B

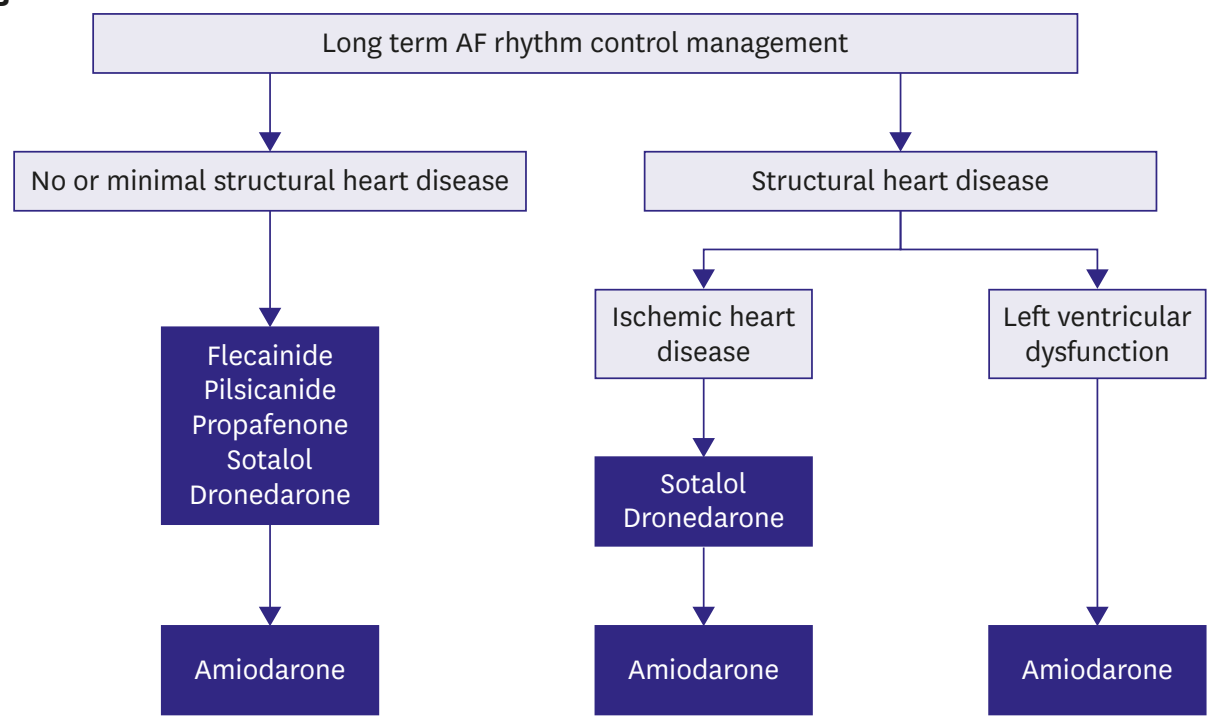

Figure 12. AF rhythm control management. (A) acute onset $A F$ and (B) long-term AF. $\mathrm{AF}=$ atrial fibrillation.

\section{Long-term rhythm control strategy}

Physician preference and the improvement of AF-related symptoms, drug compliance, pro-arrhythmic side effects, and extra-cardiac toxicities should be considered in long-term rhythm control management. AADs for the maintenance of sinus rhythm are presented in Table 9. In addition, lifestyle modifications and well-controlled cardiovascular disease could be additionally beneficial for preventing AF recurrence and maintaining sinus rhythm in patients treated with AADs during long-term rhythm control management. ${ }^{232)}$ 
Table 9. Oral AADs used to maintain sinus rhythm in patients with $\mathrm{AF}^{25)}$

\begin{tabular}{|c|c|c|c|}
\hline Drug & Dose & Contraindications and precautions & Warning signs warranting discontinuation \\
\hline Amiodarone & $\begin{array}{l}400-600 \text { mg daily in divided } \\
\text { doses for } 2-4 \text { weeks; } \\
\text { maintenance typically } \\
100-200 \text { mg q.d. }\end{array}$ & $\begin{array}{l}\text { Caution: SA or AV node dysfunction, infranodal conduction } \\
\text { disease, prolonged QT interval, liver disease, lung disease } \\
\text { Inhibits most CYPS and P-glycoprotein: increases warfarin, } \\
\text { statins, and digoxin concentration }\end{array}$ & QT prolongation $>500 \mathrm{~ms}$ \\
\hline Dronedarone & 400 mg b.i.d. & $\begin{array}{l}\text { Contraindication: NYHA class III or IV HF, permanent AF, } \\
\text { concomitant therapy with QT-prolonging drugs or powerful } \\
\text { CYP3A4 inhibitors (e.g., verapamil, diltiazem, azole antifungal } \\
\text { agents), } \mathrm{CrCl}<30 \mathrm{~mL} / \mathrm{min} \text {. } \\
\text { Caution: liver disease inhibits CYP3A, CYP2D6, P-glycoprotein: } \\
\text { increases concentration of digitalis, } \\
\text { beta-blockers, and of some statins. }\end{array}$ & QT prolongation $>500 \mathrm{~ms}$ \\
\hline Flecainide & $\begin{array}{l}\text { 50-200 mg b.i.d. } \\
\text { (usually 50-100 mg b.i.d.) }\end{array}$ & $\begin{array}{l}\text { Contraindication: } \mathrm{CAD}, \mathrm{HF}, \mathrm{CrCl}<50 \mathrm{~mL} / \mathrm{min} \\
\text { Caution: } \mathrm{SA} \text { or AV node dysfunction, infranodal conduction } \\
\text { disease, atrial flutter, liver disease. } \\
\text { CYP2D6 inhibitors (e.g., quinidine, fluoxetine, tricyclics) } \\
\text { increase plasma concentration. }\end{array}$ & $\begin{array}{l}\text { QRS duration increases } \\
>25 \% \text { above baseline }\end{array}$ \\
\hline Pilsicainide & 50 mg t.i.d. & $\begin{array}{l}\text { Contraindicated: IHD, reduced LVEF. } \\
\text { Caution: SA or AV node dysfunction, infranodal conduction } \\
\text { disease, atrial flutter, renal impairment }\end{array}$ & $\begin{array}{l}\text { QRS duration increases } \\
>25 \% \text { above baseline }\end{array}$ \\
\hline Propafenone & $\begin{array}{l}\text { Immediate release: } \\
150-300 \text { mg t.i.d. } \\
\text { Extended release: } \\
225-425 \text { mg b.i.d. } \\
\text { (usually } 225-325 \text { mg b.i.d.) }\end{array}$ & $\begin{array}{l}\text { Contraindication: IHD, reduced LVEF } \\
\text { Caution: SA or AV node dysfunction, infranodal conduction } \\
\text { disease, atrial flutter, liver disease, renal impairment, asthma } \\
\text { CYP2D6 inhibitors (e.g. quinidine, fluoxetine, tricyclics) } \\
\text { increase plasma concentration } \\
\text { Increases concentration of digitalis and warfarin }\end{array}$ & $\begin{array}{l}\text { QRS duration increases } \\
>25 \% \text { above baseline }\end{array}$ \\
\hline Sotalol & 40-160 mg b.i.d. & $\begin{array}{l}\text { Contraindication: HF, significant LV hypertrophy, } \\
\text { prolonged QT interval, hypokalemia, hypomagnesemia, } \\
\text { asthma, } \mathrm{CrCl}<50 \mathrm{~mL} / \mathrm{min}\end{array}$ & $\begin{array}{l}\text { QT interval }>500 \mathrm{~ms} \text {, } \\
\text { QT prolongation by } \\
>60 \mathrm{~ms} \text { upon therapy initiation }\end{array}$ \\
\hline
\end{tabular}

$\mathrm{AAD}$ = antiarrhythmic drug; $\mathrm{AF}$ = atrial fibrillation; $\mathrm{AV}=$ atrioventricular; b.i.d. = twice a day or twice daily; $\mathrm{CAD}=\mathrm{coronary}$ artery disease; $\mathrm{CrCl}$, creatinine clearance; CYP2D6 = cytochrome P450 2D6; CYP3A4 = cytochrome P450 3A4; HF = heart failure; IHD = ischemic heart disease; LVEF = left ventricular ejection fraction; NYHA = New York Heart Association; q.d. = once a day or once daily; SA = sinoatrial.

$\mathrm{AAD}$ safety must be considered in terms of pro-arrhythmic side effects and extra-cardiac toxicities. Flecainide, propafenone, and pilsicainide are indicated to control rhythm in $\mathrm{AF}$ patients without structural heart disease but are contraindicated in AF patients with ischemic heart disease or with left ventricular dysfunction due to poor prognosis. ${ }^{233) 234)}$ Extra-cardiac toxicity is rarely reported. ${ }^{235(236)}$ Flecainide, propafenone, and pilsicainide should be prescribed with an AV nodal blocker for the prevention of use dependency (increased ventricular rate in atrial flutter). ${ }^{237}$ Propafenone has a beta-blocker effect and CYP2D2 as a substrate (7\% of the general population has no CYP2D2). In a recent meta-analysis, class IC AAD use was not significantly correlated with all-cause mortality compared with class IA AAD and class III sotalol uses. ${ }^{184)}$ Class IC AADs also significantly reduced the recurrence of AF and had efficacy similar to dronedarone and sotalol but inferior to amiodarone (Figure 12B). 238)239)

Amiodarone can be prescribed in patients with left ventricular dysfunction. ${ }^{182}{ }^{240)} \mathrm{QT}$ interval and $U$ wave should be monitored to prevent torsade de pointes. ${ }^{241)}$ In particular, longterm amiodarone therapy may have extra-cardiac toxicity in the liver, thyroid, lung, skin, and cornea. Therefore, amiodarone should be replaced by an alternative AAD if any side effects or toxicities appear during long-term therapy. ${ }^{242)}$ Dronedarone reduces the heart rate, maintains sinus rhythm, and reduces cardiovascular mortality and hospitalization in paroxysmal or persistent AF patients. $\left.{ }^{233} 244\right)$ However, dronedarone increased the mortality rate in decompensated HF. ${ }^{245}{ }^{246)}$ Sotalol showed inferior efficacy to amiodarone ${ }^{221)}$ and similar efficacy to propafenone for maintaining sinus rhythm. ${ }^{247)}$ Sotalol could effectively suppress the re-entry mechanism. Sotalol may be the first choice for long-term rhythm control management in AF patients with ischemic heart disease. However, sotalol is prone 
to inducing QT prolongation, and caution is needed in females, renal impairment and if left ventricular hypertrophy is present. ${ }^{238)}$

\section{Recommendations for rhythm control strategies in patients with AF}

\begin{tabular}{|c|c|c|}
\hline Recommendations & Class & Level \\
\hline Rhythm control therapy is indicated for symptom improvement in patients with AF. & 1 & B \\
\hline $\begin{array}{l}\text { Management of cardiovascular risk factors and avoidance of AF triggers should be pursued } \\
\text { in patients on rhythm control therapy to facilitate maintenance of sinus rhythm. }\end{array}$ & Ila & B \\
\hline $\begin{array}{l}\text { With the exception of AF associated with hemodynamic instability, the choice between } \\
\text { electrical and pharmacological cardioversion should be guided by patient and physician } \\
\text { preferences. }\end{array}$ & IIa & $\mathrm{C}$ \\
\hline $\begin{array}{l}\text { The choice of AAD needs to be carefully evaluated, taking into account the presence of } \\
\text { comorbidities, cardiovascular risk and potential for serious proarrhythmia, extracardiac } \\
\text { toxic effects, patient preferences, and symptom burden. }\end{array}$ & 1 & A \\
\hline $\begin{array}{l}\text { Dronedarone, flecainide, propafenone, or sotalol are recommended for prevention of } \\
\text { recurrent symptomatic AF in patients with normal left ventricular function and without } \\
\text { pathological left ventricular hypertrophy. }\end{array}$ & 1 & A \\
\hline $\begin{array}{l}\text { Dronedarone is recommended for prevention of recurrent symptomatic AF in patients with } \\
\text { stable CAD, and without HF. }\end{array}$ & 1 & A \\
\hline Amiodarone is recommended for prevention of recurrent symptomatic AF in patients with HF. & 1 & A \\
\hline $\begin{array}{l}\text { Amiodarone is more effective in preventing AF recurrences than other AAD, but extracardiac } \\
\text { toxic effects are common and increase with time. For this reason, other AAD should be } \\
\text { considered first. }\end{array}$ & IIa & $\mathrm{C}$ \\
\hline $\begin{array}{l}\text { Patients on AAD therapy should be periodically evaluated to confirm their eligibility for } \\
\text { treatment. }\end{array}$ & IIa & C \\
\hline $\begin{array}{l}\text { ECG recording during the initiation of AAD therapy should be considered to monitor heart } \\
\text { rate, detect QRS and QT interval prolongation, and the occurrence of AV block. }\end{array}$ & Ila & B \\
\hline $\begin{array}{l}\text { AAD therapy is not recommended in patients with prolonged QT interval ( }>0.5 \text { seconds) or } \\
\text { those with significant sinoatrial node disease or AV node dysfunction who do not have a } \\
\text { functioning permanent pacemaker. }\end{array}$ & $\begin{array}{c}\text { III } \\
\text { (harm) }\end{array}$ & C \\
\hline $\begin{array}{l}\text { Adding atrial-based bradycardia pacing to drug treatment that induces or exacerbates } \\
\text { sinus node dysfunction should be considered to allow continuation of AAD therapy in } \\
\text { patients in whom AF ablation is declined or not indicated. }\end{array}$ & Ila & B \\
\hline $\begin{array}{l}\text { Continuation of AAD therapy beyond the blanking period after AF ablation should be } \\
\text { considered to maintain sinus rhythm when recurrences seem likely. }\end{array}$ & Ila & $B$ \\
\hline
\end{tabular}

\section{Anticoagulation in patients who undergo cardioversion}

The periprocedural risk of thromboembolic events during cardioversion can be substantially reduced by adequate anticoagulation. ${ }^{213)}$ In patients with $\mathrm{AF}$ or an atrial flutter $\geq 48$ hours or with an unknown duration, OAC with vitamin K antagonist (INR, 2.0-3.0) is recommended for at least 3 weeks before electrical or pharmacological cardioversion and 4 weeks afterward regardless of $\mathrm{CHA}_{2} \mathrm{DS}_{2}$-VASc score. ${ }^{3)}$ If early cardioversion is attempted, TEE should be performed to exclude the presence of left atrial thrombus. ${ }^{248)}$ After 4 weeks, long-term anticoagulation is decided based on each patient's risk of stroke using $\mathrm{CHA}_{2} \mathrm{DS}_{2}-\mathrm{VASc}$ score. Patients with a $\mathrm{CHA}_{2} \mathrm{DS}_{2}$-VASc score $\geq 2$ require long-term use of OAC irrespective of the cardioversion results. Subgroup analyses of phase 3 clinical trials ${ }^{249-251)}$ and recent prospective RCTs of rivaroxaban, ${ }^{252)}$ edoxaban, ${ }^{253)}$ and apixaban ${ }^{254)}$ have demonstrated that electrical cardioversion in patients treated with a NOAC for $\geq 3$ weeks had similar periprocedural thromboembolic and bleeding risks to those treated with warfarin. Therefore, anticoagulation using NOAC can be an alternative to vitamin $\mathrm{K}$ antagonist in patients who undergo cardioversion. Because routine coagulation tests do not accurately measure the anticoagulation effects of NOACs, if patient adherence to the NOAC regimen is uncertain, TEE can be performed prior to cardioversion. ${ }^{255)}$ No RCTs have compared anticoagulation strategies in patients with AF or an atrial flutter $\leq 48$ hours. It is common practice to perform cardioversion after a single dose of unfractionated heparin (UFH) or low molecular weight 
heparin (LMWH) without TEE. Although data are limited, it is reasonable to administer a single dose of NOAC $\geq 4$ hours before cardioversion instead of UFH or LMWH. Importantly, TEE or anticoagulation $\geq 3$ weeks before cardioversion can be considered in patients with a high stroke risk or an $\mathrm{AF}$ duration $\leq 48$ hours.

\section{Recommendations for stroke prevention in patients undergoing cardioversion}

\begin{tabular}{|c|c|c|}
\hline Recommendations & Class & Level \\
\hline $\begin{array}{l}\text { For cardioversion of AF/atrial flutter, effective anticoagulation is recommended for a minimum } \\
\text { of } 3 \text { weeks before cardioversion. }\end{array}$ & 1 & B \\
\hline $\begin{array}{l}\text { TEE is recommended to exclude cardiac thrombus as an alternative to preprocedural } \\
\text { anticoagulation when early cardioversion is planned. }\end{array}$ & 1 & B \\
\hline $\begin{array}{l}\text { In patients at risk for stroke, anticoagulant therapy should be continued long-term after } \\
\text { cardioversion according to the long-term anticoagulation recommendations, irrespective } \\
\text { of the method of cardioversion or the apparent maintenance of sinus rhythm. In patients } \\
\text { without stroke risk factors, anticoagulation is recommended for } 4 \text { weeks after cardioversion. }\end{array}$ & 1 & $\mathrm{~B}$ \\
\hline $\begin{array}{l}\text { In patients where thrombus is identified on TEE, effective anticoagulation is recommended for } \\
\text { at least } 3 \text { weeks. }\end{array}$ & I & C \\
\hline $\begin{array}{l}\text { Anticoagulation with heparin or a NOAC should be initiated as soon as possible before every } \\
\text { cardioversion of AF or atrial flutter. }\end{array}$ & IIa & $B$ \\
\hline $\begin{array}{l}\text { Early cardioversion can be performed without TEE in patients with a definite duration of AF } \\
<48 \text { hours. }\end{array}$ & IIa & $\mathrm{B}$ \\
\hline $\begin{array}{l}\text { In patients where thrombus is identified on TEE, effective anticoagulation is recommended for } \\
\text { at least } 3 \text { weeks. }\end{array}$ & IIa & B \\
\hline
\end{tabular}

\section{ANTICOAGULATION IN SPECIFIC CONDITIONS}

\section{Atrial fibrillation patients undergoing percutaneous coronary intervention Antithrombotic regimen}

An estimated $5-15 \%$ of AF patients may undergo PCI in the future. ${ }^{3)}$ However, it is very challenging to choose optimal antithrombotic regimens for AF patients treated with PCI. ${ }^{256)}$ Dual antiplatelet therapy (DAPT) with aspirin and a P2Y12 inhibitor (clopidogrel) is essential for patients treated with PCI to prevent stent thrombosis. ${ }^{257}$ On the other hand, $\mathrm{OAC}$ is imperative to preventing stroke in AF patients. ${ }^{258}$ Thus, theoretically, triple therapy, combining all drugs including DAPT and OAC, may be a reasonable choice as an initial antithrombotic regimen. However, prolonged triple therapy has been associated with an increased risk of bleeding and even mortality. $\left.{ }^{259} 260\right)$ In a large Korean observational study, triple therapy with aspirin, clopidogrel, and warfarin was associated with a 4.5-fold increased risk of major bleeding compared to DAPT. ${ }^{261)}$

Recent well-designed RCTs suggested dual therapy with a single antiplatelet agent and an OAC might be safer and show similar efficacy to triple therapy for preventing ischemic/ thromboembolic events. ${ }^{259) 262-264)}$ Dual therapy with clopidogrel and NOAC was suggested to be a safe initial alternative regimen to triple therapy. ${ }^{262) 263)}$ However, in patients with high ischemic event risk, short-term triple therapy still seems warranted. ${ }^{3)}$ Thus, we recommend the following (Figure 13). First, as initial antithrombotic treatment, triple therapy should be used for as short a duration as possible unless patients are at high risk of ischemic events. Second, dual therapy should be continued after the cessation of the triple therapy until 12 months after PCI. Third, dual therapy with clopidogrel and NOAC could be considered as an alternative initial antithrombotic regimen in patients with a high risk of bleeding (e.g. HAS-BLED $\geq 3$ ). Fourth, monotherapy with OAC should be considered 12 months after PCI. 


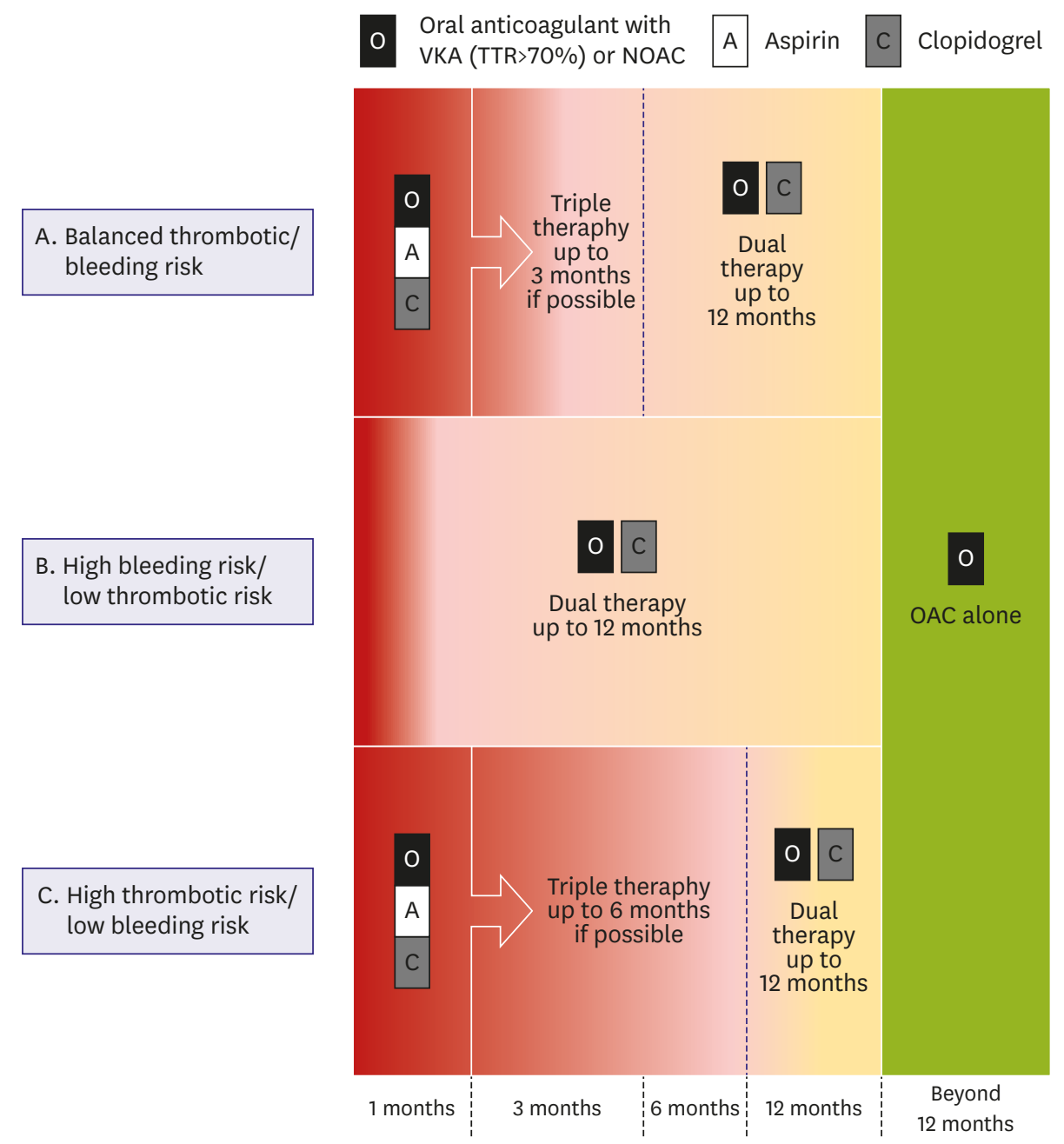

Figure 13. Suggested algorithm for antithrombotic therapy in patients undergoing $\mathrm{PCl}$.

$\mathrm{NOAC}=$ non-vitamin $\mathrm{K}$ antagonist oral anticoagulant; $\mathrm{OAC}=$ oral anticoagulant; $\mathrm{PCl}=$ percutaneous coronary intervention; TTR = time in therapeutic range.

Meanwhile, the safety of potent P2Y12 inhibitors (prasugrel, ticagrelor) has not been well evaluated in this population. Clopidogrel is the first recommended P2Y12 inhibitor. We discuss the evidence of dual therapy and monotherapy below.

\section{Dual therapy with clopidogrel and warfarin}

In an RCT (WOEST trial), dual therapy with clopidogrel and warfarin reduced the bleeding risk by $64 \%$ and adverse cardiac events by $40 \%$ compared with triple therapy with aspirin, clopidogrel, and warfarin. ${ }^{259}$ Although this study was underpowered to compare ischemic/ thromboembolic events, it has great implications for demonstrating the safety of dual therapy with clopidogrel and warfarin compared to that of triple therapy.

\section{Dual therapy with clopidogrel and non-vitamin $\mathrm{K}$ oral anticoagulants}

The efficacy and safety of dual therapy with clopidogrel and NOAC have been demonstrated in RCTs. In the PIONEER AF-PCI trial, dual therapy with a fixed dose of rivaroxaban $15 \mathrm{mg}$ and a P2Y12 inhibitor (mostly clopidogrel) was compared with triple therapies with verylow-dose rivaroxaban ( $2.5 \mathrm{mg}$ b.i.d.) or warfarin. ${ }^{263}$ In that study, the two rivaroxaban arms 
reduced the risk of clinically significant bleeding compared with triple therapy with warfarin, while the ischemic/thrombotic events were comparable. The results should be interpreted carefully. The trial design is complex (DAPT duration varied) and underpowered for the comparison of the ischemic events. Rivaroxaban $2.5 \mathrm{mg}$ has not been evaluated for stroke prevention in AF patients.

The RE-DUAL PCI trial compared dual therapy with two doses of dabigatran (110 or $150 \mathrm{mg}$ b.i.d.) combined with a P2Y12 inhibitor (clopidogrel in 88\%, ticagrelor in 12\%) and triple therapy consisting of aspirin, a P2Y12 inhibitor (clopidogrel in 92\%, ticagrelor in 8\%), and warfarin. ${ }^{262)}$ The dabigatran arms were associated with a reduced risk of major or clinically relevant nonmajor bleeding (dabigatran $110 \mathrm{mg}$ : HR, 0.52; dabigatran $150 \mathrm{mg}$ : HR, 0.72) compared to triple therapy with warfarin, while the risk of ischemic/thromboembolic events was comparable. This trial was also underpowered to compare the individual ischemic/ thromboembolic events, although as an adequately powered secondary efficacy composite outcome, the combined dabigatran arms were no significantly different to the warfarinbased arm. ${ }^{264)}$ Both used dosages of dabigatran that have been proven to prevent stroke in $\mathrm{AF}$ patients. ${ }^{265)}$

The AUGUSTUS and ENTRUST-AF trials are the ongoing RCTs of apixaban and edoxaban, respectively. ${ }^{266) 267)}$ The AUGUSTUS trial in particular will present the efficacy and safety of many different regimens of antithrombotic therapy including triple therapy with on-label dosages of NOAC.

\section{Monotherapy with oral anticoagulation}

In a nationwide observational study of $8,700 \mathrm{AF}$ patients with a history of $\mathrm{PCI} \geq 1$ year prior, the addition of the antiplatelet agent to warfarin was not associated with a reduced risk of ischemic/thromboembolic events but significantly increased bleeding risk. ${ }^{268)}$ The efficacy and safety of NOAC monotherapy in patients with stable coronary artery disease has not been well evaluated. However, global guidelines recommend the use of OAC monotherapy in AF patients with stable coronary artery disease. ${ }^{32255269)}$

\section{Anticoagulation in patients who undergo catheter ablation of atrial fibrillation}

Since catheter ablation of AF carries a risk of periprocedural thromboembolic complications, anticoagulation is indicated before, during, and after the procedure irrespective of the patient's $\mathrm{CHA}_{2} \mathrm{DS}_{2}$-VASc score. AF ablation under uninterrupted vitamin $\mathrm{K}$ antagonist use is recommended based on previous studies showing that this strategy was associated with better safety and efficacy outcomes. ${ }^{270)}$ Meta-analysis or registry data on periprocedural anticoagulation using dabigatran, ${ }^{271)}$ apixaban, ${ }^{272)}$ rivaroxaban, ${ }^{273)}$ and edoxaban ${ }^{274)}$ demonstrated similar thromboembolic and bleeding events compared with uninterrupted vitamin $\mathrm{K}$ antagonist. In addition, recent RCTs with rivaroxaban, ${ }^{275)}$ dabigatran, ${ }^{276)}$ and apixaban $^{277)}$ also showed that patients on uninterrupted NOACs had similar or even better major bleeding rates than those on vitamin K antagonist. Therefore, anticoagulation with NOAC can be an alternative to vitamin $\mathrm{K}$ antagonists in patients who undergo catheter ablation of AF. During the ablation, the intravenous administration of heparin is recommended to maintain a target activated clotting time $\geq 300$ seconds. ${ }^{270)}$ NOACs can be re-administered 3-5 hours after the procedure once adequate hemostasis is achieved. Anticoagulation should be continued for at least 2 months after ablation regardless of the patient's stroke risk or procedure results due to a thrombogenic state following ablation. 
After 2 months, long-term anticoagulation should be decided based on each individual patient's risk of stroke independent of the procedure's success.

\section{Anticoagulation therapy and renal function}

Patients with AF and moderate to severe renal dysfunction are at an increased risk of simultaneous ischemic stroke and major bleeding. ${ }^{278-281)}$ Therefore, the use of OACs in AF patients with renal dysfunction is troublesome. In AF patients with moderate to severe renal dysfunction and a $\mathrm{CHA}_{2} \mathrm{DS}_{2}$-VASc score $\geq 2$, the use of OACs was approved as beneficial for lowering the event rate of ischemic stroke despite the mildly increased risk of bleeding. ${ }^{282}$ In a meta-analysis, NOACs were better than warfarin for reducing the risk of stroke/ systemic embolism as well as major bleeding in AF patients with mild to moderate renal dysfunction. ${ }^{283}{ }^{2284}$ During NOAC use, renal function should be monitored carefully. ${ }^{285)}$

In patients with moderate renal dysfunction, NOAC dose should be reduced. Dabigatran should be reduced to $110 \mathrm{mg}$ b.i.d. in patients with creatinine clearance of $30-50 \mathrm{~mL} / \mathrm{min} .{ }^{265}$ ) Rivaroxaban should be reduced to $15 \mathrm{mg}$ q.d. in patients with creatinine clearance of 15-50 $\mathrm{mL} / \mathrm{min} .{ }^{286)}$ Apixaban should be reduced to $2.5 \mathrm{mg}$ b.i.d. in patients with serum creatinine $\geq 1.5 \mathrm{mg} / \mathrm{dL}$ and age $\geq 80$ years or body weight $\leq 60 \mathrm{~kg}$. $\left.{ }^{277}\right)$ Edoxaban should be reduced to $30 \mathrm{mg}$ q.d. in patients with creatinine clearance of $15-50 \mathrm{~mL} / \mathrm{min} .{ }^{288}$ Table 3 shows the recommended dose reduction of NOAC in Korea.

In patients with severe renal dysfunction (creatinine clearance $<15 \mathrm{~mL} / \mathrm{min}$ ), NOAC use is not recommended. OAC use may be inappropriate in patients with renal dysfunction who are on dialysis, although the data are weak and often do not consider TTR. ${ }^{289-292)}$ However, if TTR is $>70 \%$, warfarin may have some benefits even in dialysis patients. ${ }^{233)}$

However, apixaban has United States Federal Drug Administration (FDA)-approved indication for use in hemodialysis patients. Based on data from the apixaban package insert, patients with AF may receive full-dose therapy ( $5 \mathrm{mg}$ b.i.d.) while on hemodialysis as long as they are $<80$ years of age and weigh $>60 \mathrm{~kg}$ in the United States. If a patient is on dialysis and is $>80$ years of age or weighs $<60 \mathrm{~kg}$, then the dose is reduced to $2.5 \mathrm{mg}$ b.i.d. A recent study in end stage renal failure showed no significant differences between anticoagulants in the risks of stroke or systemic embolism; however, Apixaban was associated with a $28 \%$ lower risk of major bleeding than warfarin. ${ }^{294)}$ The results of the current analysis are in contradiction to bleeding-related morbidity and mortality attributed to dabigatran and rivaroxaban in a previous analysis of hemodialysis patients, suggesting that the increased bleeding risk in end-stage kidney disease is not a drug class effect for all DOACs. No prospective study has examined OAC therapy in patients with renal transplantation. Nonetheless, OAC doses should be adjusted according to the creatinine clearance of the donor's kidney.

In patients with a creatinine clearance $\geq 95 \mathrm{~mL} / \mathrm{min}$, dabigatran $150 \mathrm{mg}$ b.i.d., rivaroxaban $20 \mathrm{mg}$ q.d., and apixaban $5 \mathrm{mg}$ b.i.d. are recommended. Edoxaban $60 \mathrm{mg}$ q.d. is not recommended according to FDA approval. Recent studies showed that edoxaban was effective overall, but low-dose edoxaban had lower relative effectiveness for preventing stroke or systemic embolism than with warfarin at higher creatinine clearance levels ( $>95 \mathrm{~mL} / \mathrm{min})$ in Korean AF patients. ${ }^{295(296)}$ Similar data was observed for $\mathrm{CrCl}>95 \mathrm{~mL} / \mathrm{min}$ with apixaban and rivaroxaban, but not dabigatran..$^{293)}$ 


\section{Anticoagulation therapy in elderly patients}

Increasing age is a risk factor for simultaneous stroke and major bleeding in patients with $\mathrm{AF}^{297}$ ${ }^{299)}$ The elderly population is fragile and prone to falls. Nonetheless, OAC use is recommended in elderly AF patients because of the high benefit/risk ratio. ${ }^{300}$ Recent Asian data showed that Among patients with $\mathrm{AF} \geq 90$ years of age, warfarin was associated with a lower risk of ischemic stroke and positive net clinical benefit. Compared with warfarin, NOACs were associated with a lower risk of intracranial haemorrhage. Thus, OACs may still be considered as thromboprophylaxis for elderly patients, with NOACs being the more favorable choice. ${ }^{301302)}$

All 4 NOACs in the elderly population are approved as beneficial for the risk reduction of intracranial bleeding compared with warfarin. ${ }^{265(286-288)}$ In the ARISTOTLE trial, apixaban $5 \mathrm{mg}$ b.i.d. reduced major bleeding in patients $65-74$ years of age and $\geq 75$ years of age. ${ }^{303)}$ In the ENGAGE-TIMI trial, edoxaban $60 \mathrm{mg}$ q.d. decreased the risk of major bleeding in patients $<75$ years of age but had similar risks in patients $>75$ years of age compared with warfarin. ${ }^{288}$ However, dabigatran showed a significant age-treatment interaction in the RELY trial. Dabigatran $150 \mathrm{mg}$ b.i.d. reduced major bleeding in patients $<75$ years of age but an increased risk of major bleeding in patients $>75$ years of age compared with warfarin. ${ }^{265}$ In the ROCKET-AF trial, rivaroxaban demonstrated a similar risk of major bleeding as warfarin and no age-treatment interaction. ${ }^{286)}$ However, the J-ROCKET study and many real-world data suggested that low-dose rivaroxaban might be safe and effective in elderly Asian AF patients with relatively low body weight. ${ }^{145 / 304305)}$ Therefore, the Korean AF guideline recommends low-dose rivaroxaban ( $15 \mathrm{mg}$ q.d.) in patients aged $\geq 80$ years. $\left.{ }^{306}\right)$

\section{CONCLUSIONS}

For AF detection, ECG screening is necessary, especially in stroke survivors and the elderly. Integrated AF management, including active patient participation, a multidisciplinary approach, and technology use, is recommended from diagnosis to treatment and systematic follow-up. Such a holistic approach (the ABC pathway) can improve treatment outcomes, by considering lifestyle modifications, OAC, rate control, rhythm control by AADs, catheter ablation, and surgical intervention. Patient awareness of the disease, education and engagement with management decisions are important.

The Korean versions of separate guidelines for OAC, rate and rhythm control, risk factor management, and integrated treatment of AF patients are available in the Korean Journal of Medicine (http://ekjm.org/) or the home page of the Korean Heart Rhythm Society (http://k-hrs.org/intro.asp).

\section{ACKNOWLEDGEMENTS}

We thank professor Gregory YH Lip (University of Liverpool, UK) for comments.

\section{REFERENCES}

1. Jones C, Pollit V, Fitzmaurice D, Cowan C; Guideline Development Group. The management of atrial fibrillation: summary of updated NICE guidance. BMJ 2014;348:g3655.

PUBMED | CROSSREF 
2. January CT, Wann LS, Alpert JS, et al. 2014 AHA/ACC/HRS guideline for the management of patients with atrial fibrillation: a report of the American College of Cardiology/American Heart Association Task Force on Practice Guidelines and the Heart Rhythm Society. J Am Coll Cardiol 2014;64:e1-76.

PUBMED | CROSSREF

3. Kirchhof P, Benussi S, Kotecha D, et al. 2016 ESC Guidelines for the management of atrial fibrillation developed in collaboration with EACTS. Eur Heart J 2016;37:2893-962. PUBMED | CROSSREF

4. Chiang CE, Okumura K, Zhang S, et al. 2017 consensus of the Asia Pacific Heart Rhythm Society on stroke prevention in atrial fibrillation. J Arrhythm 2017;33:345-67. PUBMED | CROSSREF

5. Lip GY, Banerjee A, Boriani G, et al. Antithrombotic therapy for atrial fibrillation: CHEST guideline and expert panel report. Chest. 2018 [Epub ahead of print].

PUBMED | CROSSREF

6. Benjamin EJ, Wolf PA, D'Agostino RB, Silbershatz H, Kannel WB, Levy D. Impact of atrial fibrillation on the risk of death: the Framingham Heart Study. Circulation 1998;98:946-52. PUBMED | CROSSREF

7. January CT, Wann LS, Alpert JS, et al. 2014 AHA/ACC/HRS guideline for the management of patients with atrial fibrillation: a report of the American College of Cardiology/American Heart Association Task Force on practice guidelines and the Heart Rhythm Society. Circulation 2014;130:e199-267. PUBMED | CROSSREF

8. Lee H, Kim TH, Baek YS, et al. The trends of atrial fibrillation-related hospital visit and cost, treatment pattern and mortality in Korea: 10-year nationwide sample cohort data. Korean Circ J 2017;47:56-64. PUBMED | CROSSREF

9. Kim TH, Yang PS, Uhm JS, et al. $\mathrm{CHA}_{2} \mathrm{DS}_{2}$-VASc score (congestive heart failure, hypertension, age $\geq 75$ [doubled], diabetes mellitus, prior stroke or transient ischemic attack [doubled], vascular disease, age 65-74, female) for stroke in Asian patients with atrial fibrillation: a Korean nationwide sample cohort study. Stroke 2017;48:1524-30. PUBMED | CROSSREF

10. Stewart S, Hart CL, Hole DJ, McMurray JJ. A population-based study of the long-term risks associated with atrial fibrillation: 20-year follow-up of the Renfrew/Paisley study. Am J Med 2002;113:359-64. PUBMED | CROSSREF

11. Go AS, Hylek EM, Phillips KA, et al. Prevalence of diagnosed atrial fibrillation in adults: national implications for rhythm management and stroke prevention: the AnTicoagulation and Risk Factors in Atrial Fibrillation (ATRIA) Study. JAMA 2001;285:2370-5. PUBMED | CROSSREF

12. Miyasaka Y, Barnes ME, Gersh BJ, et al. Secular trends in incidence of atrial fibrillation in Olmsted County, Minnesota, 1980 to 2000, and implications on the projections for future prevalence. Circulation 2006;114:119-25. PUBMED | CROSSREF

13. Krijthe BP, Kunst A, Benjamin EJ, et al. Projections on the number of individuals with atrial fibrillation in the European Union, from 2000 to 2060. Eur Heart J 2013;34:2746-51. PUBMED | CROSSREF

14. Coyne KS, Paramore C, Grandy S, Mercader M, Reynolds M, Zimetbaum P. Assessing the direct costs of treating nonvalvular atrial fibrillation in the United States. Value Health 2006;9:348-56. PUBMED | CROSSREF

15. Stewart S, Murphy NF, Walker A, McGuire A, McMurray JJ. Cost of an emerging epidemic: an economic analysis of atrial fibrillation in the UK. Heart 2004;90:286-92. PUBMED | CROSSREF

16. Li Y, Pastori D, Guo Y, Wang Y, Lip GY. Risk factors for new-onset atrial fibrillation: a focus on Asian populations. Int J Cardiol 2018;261:92-8. PUBMED | CROSSREF

17. Allan V, Honarbakhsh S, Casas JP, et al. Are cardiovascular risk factors also associated with the incidence of atrial fibrillation? A systematic review and field synopsis of 23 factors in 32 population-based cohorts of 20 million participants. Thromb Haemost 2017;117:837-50. PUBMED | CROSSREF

18. Li YG, Pastori D, Farcomeni A, et al. A simple clinical risk score (C2HEST) for predicting incident atrial fibrillation in Asian subjects: derivation in 471,446 Chinese subjects, with internal validation and external application in 451,199 Korean subjects. Chest. 2018 [Epub ahead of print].

PUBMED | CROSSREF 
19. Kannel WB, Wolf PA, Benjamin EJ, Levy D. Prevalence, incidence, prognosis, and predisposing conditions for atrial fibrillation: population-based estimates. Am J Cardiol 1998;82:2N-9N. PUBMED | CROSSREF

20. Kim D, Yang PS, Jang E, et al. 10-year nationwide trends of the incidence, prevalence, and adverse outcomes of non-valvular atrial fibrillation nationwide health insurance data covering the entire Korean population. Am Heart J 2018;202:20-6. PUBMED | CROSSREF

21. Chao TF, Liu CJ, Tuan TC, et al. Lifetime risks, projected numbers, and adverse outcomes in Asian patients with atrial fibrillation: a report from the Taiwan nationwide AF cohort study. Chest 2018;153:453-66. PUBMED | CROSSREF

22. Yap KB, Ng TP, Ong HY. Low prevalence of atrial fibrillation in community-dwelling Chinese aged 55 years or older in Singapore: a population-based study. J Electrocardiol 2008;41:94-8. PUBMED | CROSSREF

23. Iguchi $\mathrm{Y}$, Kimura K, Aoki J, et al. Prevalence of atrial fibrillation in community-dwelling Japanese aged 40 years or older in Japan: analysis of 41,436 non-employee residents in Kurashiki-city. Circ J 2008;72:909-13. PUBMED | CROSSREF

24. Lee SR, Choi EK, Han KD, Cha MJ, Oh S. Trends in the incidence and prevalence of atrial fibrillation and estimated thromboembolic risk using the $\mathrm{CHA}_{2} \mathrm{DS}_{2}$-VASc score in the entire Korean population. Int J Cardiol 2017;236:226-31. PUBMED | CROSSREF

25. Yang PS, Ryu S, Kim D, et al. Variations of prevalence and incidence of atrial fibrillation and oral anticoagulation rate according to different analysis approaches. Sci Rep 2018;8:6856. PUBMED | CROSSREF

26. Yang PS, Joung B. Regional and socioeconomic inequality of atrial fibrillation with regular hospital visit. Korean Circ J 2018;48:635-6. PUBMED | CROSSREF

27. Lee SR, Choi EK, Han K, Cha MJ, Oh S. Prevalence of non-valvular atrial fibrillation based on geographical distribution and socioeconomic status in the entire Korean population. Korean Circ J 2018;48:622-34. PUBMED | CROSSREF

28. Kim D, Yang PS, Jang E, et al. Increasing trends in hospital care burden of atrial fibrillation in Korea, 2006 through 2015. Heart. 2018 [Epub ahead of print]. PUBMED | CROSSREF

29. Kim MH, Johnston SS, Chu BC, Dalal MR, Schulman KL. Estimation of total incremental health care costs in patients with atrial fibrillation in the United States. Circ Cardiovasc Qual Outcomes 2011;4:313-20. PUBMED | CROSSREF

30. Lee WC, Lamas GA, Balu S, Spalding J, Wang Q, Pashos CL. Direct treatment cost of atrial fibrillation in the elderly American population: a Medicare perspective. J Med Econ 2008;11:281-98. PUBMED | CROSSREF

31. Chugh SS, Jui J, Gunson K, et al. Current burden of sudden cardiac death: multiple source surveillance versus retrospective death certificate-based review in a large U.S. community. J Am Coll Cardiol 2004;44:1268-75. PUBMED | CROSSREF

32. Van Gelder IC, Rienstra M, Crijns HJ, Olshansky B. Rate control in atrial fibrillation. Lancet 2016;388:818-28. PUBMED | CROSSREF

33. Schmidt M, Ulrichsen SP, Pedersen L, Bøtker HE, Nielsen JC, Sørensen HT. 30-year nationwide trends in incidence of atrial fibrillation in Denmark and associated 5-year risk of heart failure, stroke, and death. Int J Cardiol 2016;225:30-6. PUBMED | CROSSREF

34. Schmidt M, Jacobsen JB, Johnsen SP, B $\emptyset$ tker HE, Sørensen HT. Eighteen-year trends in stroke mortality and the prognostic influence of comorbidity. Neurology 2014;82:340-50. PUBMED | CROSSREF

35. Freedman B, Camm J, Calkins H, et al. Screening for atrial fibrillation: a report of the AF-SCREEN international collaboration. Circulation 2017;135:1851-67. PUBMED | CROSSREF

36. Mairesse GH, Moran P, Van Gelder IC, et al. Screening for atrial fibrillation: a European Heart Rhythm Association (EHRA) consensus document endorsed by the Heart Rhythm Society (HRS), Asia Pacific Heart Rhythm Society (APHRS), and Sociedad Latinoamericana de Estimulación Cardíaca y Electrofisiología (SOLAECE). Europace 2017;19:1589-623. PUBMED | CROSSREF 
37. Arya A, Piorkowski C, Sommer P, Kottkamp H, Hindricks G. Clinical implications of various follow up strategies after catheter ablation of atrial fibrillation. Pacing Clin Electrophysiol 2007;30:458-62. PUBMED | CROSSREF

38. Davis RC, Hobbs FD, Kenkre JE, et al. Prevalence of atrial fibrillation in the general population and in high-risk groups: the ECHOES study. Europace 2012;14:1553-9.

PUBMED | CROSSREF

39. Siontis KC, Gersh BJ, Killian JM, et al. Typical, atypical, and asymptomatic presentations of newonset atrial fibrillation in the community: characteristics and prognostic implications. Heart Rhythm 2016;13:1418-24. PUBMED | CROSSREF

40. Lowres N, Neubeck L, Redfern J, Freedman SB. Screening to identify unknown atrial fibrillation. A systematic review. Thromb Haemost 2013;110:213-22.

PUBMED | CROSSREF

41. Boriani G, Laroche C, Diemberger I, et al. Asymptomatic atrial fibrillation: clinical correlates, management, and outcomes in the EORP-AF Pilot General Registry. Am J Med 2015;128:509-518.e2. PUBMED | CROSSREF

42. Potpara TS, Polovina MM, Marinkovic JM, Lip GY. A comparison of clinical characteristics and long-term prognosis in asymptomatic and symptomatic patients with first-diagnosed atrial fibrillation: the Belgrade Atrial Fibrillation Study. Int J Cardiol 2013;168:4744-9. PUBMED | CROSSREF

43. Hobbs FD, Fitzmaurice DA, Mant J, et al. A randomised controlled trial and cost-effectiveness study of systematic screening (targeted and total population screening) versus routine practice for the detection of atrial fibrillation in people aged 65 and over. The SAFE study. Health Technol Assess 2005;9:iii-iv. PUBMED | CROSSREF

44. Aronsson M, Svennberg E, Rosenqvist M, et al. Cost-effectiveness of mass screening for untreated atrial fibrillation using intermittent ECG recording. Europace 2015;17:1023-9. PUBMED | CROSSREF

45. Levin LA, Husberg M, Sobocinski PD, et al. A cost-effectiveness analysis of screening for silent atrial fibrillation after ischaemic stroke. Europace 2015;17:207-14.

PUBMED | CROSSREF

46. Son MK, Lim NK, Park HY. Trend of prevalence of atrial fibrillation and use of oral anticoagulation therapy in patients with atrial fibrillation in South Korea (2002-2013). J Epidemiol 2018;28:81-7. PUBMED | CROSSREF

47. Engdahl J, Andersson L, Mirskaya M, Rosenqvist M. Stepwise screening of atrial fibrillation in a 75-yearold population: implications for stroke prevention. Circulation 2013;127:930-7. PUBMED | CROSSREF

48. Halcox JP, Wareham K, Cardew A, et al. Assessment of Remote Heart Rhythm Sampling Using the AliveCor Heart Monitor to Screen for Atrial Fibrillation: the REHEARSE-AF Study. Circulation 2017;136:1784-94. PUBMED | CROSSREF

49. Chan NY, Choy CC, Chan CK, Siu CW. Effectiveness of a nongovernmental organization-led largescale community atrial fibrillation screening program using the smartphone electrocardiogram: an observational cohort study. Heart Rhythm 2018;15:1306-11. PUBMED | CROSSREF

50. Healey JS, Alings M, Ha A, et al. Subclinical atrial fibrillation in older patients. Circulation 2017;136:1276-83. PUBMED | CROSSREF

51. Glotzer TV, Hellkamp AS, Zimmerman J, et al. Atrial high rate episodes detected by pacemaker diagnostics predict death and stroke: report of the Atrial Diagnostics Ancillary Study of the MOde Selection Trial (MOST). Circulation 2003;107:1614-9. PUBMED | CROSSREF

52. Healey JS, Connolly SJ, Gold MR, et al. Subclinical atrial fibrillation and the risk of stroke. N Engl J Med 2012;366:120-9. PUBMED | CROSSREF

53. Van Gelder IC, Healey JS, Crijns HJ, et al. Duration of device-detected subclinical atrial fibrillation and occurrence of stroke in ASSERT. Eur Heart J 2017;38:1339-44. PUBMED | CROSSREF

54. Hindricks G, Pokushalov E, Urban L, et al. Performance of a new leadless implantable cardiac monitor in detecting and quantifying atrial fibrillation: results of the XPECT trial. Circ Arthythm Electrophysiol 2010;3:141-7.

PUBMED | CROSSREF 
55. Brambatti M, Connolly SJ, Gold MR, et al. Temporal relationship between subclinical atrial fibrillation and embolic events. Circulation 2014;129:2094-9.

PUBMED | CROSSREF

56. Glotzer TV, Daoud EG, Wyse DG, et al. The relationship between daily atrial tachyarrhythmia burden from implantable device diagnostics and stroke risk: the TRENDS study. Circ Arrhythm Electrophysiol 2009;2:474-80. PUBMED | CROSSREF

57. Santini M, Gasparini M, Landolina M, et al. Device-detected atrial tachyarrhythmias predict adverse outcome in real-world patients with implantable biventricular defibrillators. J Am Coll Cardiol 2011;57:167-72. PUBMED | CROSSREF

58. Boriani G, Glotzer TV, Santini M, et al. Device-detected atrial fibrillation and risk for stroke: an analysis of $>10,000$ patients from the SOS AF project (Stroke preventiOn Strategies based on Atrial Fibrillation information from implanted devices). Eur Heart J 2014;35:508-16.

PUBMED | CROSSREF

59. Freedman B, Potpara TS, Lip GY. Stroke prevention in atrial fibrillation. Lancet 2016;388:806-17. PUBMED | CROSSREF

60. Friberg L, Rosenqvist M, Lindgren A, Terént A, Norrving B, Asplund K. High prevalence of atrial fibrillation among patients with ischemic stroke. Stroke 2014;45:2599-605. PUBMED | CROSSREF

61. Perera KS, Vanassche T, Bosch J, et al. Global survey of the frequency of atrial fibrillation-associated stroke: embolic stroke of undetermined source global registry. Stroke 2016;47:2197-202. PUBMED | CROSSREF

62. Sposato LA, Cipriano LE, Saposnik G, Ruíz Vargas E, Riccio PM, Hachinski V. Diagnosis of atrial fibrillation after stroke and transient ischaemic attack: a systematic review and meta-analysis. Lancet Neurol 2015;14:377-87. PUBMED | CROSSREF

63. Adams HP Jr, Bendixen BH, Kappelle LJ, et al. Classification of subtype of acute ischemic stroke. Definitions for use in a multicenter clinical trial. TOAST. Trial of Org 10172 in Acute Stroke Treatment. Stroke 1993;24:35-41. PUBMED | CROSSREF

64. Gladstone DJ, Spring M, Dorian P, et al. Atrial fibrillation in patients with cryptogenic stroke. N Engl J Med 2014;370:2467-77. PUBMED | CROSSREF

65. Thijs VN, Brachmann J, Morillo CA, et al. Predictors for atrial fibrillation detection after cryptogenic stroke: results from CRYSTAL AF. Neurology 2016;86:261-9. PUBMED | CROSSREF

66. Proietti M, Romiti GF, Olshansky B, Lane DA, Lip GY. Improved outcomes by integrated care of anticoagulated patients with atrial fibrillation using the simple ABC (Atrial Fibrillation Better Care) pathway. Am J Med. 2018 [Epub ahead of print]. PUBMED | CROSSREF

67. Guha K, McDonagh T. Heart failure epidemiology: European perspective. Curr Cardiol Rev 2013;9:123-7. PUBMED | CROSSREF

68. Schnabel RB, Yin X, Gona P, et al. 50 year trends in atrial fibrillation prevalence, incidence, risk factors, and mortality in the Framingham Heart Study: a cohort study. Lancet 2015;386:154-62. PUBMED | CROSSREF

69. Lip GY, Heinzel FR, Gaita F, et al. European Heart Rhythm Association/Heart Failure Association joint consensus document on arrhythmias in heart failure, endorsed by the Heart Rhythm Society and the Asia Pacific Heart Rhythm Society. Europace 2016;18:12-36. PUBMED | CROSSREF

70. Schneider MP, Hua TA, Böhm M, Wachtell K, Kjeldsen SE, Schmieder RE. Prevention of atrial fibrillation by Renin-Angiotensin system inhibition a meta-analysis. J Am Coll Cardiol 2010;55:2299-307. PUBMED | CROSSREF

71. Healey JS, Baranchuk A, Crystal E, et al. Prevention of atrial fibrillation with angiotensin-converting enzyme inhibitors and angiotensin receptor blockers: a meta-analysis. J Am Coll Cardiol 2005;45:1832-9. PUBMED | CROSSREF

72. Jibrini MB, Molnar J, Arora RR. Prevention of atrial fibrillation by way of abrogation of the reninangiotensin system: a systematic review and meta-analysis. Am J Ther 2008;15:36-43. PUBMED | CROSSREF

73. Kotecha D, Holmes J, Krum H, et al. Efficacy of $\beta$ blockers in patients with heart failure plus atrial fibrillation: an individual-patient data meta-analysis. Lancet 2014;384:2235-43.

PUBMED | CROSSREF 
74. Swedberg K, Zannad F, McMurray JJ, et al. Eplerenone and atrial fibrillation in mild systolic heart failure: results from the EMPHASIS-HF (Eplerenone in Mild Patients Hospitalization And SurvIval Study in Heart Failure) study. J Am Coll Cardiol 2012;59:1598-603.

PUBMED | CROSSREF

75. Marrouche NF, Brachmann J, Andresen D, et al. Catheter ablation for atrial fibrillation with heart failure. N Engl J Med 2018;378:417-27. PUBMED | CROSSREF

76. Manolis AJ, Rosei EA, Coca A, et al. Hypertension and atrial fibrillation: diagnostic approach, prevention and treatment. Position paper of the Working Group 'Hypertension Arrhythmias and Thrombosis' of the European Society of Hypertension. J Hypertens 2012;30:239-52. PUBMED | CROSSREF

77. Kim D, Yang PS, Kim TH, et al. Ideal blood pressure in patients with atrial fibrillation. J Am Coll Cardiol 2018;72:1233-45. PUBMED | CROSSREF

78. Marott SC, Nielsen SF, Benn M, Nordestgaard BG. Antihypertensive treatment and risk of atrial fibrillation: a nationwide study. Eur Heart J 2014;35:1205-14. PUBMED | CROSSREF

79. Wachtell K, Lehto M, Gerdts E, et al. Angiotensin II receptor blockade reduces new-onset atrial fibrillation and subsequent stroke compared to atenolol: the Losartan Intervention For End Point Reduction in Hypertension (LIFE) study. J Am Coll Cardiol 2005;45:712-9. PUBMED | CROSSREF

80. Madrid AH, Bueno MG, Rebollo JM, et al. Use of irbesartan to maintain sinus rhythm in patients with long-lasting persistent atrial fibrillation: a prospective and randomized study. Circulation 2002;106:331-6. PUBMED | CROSSREF

81. Ueng KC, Tsai TP, Yu WC, et al. Use of enalapril to facilitate sinus rhythm maintenance after external cardioversion of long-standing persistent atrial fibrillation. Results of a prospective and controlled study. Eur Heart J 2003;24:2090-8. PUBMED | CROSSREF

82. Anand K, Mooss AN, Hee TT, Mohiuddin SM. Meta-analysis: inhibition of renin-angiotensin system prevents new-onset atrial fibrillation. Am Heart J 2006;152:217-22. PUBMED | CROSSREF

83. Du X, Ninomiya T, de Galan B, et al. Risks of cardiovascular events and effects of routine blood pressure lowering among patients with type 2 diabetes and atrial fibrillation: results of the ADVANCE study. Eur Heart J 2009;30:1128-35. PUBMED | CROSSREF

84. Schoen T, Pradhan AD, Albert CM, Conen D. Type 2 diabetes mellitus and risk of incident atrial fibrillation in women. J Am Coll Cardiol 2012;60:1421-8.

PUBMED | CROSSREF

85. Rizzo MR, Sasso FC, Marfella R, et al. Autonomic dysfunction is associated with brief episodes of atrial fibrillation in type 2 diabetes. J Diabetes Complications 2015;29:88-92. PUBMED | CROSSREF

86. Ziolo MT, Mohler PJ. Defining the role of oxidative stress in atrial fibrillation and diabetes. J Cardiovasc Electrophysiol 2015;26:223-5. PUBMED | CROSSREF

87. Fatemi O, Yuriditsky E, Tsioufis C, et al. Impact of intensive glycemic control on the incidence of atrial fibrillation and associated cardiovascular outcomes in patients with type 2 diabetes mellitus (from the Action to Control Cardiovascular Risk in Diabetes Study). Am J Cardiol 2014;114:1217-22. PUBMED | CROSSREF

88. Fangel MV, Nielsen PB, Larsen TB, et al. Type 1 versus type 2 diabetes and thromboembolic risk in patients with atrial fibrillation: a Danish nationwide cohort study. Int J Cardiol 2018;268:137-42. PUBMED | CROSSREF

89. Lee SR, Choi EK, Rhee TM, et al. Evaluation of the association between diabetic retinopathy and the incidence of atrial fibrillation: a nationwide population-based study. Int J Cardiol 2016;223:953-7. PUBMED | CROSSREF

90. Lip GY. The ABC pathway: an integrated approach to improve AF management. Nat Rev Cardiol 2017;14:627-8. PUBMED | CROSSREF

91. Mazurek M, Shantsila E, Lane DA, Wolff A, Proietti M, Lip GY. Guideline-adherent antithrombotic treatment improves outcomes in patients with atrial fibrillation: insights from the community-based Darlington atrial fibrillation registry. Mayo Clin Proc 2017;92:1203-13.

PUBMED | CROSSREF 
92. Proietti M, Nobili A, Raparelli V, et al. Adherence to antithrombotic therapy guidelines improves mortality among elderly patients with atrial fibrillation: insights from the REPOSI study. Clin Res Cardiol 2016;105:912-20. PUBMED | CROSSREF

93. Ancedy Y, Lecoq C, Saint Etienne C, et al. Antithrombotic management in patients with atrial fibrillation undergoing coronary stent implantation: what is the impact of guideline adherence? Int J Cardiol 2016;203:987-94. PUBMED | CROSSREF

94. Gorin L, Fauchier L, Nonin E, Charbonnier B, Babuty D, Lip GY. Prognosis and guideline-adherent antithrombotic treatment in patients with atrial fibrillation and atrial flutter: implications of undertreatment and overtreatment in real-life clinical practice; the Loire Valley Atrial Fibrillation Project. Chest 2011;140:911-7. PUBMED | CROSSREF

95. Nuño R, Coleman K, Bengoa R, Sauto R. Integrated care for chronic conditions: the contribution of the ICCC Framework. Health Policy 2012;105:55-64. PUBMED | CROSSREF

96. Bodenheimer T, Wagner EH, Grumbach K. Improving primary care for patients with chronic illness. JAMA 2002;288:1775-9. PUBMED | CROSSREF

97. Lorig KR, Holman H. Self-management education: history, definition, outcomes, and mechanisms. Ann Behav Med 2003;26:1-7. PUBMED | CROSSREF

98. Alonso-Coello P, Montori VM, Solà I, et al. Values and preferences in oral anticoagulation in patients with atrial fibrillation, physicians' and patients' perspectives: protocol for a two-phase study. BMC Health Serv Res 2008;8:221. PUBMED | CROSSREF

99. Seaburg L, Hess EP, Coylewright M, Ting HH, McLeod CJ, Montori VM. Shared decision making in atrial fibrillation: where we are and where we should be going. Circulation 2014;129:704-10. PUBMED | CROSSREF

100. Stiggelbout AM, Van der Weijden T, De Wit MP, et al. Shared decision making: really putting patients at the centre of healthcare. BMJ 2012;344:e256. PUBMED | CROSSREF

101. Hendriks JM, de Wit R, Vrijhoef HJ, Tieleman RG, Crijns HJ. An integrated chronic care program for patients with atrial fibrillation: study protocol and methodology for an ongoing prospective randomised controlled trial. Int J Nurs Stud 2010;47:1310-6. PUBMED | CROSSREF

102. Guo Y, Chen Y, Lane DA, Liu L, Wang Y, Lip GY. Mobile health technology for atrial fibrillation management integrating decision support, education, and patient involvement: mAF App Trial. AmJ Med 2017;130:1388-1396.e6. PUBMED | CROSSREF

103. Lee SS, Ae Kong K, Kim D, et al. Clinical implication of an impaired fasting glucose and prehypertension related to new onset atrial fibrillation in a healthy Asian population without underlying disease: a nationwide cohort study in Korea. Eur Heart J 2017;38:2599-607. PUBMED | CROSSREF

104. Baek YS, Yang PS, Kim TH, et al. Associations of abdominal obesity and new-onset atrial fibrillation in the general population. J Am Heart Assoc 2017;6:6. PUBMED | CROSSREF

105. Benjamin EJ, Levy D, Vaziri SM, D'Agostino RB, Belanger AJ, Wolf PA. Independent risk factors for atrial fibrillation in a population-based cohort. The Framingham Heart Study. JAMA 1994;271:840-4. PUBMED | CROSSREF

106. Wang TJ, Parise H, Levy D, et al. Obesity and the risk of new-onset atrial fibrillation. JAMA 2004;292:2471-7. PUBMED | CROSSREF

107. Gami AS, Hodge DO, Herges RM, et al. Obstructive sleep apnea, obesity, and the risk of incident atrial fibrillation. J Am Coll Cardiol 2007;49:565-71.

PUBMED | CROSSREF

108. Heeringa J, Kors JA, Hofman A, van Rooij FJ, Witteman JC. Cigarette smoking and risk of atrial fibrillation: the Rotterdam Study. Am Heart J2008;156:1163-9. PUBMED | CROSSREF

109. Conen D, Tedrow UB, Cook NR, Moorthy MV, Buring JE, Albert CM. Alcohol consumption and risk of incident atrial fibrillation in women. JAMA 2008;300:2489-96. PUBMED | CROSSREF 
110. Roh SY, Choi JI, Lee JY, et al. Catheter ablation of atrial fibrillation in patients with chronic lung disease. Circ Arrhythm Electrophysiol 2011;4:815-22. PUBMED | CROSSREF

111. Kong KA, Park J, Hong SH, Hong YS, Sung YA, Lee H. Associations between body mass index and mortality or cardiovascular events in a general Korean population. PLoS One 2017;12:e0185024. PUBMED | CROSSREF

112. Manning WJ, Weintraub RM, Waksmonski CA, et al. Accuracy of transesophageal echocardiography for identifying left atrial thrombi. A prospective, intraoperative study. Ann Intern Med 1995;123:817-22. PUBMED | CROSSREF

113. Hwang JJ, Chen JJ, Lin SC, et al. Diagnostic accuracy of transesophageal echocardiography for detecting left atrial thrombi in patients with rheumatic heart disease having undergone mitral valve operations. $A m J$ Cardiol 1993;72:677-81. PUBMED | CROSSREF

114. Lip G, Freedman B, De Caterina R, Potpara TS. Stroke prevention in atrial fibrillation: past, present and future. Comparing the guidelines and practical decision-making. Thromb Haemost 2017;117:1230-9. PUBMED | CROSSREF

115. Kim TH, Shim CY, Park JH, et al. Left ventricular diastolic dysfunction is associated with atrial remodeling and risk or presence of stroke in patients with paroxysmal atrial fibrillation. J Cardiol 2016;68:104-9. PUBMED | CROSSREF

116. Yu HT, Yang PS, Lee H, et al. Outcomes of rate-control treatment in patients with atrial fibrillation and heart failure: a nationwide cohort study. Circ J2018;82:652-8. PUBMED | CROSSREF

117. Nieuwlaat R, Olsson SB, Lip GY, et al. Guideline-adherent antithrombotic treatment is associated with improved outcomes compared with undertreatment in high-risk patients with atrial fibrillation. Am Heart J 2007;153:1006-12. PUBMED | CROSSREF

118. Stock S, Pitcavage JM, Simic D, et al. Chronic care model strategies in the United States and Germany deliver patient-centered, high-quality diabetes care. Health Aff (Millwood) 2014;33:1540-8. PUBMED | CROSSREF

119. Hart RG, Pearce LA, Aguilar MI. Meta-analysis: antithrombotic therapy to prevent stroke in patients who have nonvalvular atrial fibrillation. Ann Intern Med 2007;146:857-67. PUBMED | CROSSREF

120. Eckman MH, Singer DE, Rosand J, Greenberg SM. Moving the tipping point: the decision to anticoagulate patients with atrial fibrillation. Circ Cardiovasc Qual Outcomes 2011;4:14-21. PUBMED | CROSSREF

121. Chiang CE, Wang TD, Li YH, et al. 2010 guidelines of the Taiwan Society of Cardiology for the management of hypertension. J Formos Med Assoc 2010;109:740-73.

PUBMED | CROSSREF

122. Olesen JB, Torp-Pedersen C, Hansen ML, Lip GY. The value of the $\mathrm{CHA}_{2} \mathrm{DS}_{2}$-VASc score for refining stroke risk stratification in patients with atrial fibrillation with a $\mathrm{CHADS}_{2}$ score 0-1: a nationwide cohort study. Thromb Haemost 2012;107:1172-9. PUBMED | CROSSREF

123. Coppens M, Eikelboom JW, Hart RG, et al. The $\mathrm{CHA}_{2} \mathrm{DS}_{2}$-VASc score identifies those patients with atrial fibrillation and a $\mathrm{CHADS}_{2}$ score of 1 who are unlikely to benefit from oral anticoagulant therapy. Eur Heart $J$ 2013;34:170-6. PUBMED | CROSSREF

124. Chao TF, Liu CJ, Wang KL, et al. Using the $\mathrm{CHA}_{2} \mathrm{DS}_{2}$-VASc score for refining stroke risk stratification in 'low-risk' Asian patients with atrial fibrillation. J Am Coll Cardiol 2014;64:1658-65. PUBMED | CROSSREF

125. Kim TH, Yang PS, Kim D, et al. $\mathrm{CHA}_{2} \mathrm{DS}_{2}$-VASc score for identifying truly low-risk atrial fibrillation for stroke: a Korean nationwide cohort study. Stroke 2017;48:2984-90. PUBMED | CROSSREF

126. Kang SH, Choi EK, Han KD, et al. Risk of ischemic stroke in patients with non-valvular atrial fibrillation not receiving oral anticoagulants: Korean nationwide population-based study. Circ J2017;81:1158-64. PUBMED | CROSSREF

127. Lin LY, Lee CH, Yu CC, et al. Risk factors and incidence of ischemic stroke in Taiwanese with nonvalvular atrial fibrillation-- a nation wide database analysis. Atherosclerosis 2011;217:292-5. PUBMED | CROSSREF 
128. Steensig K, Olesen KK, Thim T, et al. Coronary artery disease is independent risk factor for stroke among patients with atrial fibrillation. J Am Coll Cardiol. 2018 [Epub ahead of print]. PUBMED | CROSSREF

129. Wang TJ, Massaro JM, Levy D, et al. A risk score for predicting stroke or death in individuals with newonset atrial fibrillation in the community: the Framingham Heart Study. JAMA 2003;290:1049-56. PUBMED | CROSSREF

130. Fang MC, Singer DE, Chang Y, et al. Gender differences in the risk of ischemic stroke and peripheral embolism in atrial fibrillation: the AnTicoagulation and Risk factors In Atrial fibrillation (ATRIA) study. Circulation 2005;112:1687-91. PUBMED | CROSSREF

131. Avgil Tsadok M, Jackevicius CA, Rahme E, Humphries KH, Behlouli H, Pilote L. Sex differences in stroke risk among older patients with recently diagnosed atrial fibrillation. JAMA 2012;307:1952-8. PUBMED | CROSSREF

132. Friberg L, Benson L, Rosenqvist M, Lip GY. Assessment of female sex as a risk factor in atrial fibrillation in Sweden: nationwide retrospective cohort study. BMJ 2012;344:e3522. PUBMED | CROSSREF

133. Mikkelsen AP, Lindhardsen J, Lip GY, Gislason GH, Torp-Pedersen C, Olesen JB. Female sex as a risk factor for stroke in atrial fibrillation: a nationwide cohort study. J Thromb Haemost 2012;10:1745-51. PUBMED | CROSSREF

134. Nielsen PB, Skjøth F, Overvad TF, Larsen TB, Lip GY. Female sex is a risk modifier rather than a risk factor for stroke in atrial fibrillation: should we use a $\mathrm{CHA}_{2} \mathrm{DS}_{2}$-VA score rather than $\mathrm{CHA}_{2} \mathrm{DS}_{2}$-VASc? Circulation 2018;137:832-40. PUBMED | CROSSREF

135. Siu CW, Lip GY, Lam KF, Tse HF. Risk of stroke and intracranial hemorrhage in 9727 Chinese with atrial fibrillation in Hong Kong. Heart Rhythm 2014;11:1401-8. PUBMED | CROSSREF

136. Guo Y, Apostolakis S, Blann AD, et al. Validation of contemporary stroke and bleeding risk stratification scores in non-anticoagulated Chinese patients with atrial fibrillation. Int J Cardiol 2013;168:904-9. PUBMED | CROSSREF

137. Tomita $\mathrm{H}$, Okumura $\mathrm{K}$, Inoue $\mathrm{H}$, et al. Validation of risk scoring system excluding female sex from $\mathrm{CHA}_{2} \mathrm{DS}_{2}$-VASc in Japanese patients with nonvalvular atrial fibrillation: subanalysis of the J-RHYTHM registry. Circ J 2015;79:1719-26. PUBMED | CROSSREF

138. Chao TF, Wang KL, Liu CJ, et al. Age threshold for increased stroke risk among patients with atrial fibrillation: a nationwide cohort study from Taiwan. J Am Coll Cardiol 2015;66:1339-47. PUBMED | CROSSREF

139. Kim TH, Yang PS, Yu HT, et al. Age threshold for ischemic stroke risk in atrial fibrillation. Stroke 2018;49:1872-9. PUBMED | CROSSREF

140. Zulkifly H, Lip GY, Lane DA. Use of the SAMe-TT $\mathrm{R}_{2}$ score to predict anticoagulation control in atrial fibrillation and venous thromboembolism patients receiving vitamin $\mathrm{K}$ antagonists: a review. Heart Rhythm 2018;15:615-23. PUBMED | CROSSREF

141. Yoon M, Yang PS, Jang E, et al. Dynamic changes of $\mathrm{CHA}_{2} \mathrm{DS}_{2}$-VASc score and the risk of ischaemic stroke in Asian patients with atrial fibrillation: a nationwide cohort study. Thromb Haemost 2018;118:1296-304. PUBMED | CROSSREF

142. Chao TF, Lip GY, Liu CJ, et al. Relationship of aging and incident comorbidities to stroke risk in patients with atrial fibrillation. J Am Coll Cardiol 2018;71:122-32. PUBMED | CROSSREF

143. Chao TF, Lip GY, Lin YJ, et al. Incident risk factors and major bleeding in patients with atrial fibrillation treated with oral anticoagulants: a comparison of baseline, follow-up and delta HAS-BLED scores with an approach focused on modifiable bleeding risk factors. Thromb Haemost 2018;118:768-77. PUBMED | CROSSREF

144. Lip GY, Wang KL, Chiang CE. Non-vitamin K antagonist oral anticoagulants (NOACs) for stroke prevention in Asian patients with atrial fibrillation: time for a reappraisal. Int J Cardiol 2015;180:246-54 . PUBMED | CROSSREF

145. Cha MJ, Choi EK, Han KD, et al. Effectiveness and safety of non-vitamin K antagonist oral anticoagulants in Asian patients with atrial fibrillation. Stroke 2017;48:3040-8.

PUBMED | CROSSREF 
146. Cho MY, Park J, Kim Y, et al. Clinical effectiveness and safety of standard-dose and low-dose non-vitamin $\mathrm{K}$ antagonist oral anticoagulants in patients with nonvalvular atrial fibrillation: a nationwide populationbased cohort study. Heart Rhythm 2017.

147. Lip GY, Clemens A, Noack H, Ferreira J, Connolly SJ, Yusuf S. Patient outcomes using the European label for dabigatran. A post-hoc analysis from the RE-LY database. Thromb Haemost 2014;111:933-42. PUBMED | CROSSREF

148. Chan NC, Coppens M, Hirsh J, et al. Real-world variability in dabigatran levels in patients with atrial fibrillation. J Thromb Haemost 2015;13:353-9. PUBMED | CROSSREF

149. Li CH, Liu CJ, Chou AY, et al. European Society of Cardiology guideline-adherent antithrombotic treatment and risk of mortality in Asian patients with atrial fibrillation. Sci Rep 2016;6:30734 PUBMED | CROSSREF

150. Kim H, Kim TH, Cha MJ, et al. A prospective survey of atrial fibrillation management for real-world guideline adherence: COmparison study of Drugs for symptom control and complication prEvention of Atrial Fibrillation (CODE-AF) Registry. Korean Circ J 2017;47:877-87. PUBMED | CROSSREF

151. Lee SR, Choi EK, Han KD, Cha MJ, Oh S, Lip GY. Temporal trends of antithrombotic therapy for stroke prevention in Korean patients with non-valvular atrial fibrillation in the era of non-vitamin K antagonist oral anticoagulants: a nationwide population-based study. PLoS One 2017;12:e0189495. PUBMED | CROSSREF

152. Lip GY, Lane DA. Bleeding risk assessment in atrial fibrillation: observations on the use and misuse of bleeding risk scores. J Thromb Haemost 2016;14:1711-4. PUBMED | CROSSREF

153. Douketis JD, Spyropoulos AC, Kaatz S, et al. Perioperative bridging anticoagulation in patients with atrial fibrillation. N Engl J Med 2015;373:823-33. PUBMED | CROSSREF

154. Douketis JD, Hasselblad V, Ortel TL. Bridging anticoagulation in patients with atrial fibrillation. $N$ Engl J Med 2016;374:93-4. PUBMED | CROSSREF

155. Man-Son-Hing M, Nichol G, Lau A, Laupacis A. Choosing antithrombotic therapy for elderly patients with atrial fibrillation who are at risk for falls. Arch Intern Med 1999;159:677-85. PUBMED | CROSSREF

156. Guo Y, Zhu H, Chen Y, Lip GY. Comparing bleeding risk assessment focused on modifiable risk factors only versus validated bleeding risk scores in atrial fibrillation. Am J Med 2018;131:185-92. PUBMED | CROSSREF

157. Chao TF, Lip GY, Lin YJ, et al. Major bleeding and intracranial hemorrhage risk prediction in patients with atrial fibrillation: attention to modifiable bleeding risk factors or use of a bleeding risk stratification score? A nationwide cohort study. Int J Cardiol 2018;254:157-61.

PUBMED | CROSSREF

158. Esteve-Pastor MA, Rivera-Caravaca JM, Shantsila A, Roldán V, Lip GY, Marín F. Assessing bleeding risk in atrial fibrillation patients: comparing a bleeding risk score based only on modifiable bleeding risk factors against the HAS-BLED score. The AMADEUS trial. Thromb Haemost 2017;117:2261-6. PUBMED | CROSSREF

159. Zulkifly H, Lip GY, Lane DA. Bleeding risk scores in atrial fibrillation and venous thromboembolism. Am J Cardiol 2017;120:1139-45.

PUBMED | CROSSREF

160. Holmes DR Jr, Kar S, Price MJ, et al. Prospective randomized evaluation of the Watchman Left Atrial Appendage Closure device in patients with atrial fibrillation versus long-term warfarin therapy: the PREVAIL trial. J Am Coll Cardiol 2014;64:1-12. PUBMED | CROSSREF

161. Holmes DR, Reddy VY, Turi ZG, et al. Percutaneous closure of the left atrial appendage versus warfarin therapy for prevention of stroke in patients with atrial fibrillation: a randomised non-inferiority trial. Lancet 2009;374:534-42.

PUBMED | CROSSREF

162. Reddy VY, Doshi SK, Sievert H, et al. Percutaneous left atrial appendage closure for stroke prophylaxis in patients with atrial fibrillation: 2.3-year follow-up of the PROTECT AF (Watchman Left Atrial Appendage System for Embolic Protection in Patients with Atrial Fibrillation) trial. Circulation 2013;127:720-9. PUBMED | CROSSREF 
163. Reddy VY, Sievert H, Halperin J, et al. Percutaneous left atrial appendage closure vs warfarin for atrial fibrillation: a randomized clinical trial. JAMA 2014;312:1988-98.

PUBMED | CROSSREF

164. Holmes DR Jr, Doshi SK, Kar S, et al. Left atrial appendage closure as an alternative to warfarin for stroke prevention in atrial fibrillation: a patient-level meta-analysis. J Am Coll Cardiol 2015;65:2614-23. PUBMED | CROSSREF

165. Boersma LV, Schmidt B, Betts TR, et al. Implant success and safety of left atrial appendage closure with the WATCHMAN device: peri-procedural outcomes from the EWOLUTION registry. Eur Heart J2016;37:2465-74. PUBMED | CROSSREF

166. Badheka AO, Chothani A, Mehta K, et al. Utilization and adverse outcomes of percutaneous left atrial appendage closure for stroke prevention in atrial fibrillation in the United States: influence of hospital volume. Circ Arrhythm Electrophysiol 2015;8:42-8.

PUBMED | CROSSREF

167. Casu G, Gulizia MM, Molon G, et al. ANMCO/AIAC/SICI-GISE/SIC/SICCH consensus document: percutaneous occlusion of the left atrial appendage in non-valvular atrial fibrillation patients: indications, patient selection, staff skills, organisation, and training. Eur Heart J Suppl 2017;19:D333-53. PUBMED | CROSSREF

168. Whitlock R, Healey J, Vincent J, et al. Rationale and design of the Left Atrial Appendage Occlusion Study (LAAOS) III. Ann Cardiothorac Surg 2014.3:45-54. PUBMED

169. Schreck DM, Rivera AR, Tricarico VJ. Emergency management of atrial fibrillation and flutter: intravenous diltiazem versus intravenous digoxin. Ann Emerg Med 1997;29:135-40. PUBMED | CROSSREF

170. Siu CW, Lau CP, Lee WL, Lam KF, Tse HF. Intravenous diltiazem is superior to intravenous amiodarone or digoxin for achieving ventricular rate control in patients with acute uncomplicated atrial fibrillation. Crit Care Med 2009;37:2174-9. PUBMED | CROSSREF

171. Tisdale JE, Padhi ID, Goldberg AD, et al. A randomized, double-blind comparison of intravenous diltiazem and digoxin for atrial fibrillation after coronary artery bypass surgery. Am Heart J1998;135:739-47. PUBMED | CROSSREF

172. Scheuermeyer FX, Grafstein E, Stenstrom R, et al. Safety and efficiency of calcium channel blockers versus beta-blockers for rate control in patients with atrial fibrillation and no acute underlying medical illness. Acad Emerg Med 2013;20:222-30. PUBMED | CROSSREF

173. Platia EV, Michelson EL, Porterfield JK, Das G. Esmolol versus verapamil in the acute treatment of atrial fibrillation or atrial flutter. Am J Cardiol 1989;63:925-9.

PUBMED | CROSSREF

174. Ellenbogen KA, Dias VC, Plumb VJ, Heywood JT, Mirvis DM. A placebo-controlled trial of continuous intravenous diltiazem infusion for 24-hour heart rate control during atrial fibrillation and atrial flutter: a multicenter study. J Am Coll Cardiol 1991;18:891-7.

PUBMED | CROSSREF

175. Steinberg JS, Katz RJ, Bren GB, Buff LA, Varghese PJ. Efficacy of oral diltiazem to control ventricular response in chronic atrial fibrillation at rest and during exercise. J Am Coll Cardiol 1987;9:405-11. PUBMED | CROSSREF

176. Goldstein RE, Boccuzzi SJ, Cruess D, Nattel S. Diltiazem increases late-onset congestive heart failure in postinfarction patients with early reduction in ejection fraction. The Adverse Experience Committee; and the Multicenter Diltiazem Postinfarction Research Group. Circulation 1991;83:52-60. PUBMED | CROSSREF

177. Darby AE, Dimarco JP. Management of atrial fibrillation in patients with structural heart disease. Circulation 2012;125:945-57. PUBMED | CROSSREF

178. Clemo HF, Wood MA, Gilligan DM, Ellenbogen KA. Intravenous amiodarone for acute heart rate control in the critically ill patient with atrial tachyarrhythmias. Am J Cardiol 1998;81:594-8. PUBMED | CROSSREF

179. Delle Karth G, Geppert A, Neunteufl T, et al. Amiodarone versus diltiazem for rate control in critically ill patients with atrial tachyarrhythmias. Crit Care Med 2001;29:1149-53. PUBMED | CROSSREF

180. Van Gelder IC, Groenveld HF, Crijns HJ, et al. Lenient versus strict rate control in patients with atrial fibrillation. N Engl J Med 2010;362:1363-73.

PUBMED | CROSSREF 
181. Al-Khatib SM, Allen LaPointe NM, Chatterjee R, et al. Rate- and rhythm-control therapies in patients with atrial fibrillation: a systematic review. Ann Intern Med 2014;160:760-73.

PUBMED | CROSSREF

182. Roy D, Talajic M, Nattel S, et al. Rhythm control versus rate control for atrial fibrillation and heart failure. N Engl J Med 2008;358:2667-77.

PUBMED | CROSSREF

183. Kirchhof P, Andresen D, Bosch R, et al. Short-term versus long-term antiarrhythmic drug treatment after cardioversion of atrial fibrillation (Flec-SL): a prospective, randomised, open-label, blinded endpoint assessment trial. Lancet 2012;380:238-46. PUBMED | CROSSREF

184. Lafuente-Lafuente C, Valembois L, Bergmann JF, Belmin J. Antiarrhythmics for maintaining sinus rhythm after cardioversion of atrial fibrillation. Cochrane Database Syst Rev 2015;(3):CD005049.

PUBMED | CROSSREF

185. Wyse DG, Waldo AL, DiMarco JP, et al. A comparison of rate control and rhythm control in patients with atrial fibrillation. $N$ Engl J Med 2002;347:1825-33. PUBMED | CROSSREF

186. Van Gelder IC, Hagens VE, Bosker HA, et al. A comparison of rate control and rhythm control in patients with recurrent persistent atrial fibrillation. N Engl J Med 2002;347:1834-40. PUBMED | CROSSREF

187. Opolski G, Torbicki A, Kosior DA, et al. Rate control vs rhythm control in patients with nonvalvular persistent atrial fibrillation: the results of the Polish How to Treat Chronic Atrial Fibrillation (HOT CAFE) Study. Chest 2004;126:476-86. PUBMED | CROSSREF

188. Chatterjee S, Sardar P, Lichstein E, Mukherjee D, Aikat S. Pharmacologic rate versus rhythm-control strategies in atrial fibrillation: an updated comprehensive review and meta-analysis. Pacing Clin Electrophysiol 2013;36:122-33. PUBMED | CROSSREF

189. de Denus S, Sanoski CA, Carlsson J, Opolski G, Spinler SA. Rate vs rhythm control in patients with atrial fibrillation: a meta-analysis. Arch Intern Med 2005;165:258-62.

PUBMED | CROSSREF

190. Kotecha D, Kirchhof P. Rate and rhythm control have comparable effects on mortality and stroke in atrial fibrillation but better data are needed. Evid Based Med 2014;19:222-3. PUBMED | CROSSREF

191. Wilber DJ, Pappone C, Neuzil P, et al. Comparison of antiarrhythmic drug therapy and radiofrequency catheter ablation in patients with paroxysmal atrial fibrillation: a randomized controlled trial. JAMA 2010;303:333-40. PUBMED | CROSSREF

192. Arbelo E, Brugada J, Hindricks G, et al. The atrial fibrillation ablation pilot study: a European survey on methodology and results of catheter ablation for atrial fibrillation conducted by the European Heart Rhythm Association. Eur Heart J 2014;35:1466-78. PUBMED | CROSSREF

193. Anselmino M, Matta M, D'Ascenzo F, et al. Catheter ablation of atrial fibrillation in patients with left ventricular systolic dysfunction: a systematic review and meta-analysis. Circ Arrhythm Electrophysiol 2014;7:1011-8. PUBMED | CROSSREF

194. Kirchhof P, Breithardt G, Camm AJ, et al. Improving outcomes in patients with atrial fibrillation: rationale and design of the Early treatment of Atrial fibrillation for Stroke prevention Trial. Am Heart J2013;166:442-8. PUBMED | CROSSREF

195. Shi LZ, Heng R, Liu SM, Leng FY. Effect of catheter ablation versus antiarrhythmic drugs on atrial fibrillation: a meta-analysis of randomized controlled trials. Exp Ther Med 2015;10:816-22. PUBMED | CROSSREF

196. Choi YJ, Kang KW, Kim TH, et al. Comparison of rhythm and rate control strategies for stroke occurrence in a prospective cohort of atrial fibrillation patients. Yonsei Med J 2018;59:258-64. PUBMED | CROSSREF

197. Kirchhof P, Mönnig G, Wasmer K, et al. A trial of self-adhesive patch electrodes and hand-held paddle electrodes for external cardioversion of atrial fibrillation (MOBIPAPA). Eur Heart J 2005;26:1292-7. PUBMED | CROSSREF

198. Mittal S, Ayati S, Stein KM, et al. Transthoracic cardioversion of atrial fibrillation: comparison of rectilinear biphasic versus damped sine wave monophasic shocks. Circulation 2000;101:1282-7. PUBMED | CROSSREF 
199. Kirchhof P, Eckardt L, Loh P, et al. Anterior-posterior versus anterior-lateral electrode positions for external cardioversion of atrial fibrillation: a randomised trial. Lancet 2002;360:1275-9. PUBMED | CROSSREF

200. Furniss SS, Sneyd JR. Safe sedation in modern cardiological practice. Heart 2015;101:1526-30. PUBMED | CROSSREF

201. Bianconi L, Mennuni M, Lukic V, Castro A, Chieffi M, Santini M. Effects of oral propafenone administration before electrical cardioversion of chronic atrial fibrillation: a placebo-controlled study. $J$ Am Coll Cardiol 1996;28:700-6.

PUBMED | CROSSREF

202. Singh SN, Tang XC, Reda D, Singh BN. Systematic electrocardioversion for atrial fibrillation and role of antiarrhythmic drugs: a substudy of the SAFE-T trial. Heart Rhythm 2009;6:152-5.

PUBMED | CROSSREF

203. Channer KS, Birchall A, Steeds RP, et al. A randomized placebo-controlled trial of pre-treatment and short- or long-term maintenance therapy with amiodarone supporting DC cardioversion for persistent atrial fibrillation. Eur Heart J 2004;25:144-50. PUBMED | CROSSREF

204. Hemels ME, Van Noord T, Crijns HJ, et al. Verapamil versus digoxin and acute versus routine serial cardioversion for the improvement of rhythm control for persistent atrial fibrillation. J Am Coll Cardiol 2006;48:1001-9. PUBMED | CROSSREF

205. Villani GQ, Piepoli MF, Terracciano C, Capucci A. Effects of diltiazem pretreatment on direct-current cardioversion in patients with persistent atrial fibrillation: a single-blind, randomized, controlled study. Am Heart J 2000;140:e12. PUBMED | CROSSREF

206. De Simone A, Stabile G, Vitale DF, et al. Pretreatment with verapamil in patients with persistent or chronic atrial fibrillation who underwent electrical cardioversion. J Am Coll Cardiol 1999;34:810-4. PUBMED | CROSSREF

207. The Digitalis in Acute Atrial Fibrillation (DAAF) Trial Group. Intravenous digoxin in acute atrial fibrillation. Results of a randomized, placebo-controlled multicentre trial in 239 patients. Eur Heart J 1997;18:649-54. PUBMED | CROSSREF

208. Atarashi H, Inoue H, Fukunami M, et al. Double-blind placebo-controlled trial of aprindine and digoxin for the prevention of symptomatic atrial fibrillation. Circ J 2002;66:553-6. PUBMED | CROSSREF

209. Schädlich PK, Schmidt-Lucke C, Huppertz E, et al. Economic evaluation of enoxaparin for anticoagulation in early cardioversion of persisting nonvalvular atrial fibrillation: a statutory health insurance perspective from Germany. Am J Cardiovasc Drugs 2007;7:199-217. PUBMED | CROSSREF

210. Schmidt-Lucke C, Paar WD, Stellbrink C, et al. Quality of anticoagulation with unfractionated heparin plus phenprocoumon for the prevention of thromboembolic complications in cardioversion for nonvalvular atrial fibrillation. Sub-analysis from the Anticoagulation in Cardioversion using Enoxaparin (ACE) trial. Thromb Res 2007;119:27-34. PUBMED | CROSSREF

211. Stellbrink C, Nixdorff U, Hofmann T, et al. Safety and efficacy of enoxaparin compared with unfractionated heparin and oral anticoagulants for prevention of thromboembolic complications in cardioversion of nonvalvular atrial fibrillation: the Anticoagulation in Cardioversion using Enoxaparin (ACE) trial. Circulation 2004;109:997-1003. PUBMED | CROSSREF

212. Shin DG, Cho I, Hartaigh B, et al. Cardiovascular events of electrical cardioversion under optimal anticoagulation in atrial fibrillation: the multicenter analysis. Yonsei Med J 2015;56:1552-8. PUBMED | CROSSREF

213. Hansen ML, Jepsen RM, Olesen JB, et al. Thromboembolic risk in 16274 atrial fibrillation patients undergoing direct current cardioversion with and without oral anticoagulant therapy. Europace 2015;17:18-23. PUBMED | CROSSREF

214. Gwag HB, Chun KJ, Hwang JK, et al. Which antiarrhythmic drug to choose after electrical cardioversion: a study on non-valvular atrial fibrillation patients. PLoS One 2018;13:e0197352. PUBMED | CROSSREF

215. Khan IA. Oral loading single dose flecainide for pharmacological cardioversion of recent-onset atrial fibrillation. Int J Cardiol 2003;87:121-8. PUBMED | CROSSREF 
216. Chevalier P, Durand-Dubief A, Burri H, Cucherat M, Kirkorian G, Touboul P. Amiodarone versus placebo and class Ic drugs for cardioversion of recent-onset atrial fibrillation: a meta-analysis. J Am Coll Cardiol 2003;41:255-62. PUBMED | CROSSREF

217. Letelier LM, Udol K, Ena J, Weaver B, Guyatt GH. Effectiveness of amiodarone for conversion of atrial fibrillation to sinus rhythm: a meta-analysis. Arch Intern Med 2003;163:777-85. PUBMED | CROSSREF

218. Khan IA, Mehta NJ, Gowda RM. Amiodarone for pharmacological cardioversion of recent-onset atrial fibrillation. Int J Cardiol 2003;89:239-48. PUBMED | CROSSREF

219. Thomas SP, Guy D, Wallace E, et al. Rapid loading of sotalol or amiodarone for management of recent onset symptomatic atrial fibrillation: a randomized, digoxin-controlled trial. Am HeartJ 2004;147:E3. PUBMED | CROSSREF

220. Vijayalakshmi K, Whittaker VJ, Sutton A, et al. A randomized trial of prophylactic antiarrhythmic agents (amiodarone and sotalol) in patients with atrial fibrillation for whom direct current cardioversion is planned. Am Heart J 2006;151:863.e1-6. PUBMED | CROSSREF

221. Singh BN, Singh SN, Reda DJ, et al. Amiodarone versus sotalol for atrial fibrillation. N Engl J Med 2005;352:1861-72.

PUBMED | CROSSREF

222. Roy D, Pratt CM, Torp-Pedersen C, et al. Vernakalant hydrochloride for rapid conversion of atrial fibrillation: a phase 3, randomized, placebo-controlled trial. Circulation 2008;117:1518-25. PUBMED | CROSSREF

223. Kowey PR, Dorian P, Mitchell LB, et al. Vernakalant hydrochloride for the rapid conversion of atrial fibrillation after cardiac surgery: a randomized, double-blind, placebo-controlled trial. Circ Arrhythm Electrophysiol 2009;2:652-9. PUBMED | CROSSREF

224. Camm AJ, Capucci A, Hohnloser SH, et al. A randomized active-controlled study comparing the efficacy and safety of vernakalant to amiodarone in recent-onset atrial fibrillation. J Am Coll Cardiol 2011;57:313-21. PUBMED | CROSSREF

225. Bash LD, Buono JL, Davies GM, et al. Systematic review and meta-analysis of the efficacy of cardioversion by vernakalant and comparators in patients with atrial fibrillation. Cardiovasc Drugs Ther 2012;26:167-79. PUBMED | CROSSREF

226. Reisinger J, Gatterer E, Lang W, et al. Flecainide versus ibutilide for immediate cardioversion of atrial fibrillation of recent onset. Eur Heart J 2004;25:1318-24. PUBMED | CROSSREF

227. Stambler BS, Wood MA, Ellenbogen KA, Perry KT, Wakefield LK, VanderLugt JT. Efficacy and safety of repeated intravenous doses of ibutilide for rapid conversion of atrial flutter or fibrillation. Ibutilide Repeat Dose Study Investigators. Circulation 1996;94:1613-21. PUBMED | CROSSREF

228. Reisinger J, Gatterer E, Heinze G, et al. Prospective comparison of flecainide versus sotalol for immediate cardioversion of atrial fibrillation. Am J Cardiol 1998;81:1450-4.

PUBMED | CROSSREF

229. Mun HS, Shen C, Pak HN, et al. Chronic amiodarone therapy impairs the function of the superior sinoatrial node in patients with atrial fibrillation. Circ J 2013;77:2255-63. PUBMED | CROSSREF

230. Alboni P, Botto GL, Baldi N, et al. Outpatient treatment of recent-onset atrial fibrillation with the "pill-inthe-pocket" approach. N Engl J Med 2004;351:2384-91. PUBMED | CROSSREF

231. Saborido CM, Hockenhull J, Bagust A, Boland A, Dickson R, Todd D. Systematic review and costeffectiveness evaluation of 'pill-in-the-pocket' strategy for paroxysmal atrial fibrillation compared to episodic in-hospital treatment or continuous antiarrhythmic drug therapy. Health Technol Assess 2010.14:iii-iv. PUBMED | CROSSREF

232. Lau DH, Nattel S, Kalman JM, Sanders P. Modifiable risk factors and atrial fibrillation. Circulation 2017;136:583-96. PUBMED | CROSSREF

233. Van Gelder IC, Crijns HJ, Van Gilst WH, Van Wijk LM, Hamer HP, Lie KI. Efficacy and safety of flecainide acetate in the maintenance of sinus rhythm after electrical cardioversion of chronic atrial fibrillation or atrial flutter. Am J Cardiol 1989;64:1317-21.

PUBMED | CROSSREF 
234. Echt DS, Liebson PR, Mitchell LB, et al. Mortality and morbidity in patients receiving encainide, flecainide, or placebo. The Cardiac Arrhythmia Suppression Trial. N Engl J Med 1991;324:781-8. PUBMED | CROSSREF

235. Chimienti M, Cullen MT Jr, Casadei G. Safety of flecainide versus propafenone for the long-term management of symptomatic paroxysmal supraventricular tachyarrhythmias. Report from the Flecainide and Propafenone Italian Study (FAPIS) Group. Eur Heart J1995;16:1943-51.

PUBMED | CROSSREF

236. Kim DS, Koh CW, Cho HK, et al. Comparision of the efficacy of propafenone and flecainide in patients with atrial fibrillation. Korean Circ J1997;27:860-6. CROSSREF

237. Aliot E, Capucci A, Crijns HJ, Goette A, Tamargo J. Twenty-five years in the making: flecainide is safe and effective for the management of atrial fibrillation. Europace 2011;13:161-73.

PUBMED | CROSSREF

238. Freemantle N, Lafuente-Lafuente C, Mitchell S, Eckert L, Reynolds M. Mixed treatment comparison of dronedarone, amiodarone, sotalol, flecainide, and propafenone, for the management of atrial fibrillation. Europace 2011;13:329-45. PUBMED | CROSSREF

239. Chun KJ, Byeon K, Im SI, et al. Efficacy of dronedarone versus propafenone in the maintenance of sinus rhythm in patients with atrial fibrillation after electrical cardioversion. Clin Ther 2014;36:1169-75. PUBMED | CROSSREF

240. Singh SN, Fletcher RD, Fisher SG, et al. Amiodarone in patients with congestive heart failure and asymptomatic ventricular arrhythmia. Survival Trial of Antiarrhythmic Therapy in Congestive Heart Failure. N Engl J Med 1995;333:77-82. PUBMED | CROSSREF

241. Kirchhof P, Franz MR, Bardai A, Wilde AM. Giant T-U waves precede torsades de pointes in long QT syndrome: a systematic electrocardiographic analysis in patients with acquired and congenital QT prolongation. J Am Coll Cardiol 2009;54:143-9. PUBMED | CROSSREF

242. Goldschlager N, Epstein AE, Naccarelli GV, et al. A practical guide for clinicians who treat patients with amiodarone: 2007. Heart Rhythm 2007;4:1250-9. PUBMED | CROSSREF

243. Singh BN, Connolly SJ, Crijns HJ, et al. Dronedarone for maintenance of sinus rhythm in atrial fibrillation or flutter. N Engl J Med 2007;357:987-99. PUBMED | CROSSREF

244. Hohnloser SH, Crijns HJ, van Eickels M, et al. Effect of dronedarone on cardiovascular events in atrial fibrillation. N Engl J Med 2009;360:668-78.

PUBMED | CROSSREF

245. Køber L, Torp-Pedersen C, McMurray JJ, et al. Increased mortality after dronedarone therapy for severe heart failure. N Engl J Med 2008;358:2678-87. PUBMED | CROSSREF

246. Connolly SJ, Camm AJ, Halperin JL, et al. Dronedarone in high-risk permanent atrial fibrillation. $N$ Engl J Med 2011;365:2268-76. PUBMED | CROSSREF

247. Roy D, Talajic M, Dorian P, et al. Amiodarone to prevent recurrence of atrial fibrillation. N Engl J Med 2000;342:913-20. PUBMED | CROSSREF

248. Klein AL, Grimm RA, Murray RD, et al. Use of transesophageal echocardiography to guide cardioversion in patients with atrial fibrillation. $N$ Engl J Med 2001;344:1411-20. PUBMED | CROSSREF

249. Nagarakanti R, Ezekowitz MD, Oldgren J, et al. Dabigatran versus warfarin in patients with atrial fibrillation: an analysis of patients undergoing cardioversion. Circulation 2011;123:131-6. PUBMED | CROSSREF

250. Piccini JP, Stevens SR, Lokhnygina Y, et al. Outcomes after cardioversion and atrial fibrillation ablation in patients treated with rivaroxaban and warfarin in the ROCKET AF trial. J Am Coll Cardiol 2013;61:1998-2006. PUBMED | CROSSREF

251. Flaker G, Lopes RD, Al-Khatib SM, et al. Efficacy and safety of apixaban in patients after cardioversion for atrial fibrillation: insights from the ARISTOTLE trial (Apixaban for Reduction in Stroke and Other Thromboembolic Events in Atrial Fibrillation). J Am Coll Cardiol 2014;63:1082-7.

PUBMED | CROSSREF 
252. Cappato R, Ezekowitz MD, Klein AL, et al. Rivaroxaban vs. vitamin $\mathrm{K}$ antagonists for cardioversion in atrial fibrillation. Eur Heart J 2014;35:3346-55.

PUBMED | CROSSREF

253. Goette A, Merino JL, Ezekowitz MD, et al. Edoxaban versus enoxaparin-warfarin in patients undergoing cardioversion of atrial fibrillation (ENSURE-AF): a randomised, open-label, phase 3b trial. Lancet 2016;388:1995-2003. PUBMED | CROSSREF

254. Ezekowitz MD, Pollack CV Jr, Halperin JL, et al. Apixaban compared to heparin/vitamin K antagonist in patients with atrial fibrillation scheduled for cardioversion: the EMANATE trial. Eur Heart J2018;39:2959-71. PUBMED | CROSSREF

255. Steffel J, Verhamme P, Potpara TS, et al. The 2018 European Heart Rhythm Association Practical Guide on the use of non-vitamin $\mathrm{K}$ antagonist oral anticoagulants in patients with atrial fibrillation. Eur Heart J 2018;39:1330-93. PUBMED | CROSSREF

256. Lip GYH, Collet JP, Haude M, et al. 2018 Joint European consensus document on the management of antithrombotic therapy in atrial fibrillation patients presenting with acute coronary syndrome and/or undergoing percutaneous cardiovascular interventions: a joint consensus document of the European Heart Rhythm Association (EHRA), European Society of Cardiology Working Group on Thrombosis, European Association of Percutaneous Cardiovascular Interventions (EAPCI), and European Association of Acute Cardiac Care (ACCA) endorsed by the Heart Rhythm Society (HRS), Asia-Pacific Heart Rhythm Society (APHRS), Latin America Heart Rhythm Society (LAHRS), and Cardiac Arrhythmia Society of Southern Africa (CASSA). Europace. 2018 [Epub ahead of print]. PUBMED | CROSSREF

257. Leon MB, Baim DS, Popma JJ, et al. A clinical trial comparing three antithrombotic-drug regimens after coronary-artery stenting. N Engl J Med 1998;339:1665-71. PUBMED | CROSSREF

258. ACTIVE Writing Group of the ACTIVE Investigators, Connolly S, Pogue J, et al. Clopidogrel plus aspirin versus oral anticoagulation for atrial fibrillation in the Atrial fibrillation Clopidogrel Trial with Irbesartan for prevention of Vascular Events (ACTIVE W): a randomised controlled trial. Lancet 2006;367:1903-12. PUBMED | CROSSREF

259. Dewilde WJ, Oirbans T, Verheugt FW, et al. Use of clopidogrel with or without aspirin in patients taking oral anticoagulant therapy and undergoing percutaneous coronary intervention: an open-label, randomised, controlled trial. Lancet 2013;381:1107-15.

PUBMED | CROSSREF

260. Rubboli A, Faxon DP, Juhani Airaksinen KE, et al. The optimal management of patients on oral anticoagulation undergoing coronary artery stenting. The 10th anniversary overview. Thromb Haemost 2014;112:1080-7. PUBMED | CROSSREF

261. Choi HI, Ahn JM, Kang SH, et al. Prevalence, management, and long-term (6-year) outcomes of atrial fibrillation among patients receiving drug-eluting coronary stents. JACC Cardiovasc Interv 2017;10:1075-85. PUBMED | CROSSREF

262. Cannon CP, Bhatt DL, Oldgren J, et al. Dual antithrombotic therapy with dabigatran after PCI in atrial fibrillation. N Engl J Med 2017;377:1513-24. PUBMED | CROSSREF

263. Gibson CM, Mehran R, Bode C, et al. Prevention of bleeding in patients with atrial fibrillation undergoing PCI. N Engl J Med 2016;375:2423-34. PUBMED | CROSSREF

264. Golwala HB, Cannon CP, Steg PG, et al. Safety and efficacy of dual vs. triple antithrombotic therapy in patients with atrial fibrillation following percutaneous coronary intervention: a systematic review and meta-analysis of randomized clinical trials. Eur Heart J 2018;39:1726-1735a. PUBMED | CROSSREF

265. Connolly SJ, Ezekowitz MD, Yusuf S, et al. Dabigatran versus warfarin in patients with atrial fibrillation. $N$ Engl J Med 2009;361:1139-51. PUBMED | CROSSREF

266. Lopes RD, Vora AN, Liaw D, et al. An open-Label, $2 \times 2$ factorial, randomized controlled trial to evaluate the safety of apixaban vs. vitamin $\mathrm{K}$ antagonist and aspirin vs. placebo in patients with atrial fibrillation and acute coronary syndrome and/or percutaneous coronary intervention: rationale and design of the AUGUSTUS trial. Am Heart J 2018;200:17-23. PUBMED | CROSSREF 
267. Vranckx P, Lewalter T, Valgimigli M, et al. Evaluation of the safety and efficacy of an edoxaban-based antithrombotic regimen in patients with atrial fibrillation following successful percutaneous coronary intervention (PCI) with stent placement: Rationale and design of the ENTRUST-AF PCI trial. Am HeartJ 2018;196:105-12.

PUBMED | CROSSREF

268. Lamberts M, Gislason GH, Lip GY, et al. Antiplatelet therapy for stable coronary artery disease in atrial fibrillation patients taking an oral anticoagulant: a nationwide cohort study. Circulation 2014;129:1577-85. PUBMED | CROSSREF

269. Valgimigli M, Bueno H, Byrne RA, et al. 2017 ESC focused update on dual antiplatelet therapy in coronary artery disease developed in collaboration with EACTS: The Task Force for dual antiplatelet therapy in coronary artery disease of the European Society of Cardiology (ESC) and of the European Association for Cardio-Thoracic Surgery (EACTS). Eur Heart J 2018;39:213-60. PUBMED | CROSSREF

270. Calkins H, Hindricks G, Cappato R, et al. 2017 HRS/EHRA/ECAS/APHRS/SOLAECE expert consensus statement on catheter and surgical ablation of atrial fibrillation. Heart Rhythm 2017;14:e275-444. PUBMED | CROSSREF

271. Hohnloser SH, Camm AJ. Safety and efficacy of dabigatran etexilate during catheter ablation of atrial fibrillation: a meta-analysis of the literature. Europace 2013;15:1407-11.

PUBMED | CROSSREF

272. Di Biase L, Lakkireddy D, Trivedi C, et al. Feasibility and safety of uninterrupted periprocedural apixaban administration in patients undergoing radiofrequency catheter ablation for atrial fibrillation: results from a multicenter study. Heart Rhythm 2015;12:1162-8. PUBMED | CROSSREF

273. Lakkireddy D, Reddy YM, Di Biase L, et al. Feasibility and safety of uninterrupted rivaroxaban for periprocedural anticoagulation in patients undergoing radiofrequency ablation for atrial fibrillation: results from a multicenter prospective registry. J Am Coll Cardiol 2014;63:982-8. PUBMED | CROSSREF

274. Kottmaier M, Bourier F, Pausch H, et al. Safety of uninterrupted periprocedural edoxaban versus phenprocoumon for patients who underwent left atrial catheter ablation procedures. Am J Cardiol 2018;121:445-9. PUBMED | CROSSREF

275. Cappato R, Marchlinski FE, Hohnloser SH, et al. Uninterrupted rivaroxaban vs. uninterrupted vitamin K antagonists for catheter ablation in non-valvular atrial fibrillation. Eur Heart J 2015;36:1805-11. PUBMED | CROSSREF

276. Calkins H, Willems S, Gerstenfeld EP, et al. Uninterrupted dabigatran versus warfarin for ablation in atrial fibrillation. N Engl J Med 2017;376:1627-36.

PUBMED | CROSSREF

277. Kirchhof P, Haeusler KG, Blank B, et al. Apixaban in patients at risk of stroke undergoing atrial fibrillation ablation. Eur Heart J 2018;39:2942-55. PUBMED | CROSSREF

278. Fox KA, Piccini JP, Wojdyla D, et al. Prevention of stroke and systemic embolism with rivaroxaban compared with warfarin in patients with non-valvular atrial fibrillation and moderate renal impairment. Eur Heart J 2011;32:2387-94. PUBMED | CROSSREF

279. Eikelboom JW, Connolly SJ, Gao P, et al. Stroke risk and efficacy of apixaban in atrial fibrillation patients with moderate chronic kidney disease. J Stroke Cerebrovasc Dis 2012;21:429-35. PUBMED | CROSSREF

280. Hohnloser SH, Hijazi Z, Thomas L, et al. Efficacy of apixaban when compared with warfarin in relation to renal function in patients with atrial fibrillation: insights from the ARISTOTLE trial. Eur Heart J 2012;33:2821-30. PUBMED | CROSSREF

281. Hijazi Z, Hohnloser SH, Oldgren J, et al. Efficacy and safety of dabigatran compared with warfarin in relation to baseline renal function in patients with atrial fibrillation: a RE-LY (Randomized Evaluation of Long-term Anticoagulation Therapy) trial analysis. Circulation 2014;129:961-70. PUBMED | CROSSREF

282. Hart RG, Pearce LA, Asinger RW, Herzog CA. Warfarin in atrial fibrillation patients with moderate chronic kidney disease. Clin J Am Soc Nephrol 2011;6:2599-604.

PUBMED | CROSSREF 
283. Ruff CT, Giugliano RP, Braunwald E, et al. Comparison of the efficacy and safety of new oral anticoagulants with warfarin in patients with atrial fibrillation: a meta-analysis of randomised trials. Lancet 2014;383:955-62. PUBMED | CROSSREF

284. Del-Carpio Munoz F, Gharacholou SM, Munger TM, et al. Meta-analysis of renal function on the safety and efficacy of novel oral anticoagulants for atrial fibrillation. Am J Cardiol 2016;117:69-75. PUBMED | CROSSREF

285. Heidbuchel H, Verhamme P, Alings M, et al. Updated European Heart Rhythm Association Practical Guide on the use of non-vitamin K antagonist anticoagulants in patients with non-valvular atrial fibrillation. Europace 2015;17:1467-507. PUBMED | CROSSREF

286. Patel MR, Mahaffey KW, Garg J, et al. Rivaroxaban versus warfarin in nonvalvular atrial fibrillation. $N$ Engl J Med 2011;365:883-91 PUBMED | CROSSREF

287. Granger CB, Alexander JH, McMurray JJ, et al. Apixaban versus warfarin in patients with atrial fibrillation. N Engl J Med 2011;365:981-92. PUBMED | CROSSREF

288. Giugliano RP, Ruff CT, Braunwald E, et al. Edoxaban versus warfarin in patients with atrial fibrillation. $N$ Engl J Med 2013;369:2093-104. PUBMED | CROSSREF

289. Wizemann V, Tong L, Satayathum S, et al. Atrial fibrillation in hemodialysis patients: clinical features and associations with anticoagulant therapy. Kidney Int 2010;77:1098-106. PUBMED | CROSSREF

290. Chan KE, Lazarus JM, Thadhani R, Hakim RM. Warfarin use associates with increased risk for stroke in hemodialysis patients with atrial fibrillation. J Am Soc Nephrol 2009;20:2223-33. PUBMED | CROSSREF

291. Winkelmayer WC, Liu J, Setoguchi S, Choudhry NK. Effectiveness and safety of warfarin initiation in older hemodialysis patients with incident atrial fibrillation. Clin J Am Soc Nephrol 2011;6:2662-8. PUBMED | CROSSREF

292. Schwartzenberg S, Lev EI, Sagie A, Korzets A, Kornowski R. The quandary of oral anticoagulation in patients with atrial fibrillation and chronic kidney disease. Am J Cardiol 2016;117:477-82. PUBMED | CROSSREF

293. Potpara TS, Ferro CJ, Lip GY. Use of oral anticoagulants in patients with atrial fibrillation and renal dysfunction. Nat Rev Nephrol 2018;14:337-51. PUBMED | CROSSREF

294. Siontis KC, Zhang X, Eckard A, et al. Outcomes associated with apixaban use in end-stage kidney disease patients with atrial fibrillation in the United States. Circulation 2018;138:1519-29. PUBMED | CROSSREF

295. Lee SR, Choi EK, Han KD, Jung JH, Oh S, Lip GY. Edoxaban in Asian patients with atrial fibrillation: effectiveness and safety. J Am Coll Cardiol 2018;72:838-53. PUBMED | CROSSREF

296. Yu HY, Kim P, Jang TH, et al. Impact of renal function on outcomes with edoxaban in real-world patients with atrial fibrillation: a nationwide cohort study. Stroke 2018;49:2421-9. PUBMED | CROSSREF

297. Hylek EM, D'Antonio J, Evans-Molina C, Shea C, Henault LE, Regan S. Translating the results of randomized trials into clinical practice: the challenge of warfarin candidacy among hospitalized elderly patients with atrial fibrillation. Stroke 2006;37:1075-80.

PUBMED | CROSSREF

298. Sharma M, Cornelius VR, Patel JP, Davies JG, Molokhia M. Efficacy and harms of direct oral anticoagulants in the elderly for stroke prevention in atrial fibrillation and secondary prevention of venous thromboembolism: systematic review and meta-analysis. Circulation 2015;132:194-204. PUBMED | CROSSREF

299. Mant J, Hobbs FD, Fletcher K, et al. Warfarin versus aspirin for stroke prevention in an elderly community population with atrial fibrillation (the Birmingham Atrial Fibrillation Treatment of the Aged Study, BAFTA): a randomised controlled trial. Lancet 2007;370:493-503. PUBMED | CROSSREF

300. Gage BF, Birman-Deych E, Kerzner R, Radford MJ, Nilasena DS, Rich MW. Incidence of intracranial hemorrhage in patients with atrial fibrillation who are prone to fall. Am J Med 2005;118:612-7. PUBMED | CROSSREF 
301. Chao TF, Liu CJ, Lin YJ, et al. Oral anticoagulation in very elderly patients with atrial fibrillation: a nationwide cohort study. Circulation 2018;138:37-47.

PUBMED | CROSSREF

302. Yamashita Y, Hamatani Y, Esato M, et al. Clinical characteristics and outcomes in extreme elderly (age $\geq$ 85 years) Japanese patients with atrial fibrillation: the Fushimi AF registry. Chest 2016;149:401-12. PUBMED | CROSSREF

303. Halvorsen S, Atar D, Yang H, et al. Efficacy and safety of apixaban compared with warfarin according to age for stroke prevention in atrial fibrillation: observations from the ARISTOTLE trial. Eur Heart $J$ 2014;35:1864-72.

PUBMED | CROSSREF

304. Hori M, Matsumoto M, Tanahashi N, et al. Rivaroxaban vs. warfarin in Japanese patients with nonvalvular atrial fibrillation in relation to age. Circ J2014;78:1349-56.

PUBMED | CROSSREF

305. Lin YC, Chien SC, Hsieh YC, et al. Effectiveness and safety of standard- and low-dose rivaroxaban in Asians with atrial fibrillation. J Am Coll Cardiol 2018;72:477-85.

PUBMED | CROSSREF

306. Joung B. Real-world data and recommended dosage of non-vitamin K oral anticoagulants for Korean patients. Korean Circ J 2017;47:833-41.

PUBMED | CROSSREF 